\title{
UCRL 10156
}

\section{University of California}

\section{Ernest 0 . Lawrence Radiation Laboratory}

TWO-WEEK LOAN COPY

This is a Library Circulating Copy which may be borrowed for two weeks.

For a personal retention copy, call Tech. Info. Division, Ext. 5545

BIO-ORGANIC CHEMISTRY QUARTERLY REPORT December 1961, January and February 1962

Berkeley. California 


\section{BIO ORGANIC CHEMISTRY QUARTERLY REPORT \\ December 1961, January and February 1962}

\section{Contents}

1. A Preliminary Investitation of the Polymerization of Formaldehyde (Ferrier and Ponnamperuma) . . . 1

2. Ultraviolet Irradiation of an Aqueous Solution of $\mathrm{HC}^{14} \mathrm{~N}$

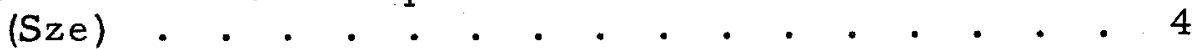

3. Further Studies on the Radiation Chemistry of Nucleic Acid Constituents (Ponnamperuma and Lemmon). . 6

4. Radiation Sensitivity of Choline Bromide (Obradovic, Smith, and Lemmon). . . . . . . . . . 19

5. The Oxidation of Free Sugars and Aldonic Acid Derivatives by Acetobacter Suboxydans (Ferrier, Bowman, and Moses) • • • . . . . . . . . . . . 21

6. Characterization of a Phosphate Ester of 2-Keto-L-Gulonic Acid-C ${ }^{14}$ Obtained from Chlorella Supplied with $\mathrm{C}^{14} \mathrm{O}_{2}$ in the Light (Moses and Ferrier) . . . . 23

7. Mechanism of the Ribulose Diphosphate Carboxylase System.

I. Preparation and Isolation of $\mathrm{C}^{14} \mathrm{O}_{2} \sim$ Enzyme (Akoyunoglou and Calvin). . . . . . . . 27

8. The Metabolism of $\mathrm{C}^{14}$-Ribulose Diphosphate by Nitrobacter Agilis (Pon and Aleem) . . . . . . . 33

9. $\mathrm{C}^{14} \mathrm{O}_{2}$ Metabolism of Hordeum Vulgare Seedlings During the Development of the Photosynthetic Apparatus

(Biggins and Park). . . . . . . . . . . 40

10. The Location and Chemical Characterization of RNA in the Chloroplasts of Spinacea Oleracea (Biggins and Park) • . • • • . • • • . . . . 48

11. Absorption Spectra of Spinach Quantasomes and Stability of the Pigments. II. Inhibition of Dark Bleaching by Stroma Extracts and by Inert Gases (Sauer) . . 54

12. ESR Studies on Chromatophores from Rhodospirillum rubrum and on Quantasomes from Spinach Chloroplasts (Singleton and Androes). . . . . . . . 69

13. Phthalocyanine Manganese and Etioporphyrin Manganese Complexes (Yamamoto) . . . . . . . . 71

$\bar{*}$ Preceding Quarterly Reports: UCRL-10032, UCRL-9900. 
Resecroh and Development:

UCRL- 10156

$\mathrm{UC}-4$ Chemistry

TID -4500 (17th Ed.)

\author{
UNIVERSITY OF CALIFORNIA \\ Lawrence Radiation Laboratory \\ Berkeley, California \\ Contract No. W-7405-eng-48
}

BIO-ORGANIC CHEMISTRY QUARTERLY REPORT

December 1961, January and February 1962

April 3, 1962 
Printed in USA. Price \$2.00. Available from the office of Technical Services

U. S. Department of Commerce

Washington 25 , D.C. 


\title{
BIO-ORGANIC CHEMISTRY QUARTERLY REPORT December 1961, January and February 1962
}

\author{
M. Calvin, Director
}

Lawrence Radiation Laboratory and Department of Chemistry University of California, Berkeley, California

April 3, 1962

\section{A PRELIMINARY INVESTIGATION OF THE POL YMERIZATION OF FORMALDEHYDE \\ R. J. Ferrier and Cyril Ponnamperuma}

It has been known for a hundred years that formaldehyde polymerizes to carbohydrate substances in alkaline media. 1 Although the reaction has long attracted much attention, only recently has a detailed qualitative analysis of the products been carried out by chromatographic methods. 2 We have started to re-examine this reaction by combining chromatography with radioactive tracer techniques in the hope of refining the quantitative aspects of the analysis.

Our particular interest has been to develop methods for determining the relative proportions of ribose and ribulose in the mixtures of sugars formed in basic media, as well as under other polymerizing conditions. The finding of large amounts of these sugars might help to explain the occurrence of ribose as the only basic sugar in the fundamental replicating molecules-the nucleic acids. Formaldehyde is thought to have been present in the primitive reducing atmosphere which existed before life first appeared. ${ }^{3}$ The ribonucleic acids must have appeared in the constitution of reproducing systems at a very early stage in the development of living organisms.

In this study, the polymerizations of formaldehyde were carried out in calcium hydroxide suspensions at $40^{\circ}$. Aliquots of the reaction mixtures were withdrawn at after various time intervals and the alkali was neutralized with sulfuric acid or, in later experiments, with carbon dioxide. The hydrolysis with sulfuric acid that was used initially to break down any - $C_{1}-\mathrm{O}-\mathrm{C}_{1}-\mathrm{O}-$ polymers was shown to be unnecessary, as identical products were obtained with this treatment and with simple carbon dioxide neutralization.

\footnotetext{
IA. Butlerow, Annalen 120, 295 (1861).

${ }^{2}$ E. Pfeil and H. Ruckert, Annalen 641, 121 (1961).

${ }^{3}$ E. El'piner and A. V. Sokol'skaya, in Proceedings of the First International Symposium on the Origin of Life on Earth, Moscow, 1957, (Pergamon Press, London, 1959), p. 173.
} 
The formaldehyde used in the experiments was obtained in 1949 from Oak Ridge National Laboratory as a $20 \%$ solution in methanol. The quoted specific radioactivity, $2.13 \mathrm{mC} / \mathrm{ml}$, has been redetermined by liquid scintillation counting and found to be $2.60 \mathrm{mC} / \mathrm{ml}$. To $0.1 \mathrm{ml}$ of this solution $0.9 \mathrm{ml}$ of water was added, and then rapidly, with shaking, finely powdered calcium oxide $(7.5 \mathrm{mg})$. The solution was kept at $40^{\circ} \mathrm{C}$ and at successive times $0.1-\mathrm{ml}$ aliquot samples were withdrawn, neutralized with carbon dioxide, and evaporated to dryness. The residues were redissolved in water $(1.0 \mathrm{ml})$ and portions $(0.04 \mathrm{ml})$ were applied to the starting line of a paper chromatogram which was then developed in the upper layer of a solvent mixture containing butanol:ethanol: water $(4: 1: 5$ by volume).

Seven discrete radioactive zones were detected by radioautography on the chromatogram from each aliquot sample. The radioactivities (counts/min $\times 10^{-2}$, background subtracted; counter efficiency $8 \%$ ) in each of these areas are shown in Table $1-I$.

Table 1-I. Radioactivities of zones from chromatograms of formaldehyde $-\mathrm{C}^{14}$ after polymerization (in counts $/ \mathrm{min} \times 10^{-2}$ )

Radioactive
components

A

$\mathrm{B}$

C

$\mathrm{D}$

$\mathrm{E}+\mathrm{F}$

G

Total

\begin{tabular}{cccccc}
\hline 1 & & \multicolumn{3}{c}{ Time $(\mathrm{hr})$} & \multicolumn{2}{c}{} \\
\hline 192 & 5 & 24 & 48 & $\frac{72}{90}$ \\
414 & 224 & 542 & 544 & 556 & 562 \\
104 & 54 & 42 & 42 & 40 & 42 \\
108 & 76 & 88 & 74 & 78 & 80 \\
38 & 30 & 42 & 30 & 32 & 52 \\
26 & 24 & 44 & 30 & 30 & 26 \\
\hline 862 & 862 & 936 & $\frac{888}{912}$ & 914
\end{tabular}

* The chromatographic mobilities increased from A to G.

After repeated evaporation of an aqueous solution of formaldehyde, extraction of the residue with water, and determination of the remaining radioactivity by scintillation counting using an internal standard of ${ }^{4} \mathrm{C}$ toluene, we found that $99.5 \%$ of the aldehyde could be removed by this method. When applied to samples of the polymerized mixtures the procedure was unreliable as a means of determining the extent to which polymerization had occurred, presumably because of nonuniform binding of volatile compounds on the inorganic residues. Reproducible results were obtained when the residues from single evaporations of the neutralized reaction mixtures were dissolved in wate $r_{8}$ a known fraction of the extracts was chromatographed, and the total radioactivity of the resolved components on the developed paper was determined with an end-window $G-M$ tube of known efficiency. $A$ comparison of the results obtained by both methods is given in Table $1-I I$. 
Table 1-II. Amount of formaldehyde converted to involatile products (in \%)

\begin{tabular}{|c|c|c|c|c|c|c|}
\hline & \multicolumn{4}{|c|}{ Time of sampling $(\mathrm{hr})$} & \multirow[b]{2}{*}{72} & \multirow[b]{2}{*}{90} \\
\hline & 1 & 5 & 24 & 48 & & \\
\hline G-M counting of paper & 51 & 51 & 59 & 54 & 57 & 57 \\
\hline $\begin{array}{l}\text { Liquid scintillation counting } \\
\text { of residue }\end{array}$ & 77 & 74 & 67 & 56 & 59 & 81 \\
\hline
\end{tabular}

Samples of each of the components $A$ through $G$ were eluted and rechromatographed in parallel with nonradioactive markers. Tentative assignments of structures were made: A (very low mobility), acidic degradation products; $B$ (elongated spot), pentoses and hexoses; $C$, the tetroses; $D$, glyceraldehyde; $E$ and $F$ (each of which on rechromatography gave the same two spots), dihydroxy acetone; and G, glycolic aldehyde. and $1-$ II.

The following observations were made from the results in Tables $1-I$

(a) The components of each mixture were the same.

(b) The amounts of components $B$ through $G$ decreased with time (especially during early stages in the reaction), while $A$ increased. This is attributed to the alkaline degradation of the carbohydrate products into chromatographically slow-moving saccharinic acids.

(c) The total percentage of formaldehyde converted into nonvoltile products is roughly constant over the time range selected.

In later experiments it became clear that under the conditions employed the formaldehyde polymerized at a measurable rate during the first hour, and also that the suspended calcium hydroxide aided the reaction. A saturated solution of calcium hydroxide was a less efficient polymerizing medium. Further detailed analysis of fraction B by two-dimensional paper chromatography indicated that the main components could readily be resolved. As yet they are uncharacterized.

$\overline{4}$ J. Kenner, Chem. \& Ind. (London) 727 (1955). 
2. ULTRAVIOLET IRRADIATION OF AN AQUEOUS SOLUTION OF $\mathrm{HC}^{14} \mathrm{~N}$ Theresa Wang Sze

Ord has presented evidence for the formation of adenine in heated aqueous solutions of ammonium cyanide, 1 and for the appearance of amino acids--alanine, glycine, and aspartic acid--in heated ammonium hydroxide solutions saturated with HCN gas. 2 Calvin and Palm have reported the presence of urea, and probably thymine as well, in reaction mixtures formed by electron irradiation of aqueous solutions of $\mathrm{HCN}_{0} 3$

In order to investgate further the possible role of $\mathrm{HCN}$ in primordial-or prebiotic--chemistry, we have carried out a study of the reactions of HCN and water under ultraviolet irradiation.

\section{Experimental Procedure}

$\mathrm{C}^{14}$-labeled $\mathrm{HCN}$ was prepared by heating $\mathrm{NH}_{4} \mathrm{Cl}_{2} \mathrm{BaC}^{14} \mathrm{O}_{3}$, and potassium metal in a sealed tube at $640^{\circ}$. $4 \mathrm{~A}$ few $\mathrm{ml}$ of the $\mathrm{HC}^{\mathrm{l}} \mathrm{N}$ s solution $(0.074 \mathrm{M}, 160 \mu \mathrm{C} / \mathrm{ml})$ in a quartz tube was irradiated by a high-pressure mercury lamp (Hanovia $A H 6$ ), at a distance of $15 \mathrm{~cm}$, for different periods of time. Samples of the $\mathrm{HC}^{14} \mathrm{~N}$ solution before and after irradiation were evaporated to dryness at room temperature, and radioactivity in the residue determined to estimate the amount of HCN transformed into nonvoltile material. Shown below are the nonvolatile fractions found after different periods of time:

\begin{tabular}{cc}
\hline $\begin{array}{c}\text { Time of } \\
\text { irradiation } \\
(\text { hr })\end{array}$ & $\begin{array}{c}\text { Nonvolatile material } \\
\text { formed } \\
(\%)\end{array}$ \\
\hline 1 & 1 \\
2 & 5.8 \\
4 & 6.5 \\
8 & 11.5 \\
12 & 14 \\
\hline
\end{tabular}

IJ. Oró, Biochem. Biophys. Research Communs. 2, 407 (1960).

${ }^{2}$ J. Orb and S. S. Kamat, Nature 190, 442 (1961).

${ }^{3}$ C. Palm and M. Calvin, in Bio-Organic Chemistry Quarterly Report, UCRL-9900, Oct. 1961 , p. 65.

${ }^{4}$ F. L. J. Sixma, H. Hendriks, K. Helle, H. Hollstein, and R. van Loing, Rec. trav. chim. 73, 161 (1954). 
One-tenth $\mathrm{ml}$ of the $12-\mathrm{hr}$ irradiated $\mathrm{HC}^{14} \mathrm{~N}$ solution (initially containing $20 \mu \mathrm{g}$ of $\mathrm{HCN}$ and $16 \mu \mathrm{C}$ of $\mathrm{C}^{14}$ ) was placed on Whatman No. 4 oxalic acid-washed chromatographic paper and run in two solvent systems, nbutanol-propionic acid-water and n-propanol-ammonia-water. Radioautographs of the chromatograms of the crude reaction mixture showed that more than 30 labeled compounds are formed in this irradiation.

Since urea has been found in both refluxed and irradiated HCN solutions, we cochromatographed an aliquot portion of our $12-\mathrm{hr}$ solution with urea and sprayed the resultant chromatogram with a solution of $1 \%$ dimethylaminobenzaldehyde in $2 \%$ alcoholic $\mathrm{HCl} .5$ The coincidence of radioactivity with the lemon-yellow color showed that urea was formed in a relatively small yield (about $2 \%$ ).

Attempts have been made to identify some of the other products formed by irradiation. Adenine, found by Orb on heating $\mathrm{NH}_{4} \mathrm{CN}$, does not appear to be present on our chromatograms. We made an effort to synthesize aminomalononitrile, which is one of the proposed intermediates in the polymerization of HCN to form adenine. 6 Although a synthesis has been reported, 7 the yield is low and we have been unable to obtain a sample for chromatography. We prepared aminomalonic acid, the hydrolysis product of aminomalononitrile, by making the 2,4-dinitrophenylhydrazone of ketomalonic acid and hydrogenating it at 3 atm pressure over platinum oxide catalyst. 8 The aminomalonic acid is formed along with its decarboxylation product, glycine. Its presence, together with that of glycine, was shown by chromatography. Spraying with $0.25 \%$ ninhydrin in acetone showed two spots corresponding to glycine and, presumably, aminomalonic acid. However, cochromatography with irradiated $\mathrm{HC}^{14} \mathrm{~N}$ solutions showed no correspondence of the aminomalonic acid to the compounds formed on irradiation.

The Rf values of some compounds studied in this work are as follows.

\begin{tabular}{|c|c|c|}
\hline & n-Butanol-propionic acid- $\mathrm{H}_{2} \mathrm{O}$ & $\mathrm{n}-$ Propanol $-\mathrm{NH}_{4} \mathrm{OH}$ \\
\hline $\begin{array}{l}\text { Adenine } \\
\text { Alanine } \\
\text { Aminomalonic acid } \\
\text { Glycine } \\
\text { Hypoxanthine } \\
\text { Urea }\end{array}$ & $\begin{array}{l}0.79 \\
0.46 \\
0.25 \\
0.35 \\
0.54 \\
0.67\end{array}$ & $\begin{array}{l}0.65 \\
0.64 \\
0.58 \\
0.59 \\
0.63 \\
0.71\end{array}$ \\
\hline
\end{tabular}




\section{FURTHER STUDIES ON THE RADIATION CHEMISTRY OF NUCLEIC ACID CONSTITUENTS}

\section{Cyril Ponnamperuma and Richard M. Lemmon}

In continuing our study of the chemical effect of ionizing radiation on aqueous solutions of nucleic acid constituents, 1 we have investigated the following:

1. The formation of 8 -hydroxyadenine from adenine;

2. The radiation decomposition of nucleosides;

3. The effect of radiation on RNA.

\section{The formation of 8 -hydroxyadenine from adenine}

When an aqueous solution of adenine was irradiated, two types of effects were observed. In one case, the purine ring was preserved; in the other, the ring structure was destroyed. 2 Deamination, or the conversion of adenine to hypoxanthine, is an example of the first type. ${ }^{3}$ An example of the second type of effect is the opening of the imidazole ring. The identification of the 4,6-diamino-5-formamidopyrimidine and the 4-amino-5formamido-6-hydroxypyrimidine has already been reported. 4

A second compound formed by the radiolysis of adenine without destruction of the purine ring was identified as 8-hydroxyadenine (Fig. 3-1). The steps by which the identity of this compound (hereafter referred to as compound B) was established were as follows.

As the chromatographic characteristics of compound $B$ were very similar to those of the 4,6-diamino-5-formamidopyrimidine already identified, it was thought to be an isomer of this compound. The identified compound is presumably formed by the fission on the $\mathrm{C}-8-\mathrm{to}-\mathrm{N}-9$ bond of adenine. If the ring opening took place by the fission of the $\mathrm{N}-7-\mathrm{to}-\mathrm{C}-8$ bond, the 5,6-diamino-4-formamido compound might also be formed.

Although several methods are available for the preparation of the 4,6-diamino-4-formamidopyrimidine, 5,6 the 5,6-diamino-4-formamido compound has not been reported in the literature. In fact, with the 4,6diamino pyrimidine no formylation can be accomplished. 7

${ }^{1}$ Cyril Ponnamperuma and Richard M. Lemmon, in Bio-Organic Chemistry Quarterly Report, UCRL-10032, Dec. 1961, p. 90.

${ }^{2}$ Cyril Ponnamperuma and Richard M. Lemmon, in Bio-Organic Chemistry Quarterly Report, UCRL-9652, April 1961, p. 50.

${ }^{3}$ C. Ponnamperuma, R. M. Lemmon, E. L. Bennett, and M. Calvin, Science 134,113 (1961).

${ }^{4}$ Cyril Ponnamperuma and Richard M. Lemmon, in Bio-Organic Chemistry Quarterly Report, UCRL-9900, Oct. 1961 , p. 81.

${ }^{5}$ L. F. Cavalieri and A. Bendich, J. Am. Chem. Soc. 72, 2593 (1950).

${ }^{6}$ L. F. Cavalieri and A. Bendich, J. Am. Chem. Soc. 71,533 (1949).

${ }^{7}$ G. B. Brown (Sloan-Kettering Institute, New York), personal communication. 


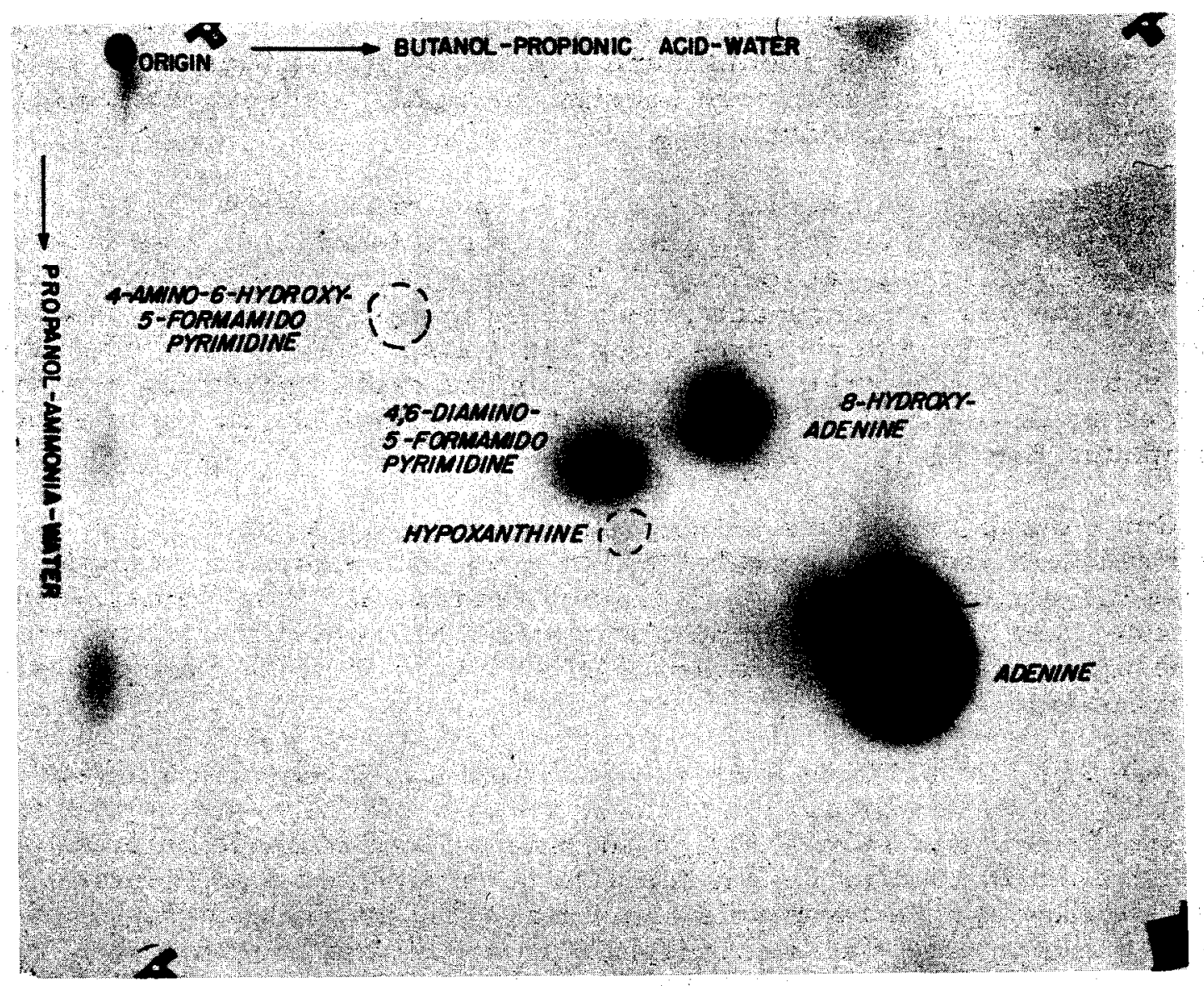

$\mathrm{ZN}-3093$

Fig. 3-1. Autoradiograph of adenine-2-C $\mathrm{C}^{14}$ $(0.1 \%$ aqueous soln) irradiated at $2 \times 10^{6}$ rads. 
Compound $\mathrm{B}$ was unaffected by hydrolysis with $1 \mathrm{~N} \mathrm{HCl}$ for 1 hour. In addition, heat cyclization at $200^{\circ}$ produced no adenine from it, whereas a formamidopyrimidine would have been expected to give a quantitative yield of adenine. 6 The possibility that compound $B$ could be the 5,6 diamino-4-formamido compound was therefore ruled out.

When the radiolysis was repeated with adenine $-8-C^{14}$, the resulting chromatogram gave an autoradiograph identical with that obtained from irradiated adenine $-2-\mathrm{C}^{14}$ solution. No radioactivity was lost when compound $\mathrm{B}$ from adenine-8-C $\mathrm{C}^{14}$ was hydrolyzed with $1 \mathrm{~N} \mathrm{HCl}$. This clearly indicated that both carbon atoms 2 and 8 of the purine system were present in compound $B$. It was therefore considered highly probable that the purine ring was intact in this product.

A shadowgram of adenine $-2-\mathrm{C}^{14}$ solution irradiated at $2 \times 10^{6}$ rads and chromatographed on Whatman No. 4 paper in two dimensions indicated that compound $B$ was uv-absorbing. 8 . The spectrum of the material was masked by the heavy background produced by the oxidation products of the solvents. As adenine derivatives are almost insoluble in ether, the interfering substances were removed by washing the paper containing compound $B$ with ether before eluting it with water. Figure 3-2 shows the uv spectrum of compound $\mathrm{B}$ at $\mathrm{pH} 2,7$, and 10 .

Since compound $B$ was readily produced, giving a yield of $5.5 \%$ at $2 \times 10^{6}$ rads, it was thought probable that it was the result of a simple process of hydroxylation. 6-N-Hydroxylaminopurine, isoguanine, adenine $\mathrm{l}-\mathrm{N}$-oxide, and 8-hydroxyadenine are possible hydroxylation products of adenine (Fig. 3-3). The formation of a 3-, 7-, or 9-oxyderivative has been considered unlikely. 9

Adenine $1-\mathrm{N}$-oxide is formed by the action of $\mathrm{H}_{2} \mathrm{O}_{2}$ on a solution of adenine. 9,10 As radiolysis products of organic solutions are very similar to the reaction products of $\mathrm{H}_{2} \mathrm{O}_{2}, 1 \mathrm{l}$ adenine $\mathrm{l}-\mathrm{N}$-oxide could be produced by the irradiation of adenine. It has also been reported that adenine $\mathrm{I}-\mathrm{N}-$ oxide is formed by the radiolysis of adenine. 12 However, adenine $1-\mathrm{N}-$ oxide has a characteristic uv absorption spectrum with maxima at $231 \mathrm{~m} \mu$ and $262.5 \mathrm{m \mu}$. 10 The molar extinction coefficient at $231 \mathrm{m \mu}$ is $41.5 \times 10^{3}$, whereas at $262.5 \mathrm{m \mu}$ it is only $8.1 \times 10^{3}$. Although adenine $1-\mathrm{N}$-oxide has $R_{f}$ values very similar to compound $B$ in four different solvent systems

8 J. Smith and R. Markham, Biochem. J. 45, 294 (1949).

${ }^{9}$ M. A. Stevens and G. B. Brown, J. Am. Chem. Soc. 80, 2759 (1958).

10 M. A. Stevens, D. I. Magrath, H. W. Smith, and G. B. Brown, J. Am. Chem.Soc. 80, 2755 (1958).

${ }^{11}$ G. Scholes and J. Weiss, Exptl. Cell. Research Supp. 2, 219 (1952).

$12 E$. R. Lochman, Doctoral dissertation, Technical University of Berlin, 1961 . 


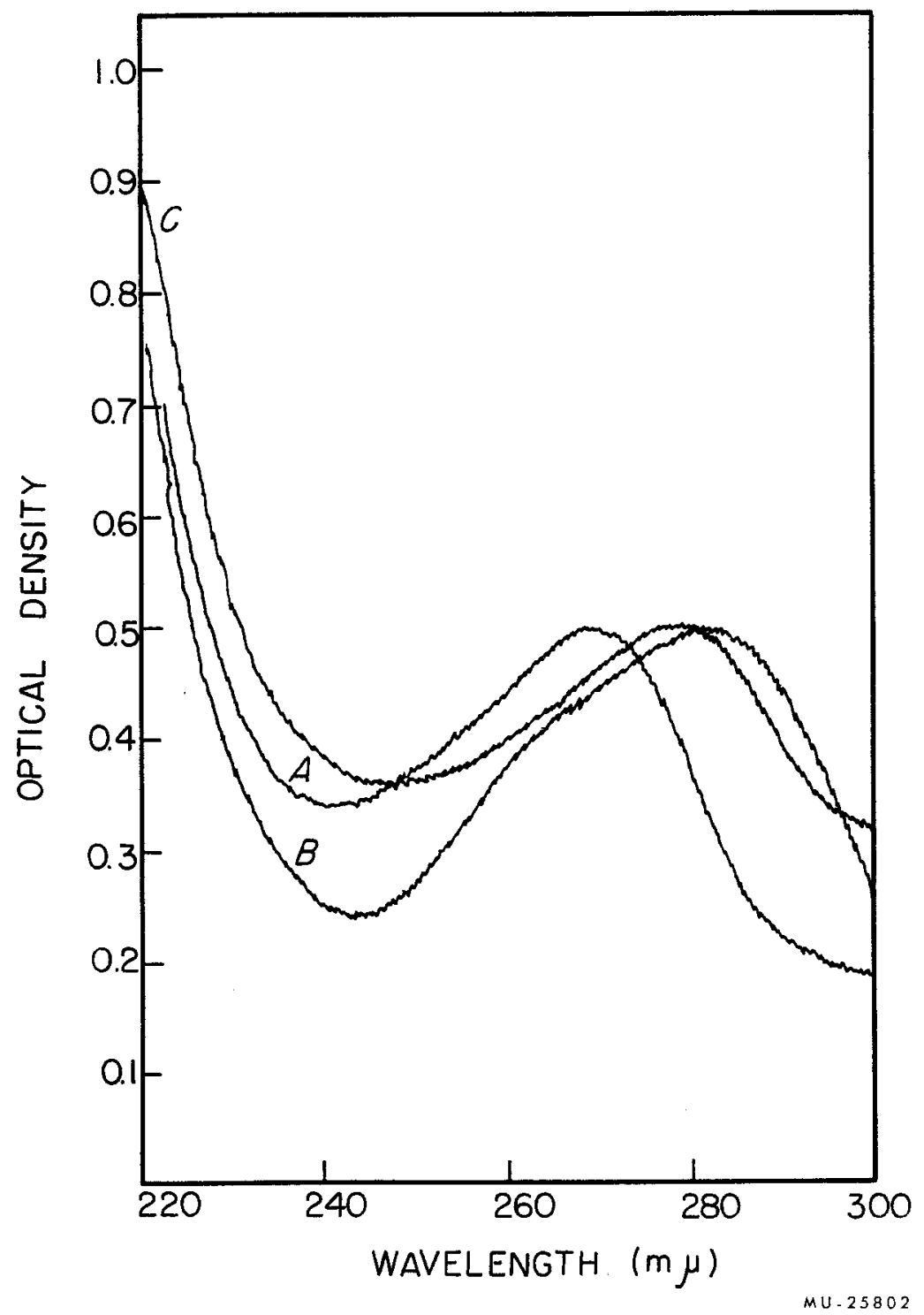

Fig. 3-2. The uv spectrum of compound B. $\mathrm{A}$ at $\mathrm{pH} 7$

$\mathrm{B}$ at $\mathrm{pH} 2$

$\mathrm{C}$ at $\mathrm{pH} 10$ 

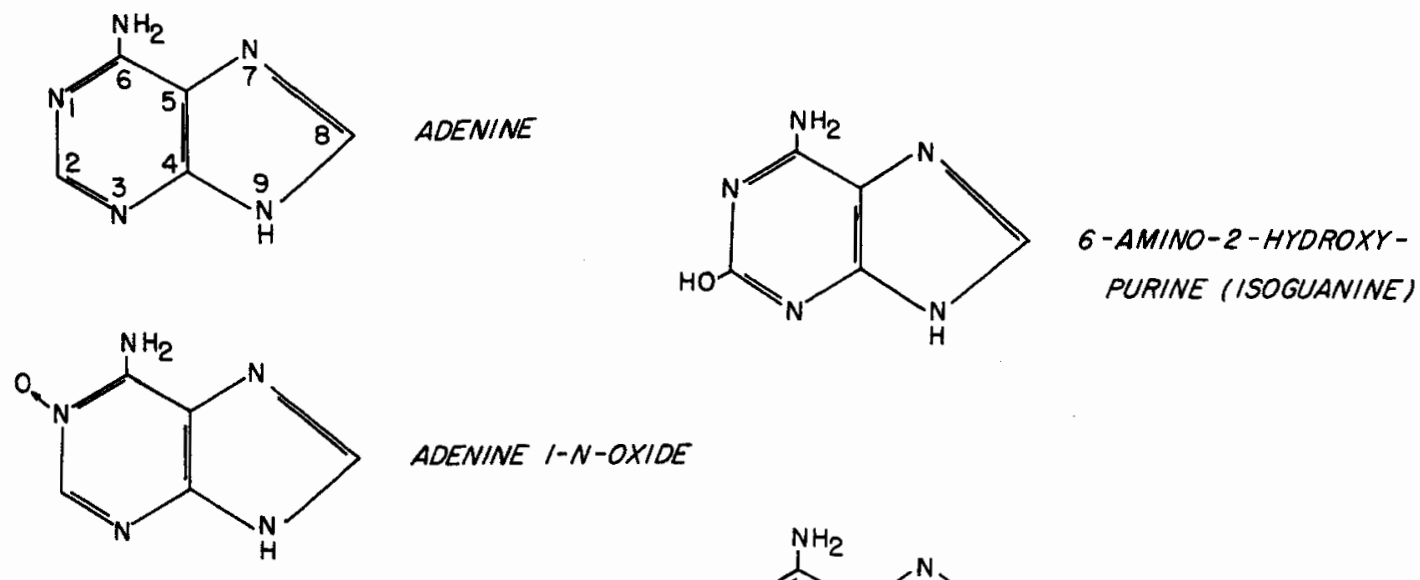

ADENINE /-N-OXIDE<smiles>Oc1ncnc2c1N1CNC2N1</smiles>

6-N-HYOROXYL -

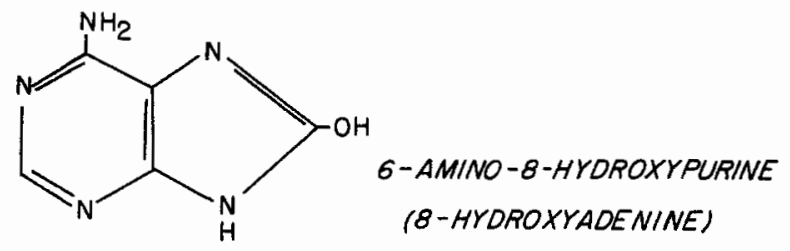
AMINOPURINE

Fig. 3-3. Some substituted purines. 
(propanol-ammonia-water; ${ }^{13}$ butanol-propionic acid-water; ${ }^{14}$ isobutyric acid-ammonia-EDTA; 15 and $n$-butanol-water ${ }^{16}$ ), complete coincidence between adenine $1-\mathrm{N}$-oxide and compound $\mathrm{B}$ was not obtained when the chromatograms were examined with the aid of shadowgrams and autoradiographs. This established that compound $\mathrm{B}$ was not adenine $1-\mathrm{N}$-oxide.

It could be assumed that compound B was isoguanine, which is found in the radiation products of adenine-1-N-oxide. 17 But the uv absorption
spectrum of isoguanine at $\mathrm{pH} 7 \mathrm{had}$ two maxima, at $238 \mathrm{m \mu}$ and $286 \mathrm{m \mu}, 18$ indicating that compound $\mathrm{B}$ was not isoguanine.

Nor could compound B be identical with 6-hydroxylaminopurine. Although the latter has uv spectral characteristics very similar to those of compound $\mathrm{B}$ at $\mathrm{pH} 2$ and $\mathrm{pH} 7,19$ it is unstable in basic solution, whereas compound $B$ is stable. Besides, the 6-hydroxylaminopurine reduced alkaline phosphomolybdate reagent, as well as $\mathrm{AgNO}_{3}, 19$ and produced a deep blue color with $\mathrm{FeCl}_{3} .20$ None of these reagents was affected by compound $B$.

Its spectral characteristics and stability to heat and acid treatment seemed to indicate that compound B was 8-hydroxyadenine. The latter was prepared by passing phosgene into a solution of 4, 5,6-triaminopyrimidine sulfate. 21 One gram of 4,5,6-triaminopyrimidine sulfate was dissolved in $40 \mathrm{ml}$ of $10 \% \mathrm{NaOH}$, and phosgene was passed in for 2 hours; $5 \mathrm{ml}$ of $2 \mathrm{~N} \mathrm{H}_{2} \mathrm{SO}_{4}$ was added to the reaction mixture. On cooling, the 8-hydroxadenine sulfate separated. The product was recrystallized from $2 \underline{\mathrm{N}} \mathrm{H}_{2} \mathrm{SO}_{4}$. Analytical data were as follows:

$$
\begin{array}{lll}
\text { For }\left(\mathrm{C}_{5} \mathrm{H}_{5} \mathrm{ON}_{5}\right)_{2} \mathrm{H}_{2} \mathrm{SO}_{4} & \\
\text { Calculated } & \text { C, } 30.03 \% & \mathrm{H}_{2} 3.02 \% \\
\text { Found } & \text { C. } 30.05 \% & \mathrm{H}, 3.10 \%
\end{array}
$$

Twenty-five $\mu$ g of 8 -hydroxyadenine was cochromatographed on paper with $25 \mu 1$ of adenine $-2-C^{14}$ solution irradiated at $2 \times 10^{6}$ rads. The radio. activity of compound $B$ coincided chromatographically with the uv absorption of the 8-hydroxyadenine. This coincidence was obtained in four different solvent systems, establishing that compound B was 8-hydroxyadenine.

13 E. L. Bennett, Biochim. Biophys. Acta 11, 487 (1953).

${ }^{14} \mathrm{M}$. Goodman, in University of California Radiation Laboratory Report UCRL-1961, Sept. 1952, p. 67.

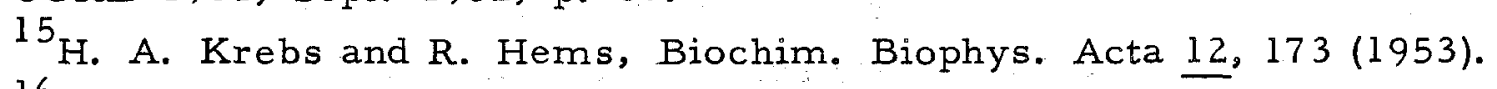

${ }^{16}$ F. Weygand, R. Junk, and D. Leber, Z. physiol. Chem. 291, 191 (1952).

${ }^{17}$ G. B. Brown (Sloan-Kettering Institute, New York), personal communication.

${ }^{18}$ L. F. Cavalieri, A. Bendich, J. F. Tinker, and G. B. Brown, J. Am. Chem. Soc. 70, 3875 (1948).

19 A. Giner-Sorolla and A. Bendich, J. Am. Chem. Soc. 80, 3932 (1958).

20 A. Hantzsch and C. H. Desch, Ann. 323, 23 (1902).

21 L. F. Cavalieri and A. Bendich, J. Am. Chem. Soc. 72, 2587 (1950). 
This was further confirmed by the uv absorption spectra of compound $B$ (Fig. 3-4), which had the same characteristics as those of 8 ohydroxyadenine at $\mathrm{pH} 2,7$, and 10 .

\section{The radiation decomposition of nucleosides}

Some of the chemical changes that occur when nucleosides are irradiated have been reported by Scholes and Weiss. 22,23 One of the results described was the formation of free ribose from nucleosides. Hydroperoxides have also been shown to be formed from the nucleosides of the pyrimidines when irradiated in the presence of oxygen. 24

In this investigation, $\mathrm{C}^{14}$-labeled nucleosides were irradiated in aqueous solutions to determine whether the changes observed in the free base also took place in the nucleoside. Of special interest was the question of deamination.

$C^{14}$-labeled adenosine, guanosine, and cytidine were obtained from Schwarz BioResearch, Mount Vernon, New York. Their specific activities were

$$
\begin{aligned}
& \text { Adenosine-8-C } \mathrm{C}^{14}, \quad 5 \mu \mathrm{C} / \mathrm{mg} \text {; } \\
& \text { Cytidine-2-C } \mathrm{C}^{14}, \quad 4 \mu \mathrm{C} / \mathrm{mg} \text {; } \\
& \text { Guanosine-2-C } \mathrm{C}^{14} \text {, } \quad 3.1 \mu \mathrm{C} / \mathrm{mg} \text {. }
\end{aligned}
$$

Two hundred and fifty $\mu l$ of $0.1 \%$ aqueous solutions of these nucleosides were irradiated in the absence of air at a dose of $2 \times 10^{6}$ rads. The radiation products were chromatographed on paper in two dimensions, with butanol-propionic acid-water 14 and propanol-ammonia-water 13 as solvents. In every case there was a release of free base: adenine from adenosine, guanine from guanosine, and cytosine from cytidine.

Cochromatography with inactive carrier, combined with autoradiography and uv shadowgrams, demonstrated the deamination of these bases. Hypoxanthine was detected in the radiation products of adenosine, xanthine in guanosine, and uracil in cytidine. The yield of free bases and hydroxy bases formed from the nucleosides is shown in Table 3-I.

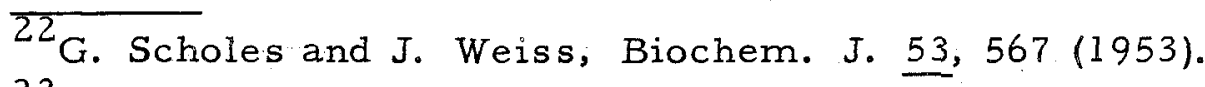

${ }^{23}$ G. Scholes and J. Weiss, Biochem. J. 56,65 (1954).

${ }^{24}$ M. Daniels, G. Scholes, and J. Weiss, J. Chem. Soc. 3771 (1956). 


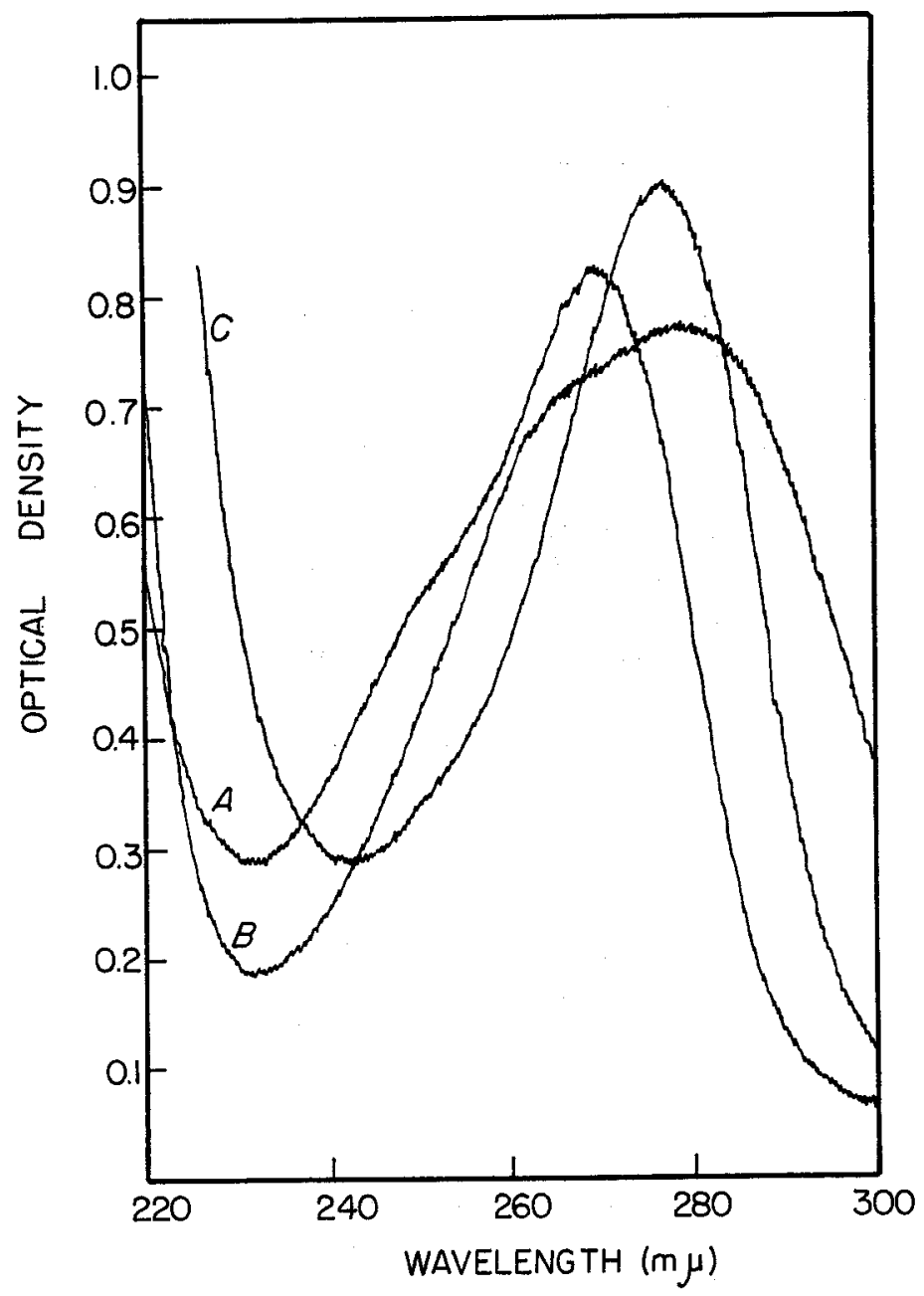

MU -25803

Fig. 3-4. The uv spectrum of 8-hydroxyadenine.
A $\mathrm{pH} 7$
$\mathrm{B}$ pH 2
C $\mathrm{pH} 10$ 
Table 3-I. Formation of bases and hydroxy bases from nucleosides irradiated at $2 \times 10^{6}$ rads (amounts, in percent, following irradiation).

\begin{tabular}{|c|c|c|c|c|c|}
\hline Nucleoside & & Base & & Hydroxy base & \\
\hline Adenosine & $18 \%$ & Adenine & $35 \%$ & Hypoxanthine & $2 \%$ \\
\hline Cytidine & $20 \%$ & Cytosine & $9 \%$ & Uracil & $0.5 \%$ \\
\hline Quanosine & $25 \%$ & Guanine & $14 \%$ & Xanthine & $2 \%$ \\
\hline
\end{tabular}

A conclusion based on $R_{f}$ values is that some deamination took place before the release of the ribose to give inosine from adenosine, xanthosine from guanosine, and uridine from cytidine. The quantitative aspects are now being examined by cochromatography with inactive carriers.

In addition to hypoxanthine, 4,6-diamino-5-formamidopyrimidine and 8-hydroxyadenine (formed in the radiolysis of adenine) were also detected in the radiation-decomposition products of adenosine. The main products were adenine (35\%), 4,5-diamino-5-formamidopyrimidine (3\%), 8-hydroxyadenine $(4 \%)$, and hypoxanthine $(2 \%)$, indicating that the fission of the glycosidic linkage takes place before the attack on the base.

The liv spectra of $0.1 \%$ solutions of adenosine, guanosine, and cytidine, irradiated at $2 \times 10^{6}$ rads, are shown in Figs. 3-5, 3-6, and 3-7. In adenosine, there is a decrease of about $40 \%$ in the optical density of the solution at $260 \mathrm{~m} \mu$. In guanosine, the peak at $252 \mathrm{m \mu}$ has disappeared and a new peak has appeared at $225 \mathrm{m \mu}$, where the unirradiated solution showed a minimum. In cytidine, the absorption has disappeared completely, possibly owing to the destruction of the chromophore in the pyrimidine ring or the formation of a pyrimidine glycol described by Ekert and Monier.

\section{The effect of radiation on RNA}

Several workers have described the physicochemical changes produced when nucleic acids were irradiated in solution. 26, 27 Many of these changes have been explained in terms of the fission of sugar phosphate bonds in the backbone of the molecule, and the rupture of hydrogen bonds. 28

It is of considerable importance to know whether the changes which the base (either in a nucleoside or a nucleotide) undergoes when irradiated occur in the case of the polymer.

$\overline{25}$ B. Ekert and R. Monier, Nature 188, 309 (1960).

${ }^{26}$ R. A. Cox, W. G. Overend, A. R. Peacocke, and S. Wilson, Nature 176,919 (1955).

${ }^{27}$ G. Scholes and J. Weiss, Nature 164, 709 (1949).
${ }^{28}$ G. Scholes and J. Weiss, Nature 166, 640 (1950). 


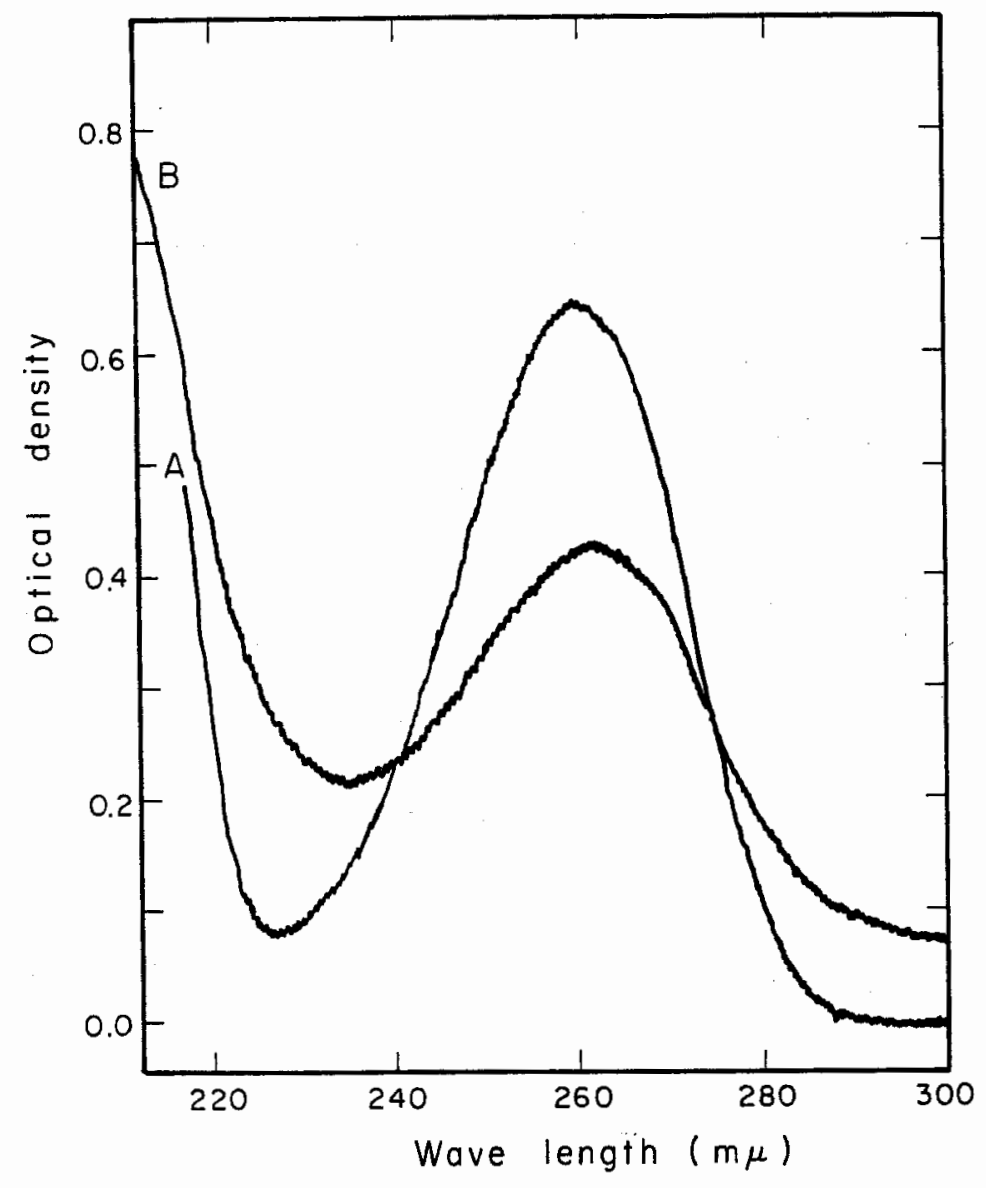

Fig. 3-5. The uv spectrum of adenosine. A unirradiated

B $2 \times 10^{6} \mathrm{rads}$ 


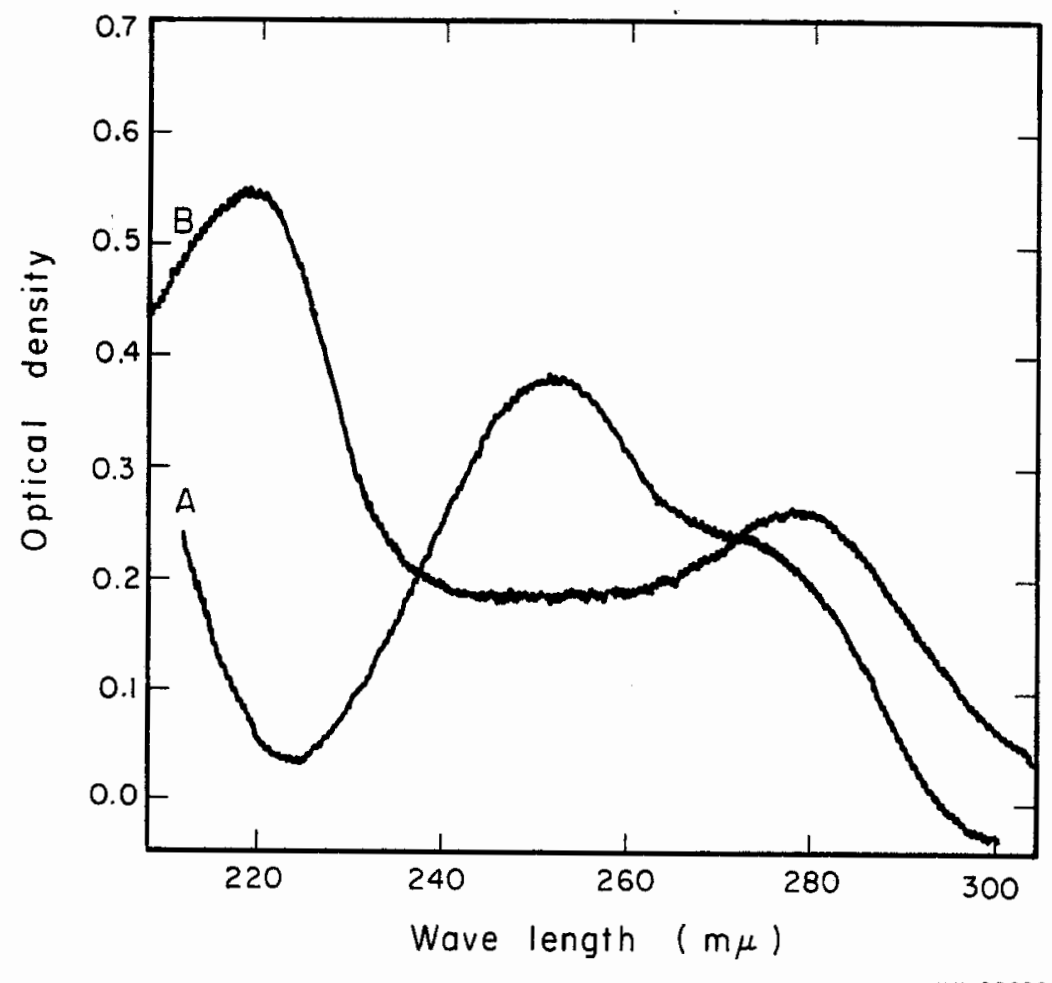

Fig. 3-6. The uv spectrum of guanosine. A unirradiated

B $2 \times 10^{6}$ rads 


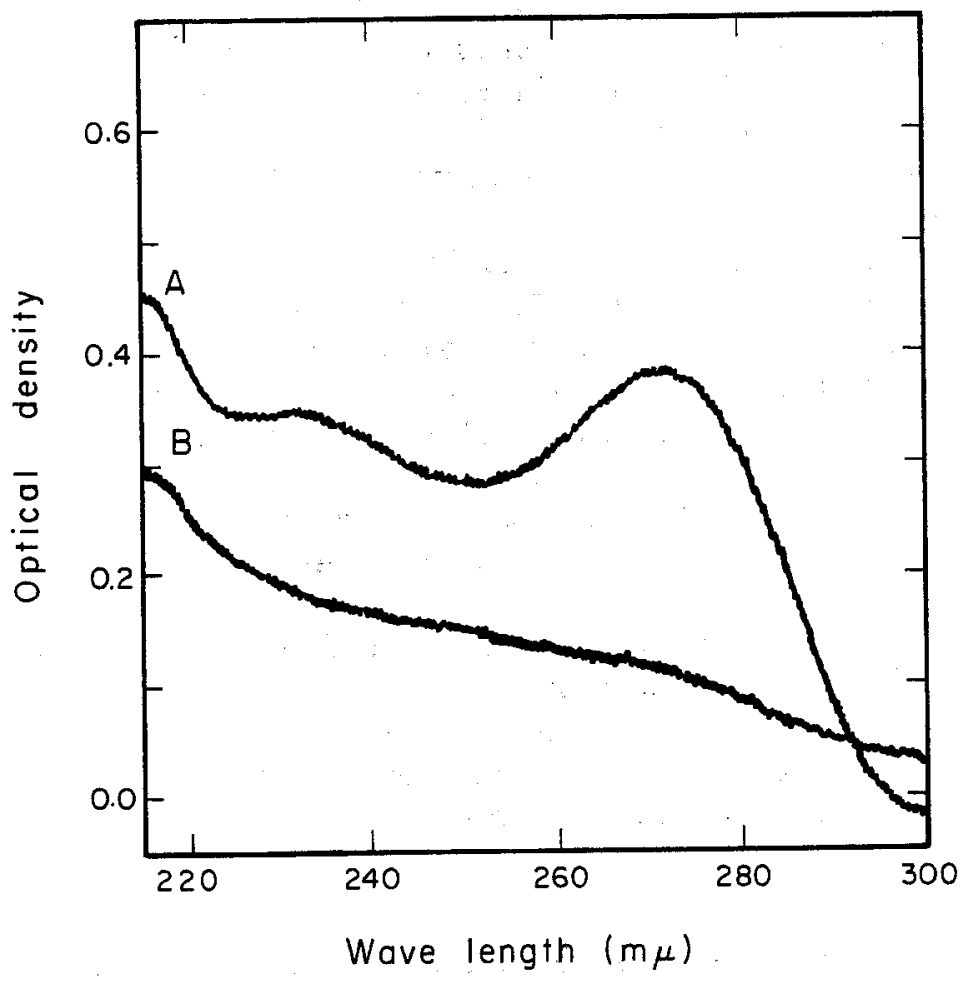

Fig. 3-7. The uv spectrum of cytidine. A unirradiated

B $2 \times 10^{6} \mathrm{rads}$ 
An exploratory experiment was performed with RNA to find out whether adenylic acid could be deaminated to inosinic acid when a solution of RNA was irradiated at $2 \times 10^{6}$ rads. 3

RNA randomly labeled with $\mathrm{C}^{14}$ of specific activity $30 \mu \mathrm{C} / \mathrm{mg}$ was obtained from Schwarz BioResearch, Mount Vernon, New York. Two hundred and fifty $\mu$ of a $0.1 \%$ solution of RNA was irradiated at $2 \times 10^{6}$ rads.

Several methods have been described for the hydrolysis of nucleic acids to the constituent nucleotides, nucleosides, and free bases. 29 Many of these methods give rise to deamination. Thus, $1 \mathrm{~N}$ alkali at $37^{\circ}$ has caused $10 \%$ to $33 \%$ deamination in cytidylic acid. 30 Cytidylic acid was deaminated to the extent of $2 \%$ in $0.01 \mathrm{~N} \mathrm{NaOH}$ and $12 \%$ in $0.1 \mathrm{~N} \mathrm{NaOH}$, but no deamination was detected at $\mathrm{pH} 11.31$ This latter method, therefore was used for the hydrolysis of RNA in the experiment.

One hundred $\mu$ l each of RNA irradiated at $2 \times 10^{6}$ rads, and unirradiated RNA, were treated with $100 \mu l$ of $0.002 \mathrm{~N} \mathrm{NaOH}$ at $37^{\circ}$ for 24 hours. Twentyfive $\mu l$ of each solution were then chromatographed two-dimensionally, with inactive inosinic acid used as carrier. As the radioactive spots on the autoradiograph were not well defined, the spots corresponding to the inosinic acid were cut out and rechromatographed in isobutyric acid-ammonia-EDTA. 15 A trace of radioactivity $(0.01 \%)$ was detected in the inosinic acid spot corresponding to the blank, and $0.5 \%$ in that from the irradiated material.

In a further experiment, the irradiated RNA solution was subjected to paper ionophoresis 32 at 600 volts for 6 hours in propionate buffer at $\mathrm{pH} 3.4$. About $0.5 \%$ radioactivity was detected in the spot corresponding to the inactive carrier inosinic acid. It appears therefore that deamination takes place in the free base and in the nucleoside, as well as in the polymer.

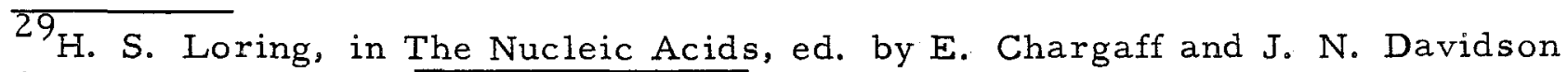
(Academic Press, New York, 1955), Vol. I, p. 191. $30_{D}$. H. Marrian, V. L. Spicer, M. E. Balis, and G. B. Brown, J. Biol. Chem. 189, 533 (1951).

${ }^{31}$ H. S. Loring, H. W. Bortner, L. W. Levy, and M. L. Hammell, J. Biol. Chem. 196, 807 (1952).

${ }^{32}$ D. P. Burma, Science 118, 694 (1953). 


\section{RADIATION SENSITIVITY OF CHOLINE BROMIDE}

Sylvia Obradovic, * Margaret A. Smith, and Richard M. Lemmon

It has been shown that the great radiation sensitivity of crystalline choline chloride disappears when the crystals are maintained at $150^{\circ} .1$

Shanley and Collin have shown that choline chloride changes in the temperature range 73 to $80^{\circ}$ from an orthorhombic to a partially disordered cubic form. 2 It is now well established that the radiation sensitivity of crystalline choline chloride is associated with its normal form at room temperature, and that with the crystal-phase change near $80^{\circ}$ the compound loses its extraordinary radiosensitivity.

Only one analog of choline chloride - namely, choline bromide - shows any tendency toward radiosensitivity in the crystalline form. Gvalue measurements for the bromide indicate a radiosensitivity about onefourth or one-third that of the chloride. ${ }^{3}$ Of further interest is the fact that choline bromide also exists as orthorhombic crystals at room temperature. 4 The purpose of the work reported here was to determine whether or not choline bromide also changes to a more radiation-resistant crystal form at a higher temperature.

\section{Experimental Procedure}

The choline bromide was prepared from choline chloride (Eastman "white label") by shaking the chloride with excess $\mathrm{Ag}_{2} \mathrm{O}$, filtering off the $\mathrm{AgCl}$ and excess oxide, and titrating the solution to neutrality with $\mathrm{HBr}$. The solution was evaporated to dryness and the choline bromide was re crystallized from ethanol-ether. The elemental analysis showed C, $32.83 \%$; $\mathrm{H}, 7.77 \%$ (the theoretical values are $\mathrm{C}, 32.62 \% ; \mathrm{H}, 7.66 \%$ ).

The microscopic examinations were carried out on a Kofler hot: stage equipped with crossed Nicol prisms. At room temperature the choline bromide crystals were observed to be rhomb-shaped plates; they were birefringent and anisotropic. The crystals were observed to lose their birefringence at $91 \pm 10$ (uncorrected). It therefore appears that at this temperature the crystals undergo polymorphic transformation into an isotropic cubic form.

The choline bromide crystals were irradiated in evacuated Pyrex tubes. The irradiations were carried out on a 5-Mev linear electron

\footnotetext{
*National Science Foundation Research Participant, 1961.

${ }^{1}$ I. Serlin, Science 126, 261 (1957).

${ }^{2}$ P. Shanley and R. L. Collin, Paper No. 143, Radiation Research Society Meeting, Washington, D. C., May 15-17, 1961.

${ }^{3}$ R. M. Lemmon et al., J. Am. Chem. Soc. 80, 2730 (1958).

${ }^{4}$ M. E. Senko and D. H. Templeton, Acta Cryst. 13, 281 (1960).
} 
accelerator in a manner previously described. ${ }^{5}$ Some of the samples were irradiated at room temperature. The others were heated to $100^{\circ}$ (by an infrared lamp), and kept at that temperature for 5 minutes before the electron irradiation was begun. The temperature was maintained at 100 to $125^{\circ}$ during the irradiation.

The amounts of radiation decomposition were determined by measuring the amounts of trimethylamine produced. This method is reliable for determining the degree of radiation decomposition of choline chloride. 6 It is probably also a valid index of the decomposition of the bromide.

\section{Results}

Five samples of choline bromide were irradiated at room temperature, and five at 100 to $125^{\circ}$. The radiation dose in all cases was either $4 \times 10^{7}$ or $5 \times 10^{7}$ rads. The measured $G$ values of the room-temperature samples ranged from 5.9 to 8.4 (average 6.6). The $G$ values for the high-temperature decompositions ranged from 4.2 to 5.1 (average 4.7). Under electron irradiation, therefore, choline bromide does appear to be more stable at $100^{\circ}$ than at room temperature - - but the difference in stability is a modest one. Perhaps under $\gamma$ irradiation, with the input of energy per unit time much lower, the difference between the high-and low-temperature $G$ values might become more pronounced.

It must be remembered that in the case of choline bromide, unlike that of choline chloride, we do not know that the production of volatile amine is a valid index of the degree of radiation decomposition. Further work to settle this point, and to measure the decomposition of choline bromide at high and low temperatures under $\gamma$ irradiation, is clearly called for.

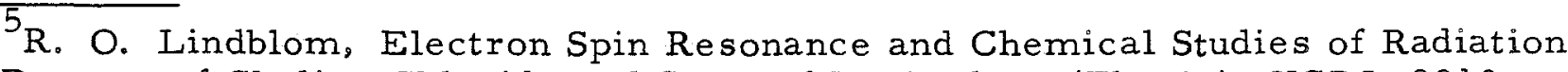
Damage of Choline Chloride and Some of Its Analogs. (Thesis), UCRL-8910, October 19, 1959, pp. 9-10.

6 


\section{THE OXIDATION OF FREE SUGARS AND ALDONIC ACID DERIVATIVES BY ACETOBACTER SUBOXYDANS}

Robert J. Ferrier, Harold Bowman, and V. Moses.

Acetobacter suboxydans has been used extensively ${ }^{1}$ to prepare ketoses from acyclic carbohydrate derivatives possessing D-erythro-diols adjacent to the terminal hydroxymethyl group, i.e.,<smiles>OCC(O)C(O)CO</smiles>

Cyclitols have also been shown to be susceptible to oxidation by this organism. ${ }^{2}$ and two of us have recently found that pyranosides will undergo oxidation, but at a very low rate. 3

The free aldoses might be expected to yield keto sugars, aldonic acids or keto acids, but little attention has been given to their mode of reaction. $D$-Glucose and its 2 -deoxy derivative 4 are the only members to have been subjected to oxidation by this bacterium. Glucose can give rise to gluconic acid, 42 keto-gluconic acid, 4,5 and 5 keto-gluconic acid; ${ }^{5}$ the proportions of the products depend upon the precise conditions used. Some derivatives of aldonic acids have been investigated, and keto products from ammonium $D$-arabonate, $6 a-D$-glucóheptonic- $\gamma$-lactone, 6 and calcium galactonate 7 are amongst those reported.

We have subjected a series of aldoses to oxidation by Acetobacter suboxydans and have followed the reactions manometrically noting the volumes of oxygen absorbed and carbon dioxide released. Each of the aldoses chosen (D-glucose, D-mannose, D-galactose, 2-deoxy-D-glucose, D-ribose, D- and L-arabinose, D-and L-xylose, and D-lyxose) reacted, with the consumption of $0.5 \mathrm{~mol}$ oxygen before carbon dioxide was liberated, indicating that a one-step oxidation had occurred. Chromatographic investigation indicated that in every case an acidic product had been formed, and no evidence was found for any keto sugar. Keto sugars would be expected to have chromatographic properties similar to those of the starting materials and quite different from those of the acids. The products of the oxidations

I. K. N. Jones, M. B. Perry, and J. C. Turner, Canad. J. Chem. 39, 965 (1961).

${ }^{2}$ B. Magasanik, R. E. Franzl, and E. Chargaff, J.Am. Chem. Soc. 74, 2618 (1952); L. Anderson, K. Tomita, P. Kussi, and S. Kirkwood, J. Biol. Chem. 204, 769 (1953); T. Posternak and F. Ravenna, Helv. Chem. Acta 30, 441 (1947); L. Anderson, R. Takeda, S. J. Angyal, and D. J. McHugh, Arch. Biochem. Biophys. 78, 518 (1958).

${ }^{3} \mathrm{~V}$. Moses and R. J. Ferrier, Biochem. J., in press.

4 T. E. King and V. H. Cheldelin, ibid. 68, $31 \mathrm{P}$ (1958).

5 J. A. Fewster, ibid. $68,19 \mathrm{P}(1958)$

${ }^{6}$ Liebster, Kulhånek, and Tadea, Chem. listy 47, 1075 (1953).

7 Ettel, Liebster, and Tadea, ibid. 46, 45 (1952). 
of the D-aldoses (with the exception of 2-deoxy-D-glucose) were isolated from larger-scale experiments and were shown by titration to be acidic in nature. It is thus apparent that the reducing function at $C_{(1)}$ in the aldoses is the most susceptible point for oxidation by the organism, even in those sugars (D-glucose, D-mannose, 2-deoxy-D-glucose, D-ribose, and Darabinose) possessing the necessary terminal grouping in the acyclic form (which could be available to the cells on disturbance of the equilibrium existing in solution between the various isomeric forms of the sugars).

The ketoses D- and L-ribulose, D-xylulose, L-sorbose, and D-fructose were next investigated. Of these, only the first and last possess, in the acyclic configuration, the required terminal group, and only D-ribulose was found to react to give a discrete product (tentatively assigned the structure $1,3,5$-trihydroxypentane-2,4-dione $\left.{ }^{3}\right)$. The fact that $\mathrm{D}$-fructose does not yield a keto product is presumably a result of its known existence in the cyclic form. This therefore is the first indication that the ketopentoses exist in aqueous solution appreciably as the acyclic species.

D-Ribono- $\gamma$-lactone and 2 -hydroxymethyl-D-ribono- $\gamma$-lactone did not yield discrete products but were slowly metabolized after the slow formation of a presumably adaptive enzyme system. The derived sodium salts of these substances also failed to yield keto products, but a more thorough investigation of the reactions of salts of these acids might indicate that $C_{(4)}$ was susceptible to oxidation, since ammonium D-arabonate yields the 4-keto derivative. 6 Methyl D-arabonate does give a one-step oxidation product, but its structure has not yet been determined.

\section{Experimental Procedure}

The gas exchanges were followed at $30^{\circ}$ in a Warburg respirometer using cells which had been grown for 4 days at $28^{\circ}$. The reaction flasks contained (a) cell suspension, $1.7 \mathrm{ml}$ (20 to $25 \mu 1$ wet-packed cells $/ \mathrm{ml}$ ) in $67 \mathrm{mM} \mathrm{KH} 2 \mathrm{PO}_{4}$ at $\mathrm{pH} 6.7$; (b) substrates, $0.3 \mathrm{ml}(50 \mu \mathrm{mole} / \mathrm{ml})$ in $67 \mathrm{mM}$ $\mathrm{KH}_{2} \overline{\mathrm{PO}}_{4}$ at $\mathrm{pH} 6.7$ (side $\mathrm{arm}$ ); (c) $\mathrm{KOH}, 0.1 \mathrm{ml}(15 \%)$, in the center well of those vessels in which $\mathrm{CO}_{2}$ was absorbed.

The larger-scale oxidations were carried out with about $1.0 \mathrm{~g}$ substrate in $25 \mathrm{ml}$ cell suspension containing about $0.5 \mathrm{ml}$ wet-packed cells in distilled water. The reacting mixtures were shaken at $28^{\circ}$ in $250-\mathrm{ml}$ flasks under an atmosphere of oxygen, and the oxidations were followed polarimetrically. 


\section{CHARACTERIZATION OF A PHOSPHATE ESTER OF 2-KETO-L-GULONIC ACID-C 14 OBTAINED FROM CHLORELLA SUPPLIED WITH C ${ }^{14} \mathrm{O}_{2}$ IN THE LIGHT}

V. Moses and Robert J. Ferrier

Several years ago a hitherto unrecognized compound was obtained chromatographically from extracts of Chlorella supplied in the light with $\mathrm{C}^{14} \mathrm{O}_{2}$. ${ }^{1}$ From its chromatographic position the compound was considered to be a diphosphate ester. After removal of the phosphate groups with phosphatase, the compound behaved as a 6-carbon monocarboxylic ketoaldonic acid. For various reasons, 1 the compound was assigned the general structure<smiles>O=C(O)C(O)C(O)C(=O)CO</smiles>

Reduction of the dephosphorylated substance with borohydride resulted in an aldonic acid believed to be one of four possible $2-C$-hydroxymethylpentonic acids. Only one of these, hamamelonic acid (2-C-hydroxymethylD-ribonic acid), was available as an authentic substance. Although the unknown compound after reduction was very similar to hamamelonic acid, it was obviously not identical, and was therefore considered to be an epimeric mixture of two of the four possible isomers; two epimers would be produced following reduction of the ketone function.

More recently, all four of these isomers have become available, 2 and it was soon apparent that reduction of the keto acid formed by Chlorella did not result in a mixture of two of these six carbon branched-chain aldonic acids. Attention then turned to the possibility of the keto acid's being a straight chain compound, and it was eventually found that reduction with borohydride produced a mixture, in varying proportions, of gulonic and idonic acids. Dr. Frank Loewus, of the Western Regional Laboratory in Albany, kindly undertook to establish the optical configuration of the gulonic acid formed on reduction. The latter was cocrystallized separately with authentic L- and D-gulonic acid, and was shown unequivocally to possess the L configuration.

Four ketogulonic acids are possible, with the ketone function on the $2,3,4$, or 5 carbon atom. Reduction of these would produce, in addition to gulonic acid, idonic, galactonic, allonic, or mannonic acid, respectively. (See Fig. 6-1.) 3-Ketogulonic acid is a $\beta$-keto acid and has been shown to be very unstable; our compound, which is quite stable, was therefore not

\footnotetext{
IV. Moses and M. Calvin, Proc. Natl. Acad. Sci. U.S. 44, 260 (1958).

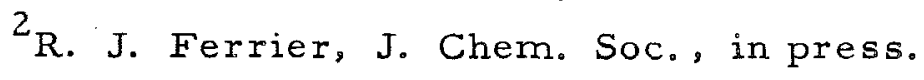




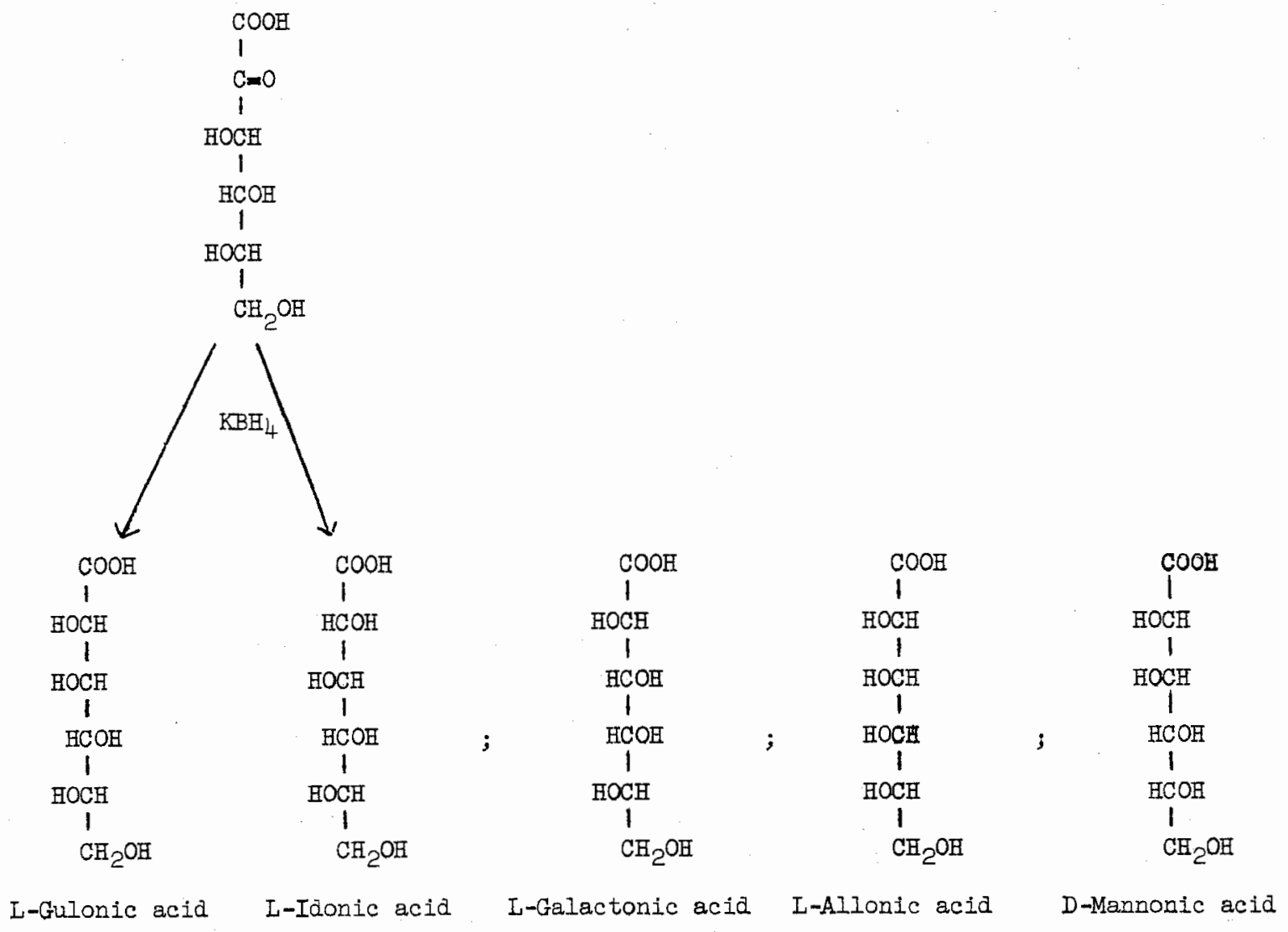

Fig. 6-1. Reduction products of ketogulonic acid. 
the 3-keto compound. The reduction product other than gulonic acid was shown chromatographically to be different from allonic and mannonic acid, but to be identical with idonic acid. The structure of the original keto acid was thus established as that of 2 -keto-L-gulonic acid.

The available evidence concerning the number of phosphate groups may be summarized as follows:

1. The phosphate ester was originally isolated from the "diphosphate area" of the chromatogram. 6-Phosphogluconate runs in the "monophosphate area." However, we have no information on the chromatographic position of any monophosphate ester of a ketohexonic acid.

2. When the phosphate ester was supplied to chloroplasts, ${ }^{3}$ one of the products obtained was a spot which chromatographed in the monophosphate area, and which gave 2-ketogulonic acid on hydrolysis. This was a different substance from the starting material, some of which remained unmetabolized by the chloroplasts, and was recovered from the diphosphate area; the material recovered from the diphosphate area also gave 2-ketogulonic acid on hydrolysis.

3. Phosphate esters of 2-ketogulonic acid have now been obtained from both the monophosphate and diphosphate areas of chromatographic separations of extracts of Chlorella given $\mathrm{C}^{14} \mathrm{O}_{2}$ in the light; both esters yield 2-ketogulonate on hydrolysis. The present indications are thus that the original compound was a diphosphate ester. This, however, has not yet been demonstrated unequivocally - - no evidence is available pertaining to the position of the phosphate groups on the molecule.

Two significant observations have been made concerning the route of biosynthesis of 2 -keto-L-gulonic acid diphosphate. From kinetic studies with Chlorella of the sequence of incorporation of $\mathrm{C}^{14}$ from $\mathrm{C}^{14} \mathrm{O}_{2}$ into a number of substances in the light, it was found that $\mathrm{C}^{14}$ appeared in the diphosphate ester before it appeared in the corresponding monophosphate. This indicates that 2-keto-L-gulonic acid diphosphate may be formed either from a pre-existing diphosphate compound, or by the combination of two monophosphate esters, each containing three carbon atoms, or one containing four and the other two carbon atoms. The monophosphate of 2-ketoL-gulonic acid found in Chlorella is probably an intermediate involved in the further metabolism of the diphosphate, possibly en route to L-ascorbic acid. These kinetic studies did not yield any information on the precursor of the diphosphate, mainly because the amount of $\mathrm{C}^{14}$ found in 2-keto-Lgulonic acid diphosphate was much less than in the possible precursors (e.g., the mono- and diphosphates of glucose and fructose).

$\overline{3}$ V. Moses and M. Calvin, Biochim. Biophys. Acta 31, 550 (1959). 
Whereas $\mathrm{C}^{14}$ is incorporated into 2 -keto-L-gulonic acid diphosphate from $\mathrm{C}^{14} \mathrm{O}_{2}$ in the light, it may also be incorporated from glucose-U-C 14 in the dark. 4 In cells given labeled glucose in the dark, C14 is not found in ribulose diphosphate, and the carbon-reduction cycle is not operative. It thus seems probable that 2-keto-L-gulonic acid diphosphate is not, as suggested earlier, 1 an early photosynthetic product formed directly from the carboxylation product of ribulose diphosphate, but is formed at a later stage in biosynthesis, possibly from a hexose phosphate.

${ }^{4}$ V. Moses, O. Holm-Hansen, J. A. Bassham, and M. Calvin, J. Mol. Biol. 1, 21 (1959). 


\section{MECHANISM OF THE RIBULOSE DIPHOSPHATE \\ CARBOXYLASE SYSTEM. \\ I. PREPARATION AND ISOLATION OF C ${ }^{14} \mathrm{O}_{2} \sim$ ENZYME}

George Akoyunoglou and M. Calvin

Pon, studying the carboxydismutase system, found that a preincubation of the enzyme with $\mathrm{Mg}^{++}$ions and bicarbonate increases its activity. $\mathrm{He}$ suggested two possible interpretations of this phenomenon: (a) The enzyme combines first with the metal ion and bicarbonate and then reacts with RuDP; or (b) the metal ion or bicarbonate activates the enzyme by reaction at some site other than the active site. A conformation change of the enzyme is induced accompanying the activation process. 2,3

A proof of the first interpretation would be the isolation of a " $\mathrm{CO}_{2} \sim$ enzyme" complex which would subsequently react with $\mathrm{RuDP}$. Indirect evidence, particularly with biotin enzymes, shows that $\mathrm{CO}_{2}$ enzyme complexes (active $\mathrm{CO}_{2}$ ) are sometimes formed. Lynen ${ }^{4}$ was able to prepare a $\mathrm{CO}_{2}$ biotin unstable complex by adding biotin as substrate in place of methylcrotonyl CoA in the methylcrotonyl CoA carboxylase system. Recently Ochoa et al. 5 prepared and separated a $\mathrm{CO}_{2}$ enzyme complex (propionyl CoA carboxylase), using Dowex 1-C1 (X8, 200 to 400 mesh) ion-exchange column which was eluted with $0.02 \mathrm{M}$ tris-HCl buffer, pH 8.0, containing $0.001 \mathrm{M}$ GSH. 5

\section{Experimental Procedure}

Preparation of Carboxydismutase

The enzyme was obtained from spinach chloroplasts (Spinacea oleracea), as described by Pon. 1 The chloroplasts were first isolated and then lysed osmotically to yield the chloroplast extract. The extract was fractionated with ammonium sulfate. The final enzyme solution contained $36 \mathrm{mg}$ of protein per $\mathrm{ml}$.

Preparation of $\mathrm{C}^{14} \mathrm{O}_{2} \sim$ Enzyme

The complex was prepared as described in the legends to Figs. $7-1$ through $7-3$.

\footnotetext{
$\overline{{ }^{1} \text { Ning G. }}$. Pon, Studies on the Carboxydismutase System and Related Materials (thesis), UCRL-9373, Aug. 1960.

${ }^{2}$ M. Calvin and N. G. Pon, J. Cellular Comp. Physiol. 54, Suppl. 1, 51-74 (1959).

${ }^{3}$ B. C. Malstrom and A. Rosenberg, Advances in Enzymol. 21, 131 (1959).

${ }^{4}$ F. Lynen, J. Knappe, E. Lorch, G. Juttung, and E. Ringelmann, Angew.

Chem. $71,481-486$ (1959).

${ }^{5}$ Y. Kaziro and S. Ochoa, J. Biol. Chem. 236, 3131 (1961).
} 


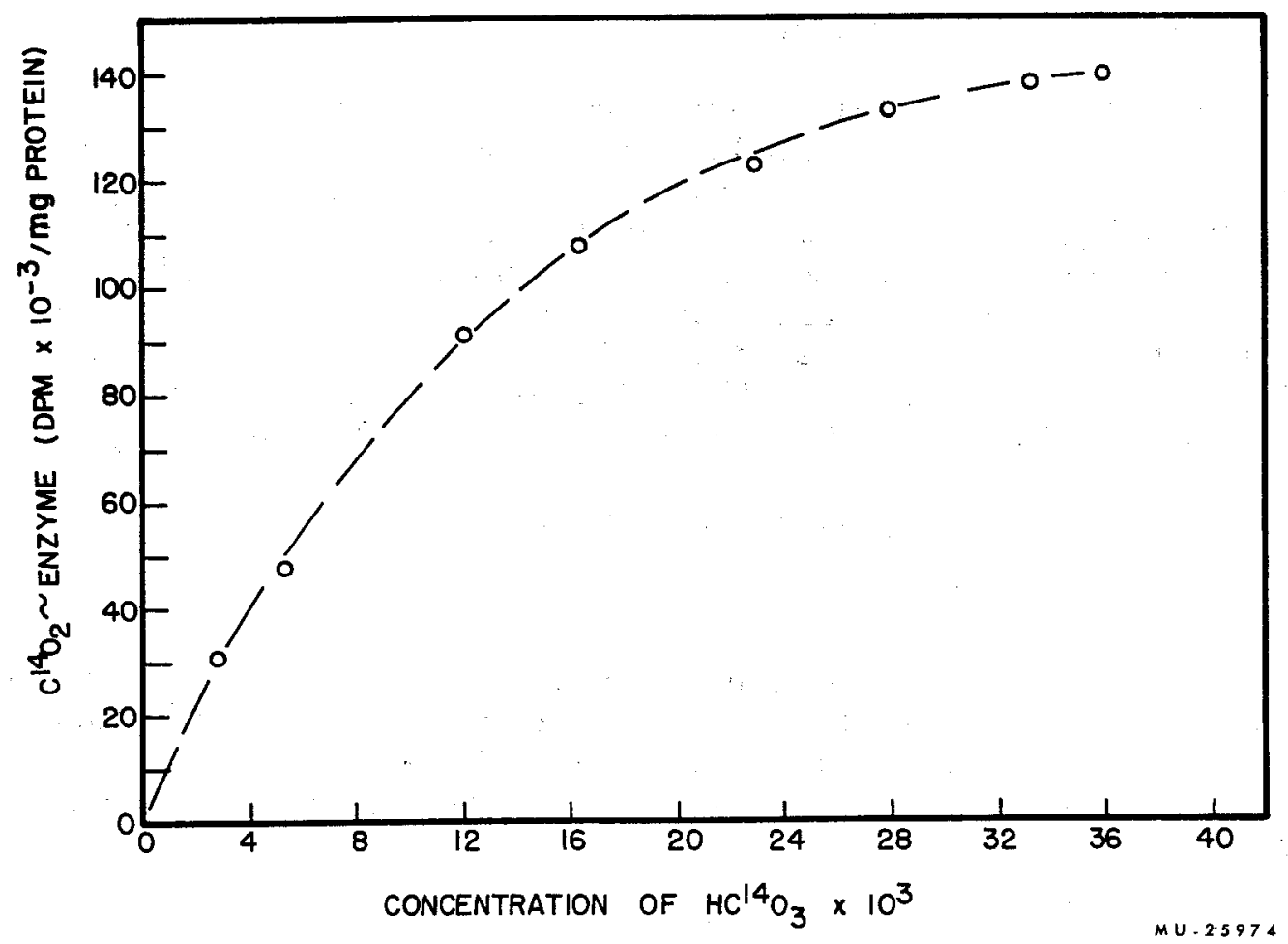

Fig. 7-1. The dependence of the amount of $\mathrm{C}^{14} \mathrm{O}_{2} \sim$ enzyme formed on bicarbonate concentration.

Carboxylation of Enzyme: Each reaction mixture contained ( $\mu$ moles): tris buffer ( $\mathrm{pH} 8.3$ ), 125; $\mathrm{MgCl}, 5 ; \mathrm{NaHC}^{14} \mathrm{O}_{3}$, see curve (specific activity $21 \mu \mathrm{C} / \mu \mathrm{mole})$; enzyme [extracted from chloroplasts of Spinacea oleracea and fractionated with $\left.\left(\mathrm{NH}_{4}\right)_{2} \mathrm{SO}_{4}\right], 2 \mathrm{mg}$. Final volume $0.5 \mathrm{ml}$. Preincubation (without bicarbonate) $5 \mathrm{~min}$ at $0^{\circ}$. Incubation $10 \mathrm{~min}$ at $0^{\circ}$. The $\mathrm{C}^{14} \mathrm{O}_{2} \sim$ enzyme complex was isolated by ion-exchange chromatography. 


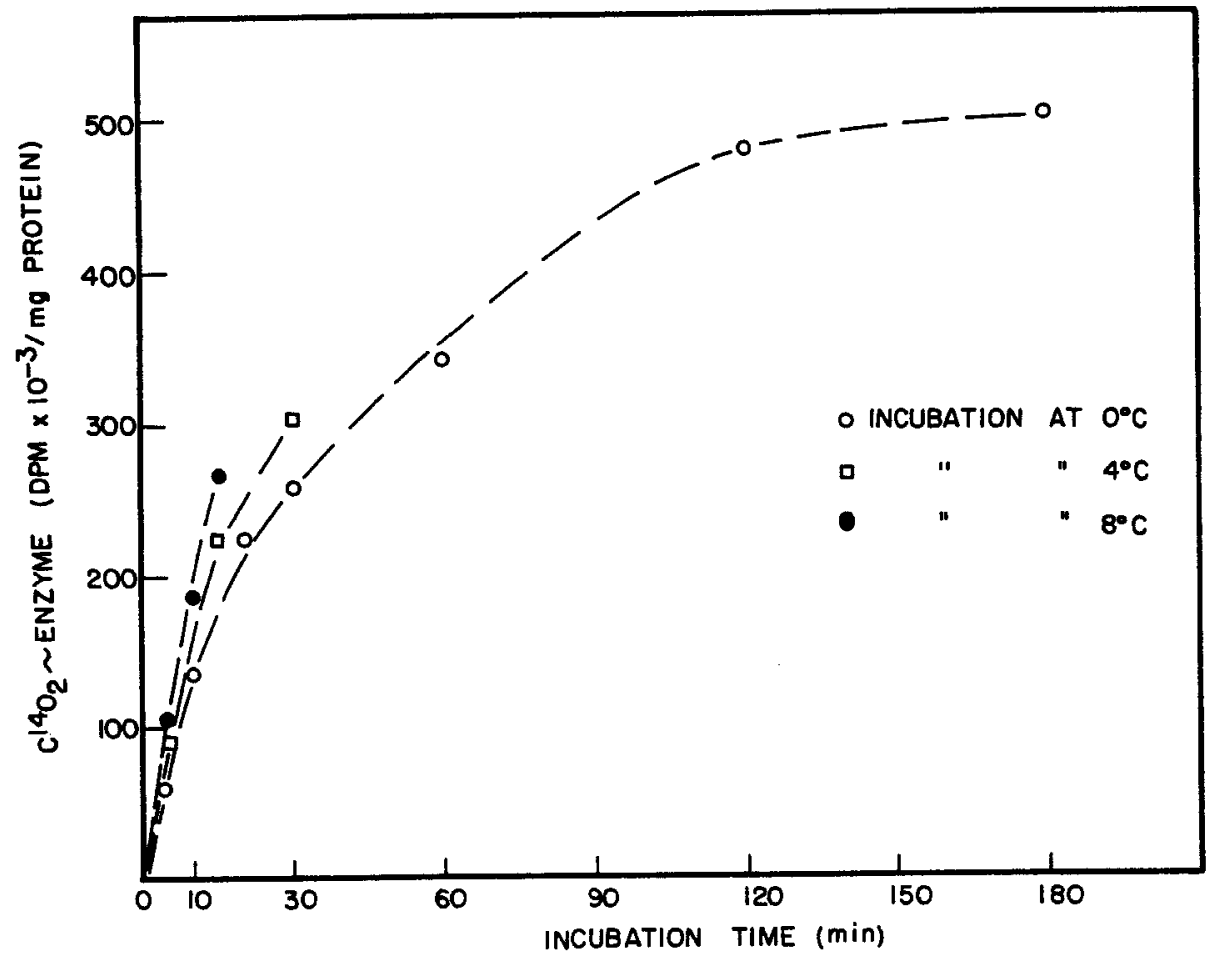

Fig. 7-2. Rate of $\mathrm{C}^{14} \mathrm{O}_{2} \sim$ enzyme formation. Carboxylation of enzyme: Each reaction mixture contained (umoles): tris buffer ( $\mathrm{pH} \mathrm{8.3),} 125 ; \mathrm{MgCl}_{2}, 5 ; \mathrm{NaHC}^{14} \mathrm{O}_{3}, 18$ (specific activity $21 \mu \mathrm{C} / \mu \mathrm{mole}$ ) (final concentration of bicarbonate $\left(36 \times 10^{-3} \mathrm{M}\right)$; and enzyme [extracted from chloroplasts of Spinacea oleracea and fractionated with $\left.\left(\mathrm{NH}_{4}\right)_{2} \mathrm{SO}_{3}\right], 2 \mathrm{mg}$. Final volume $0.5 \mathrm{ml}$. Preincubation (without bicarbonate) $5 \mathrm{~min}$ at $00^{\circ}$; Incubation time, see curve. The $\mathrm{C}^{14} \mathrm{O}_{2} \sim$ enzyme complex was isolated by ionexchange chromatography. 


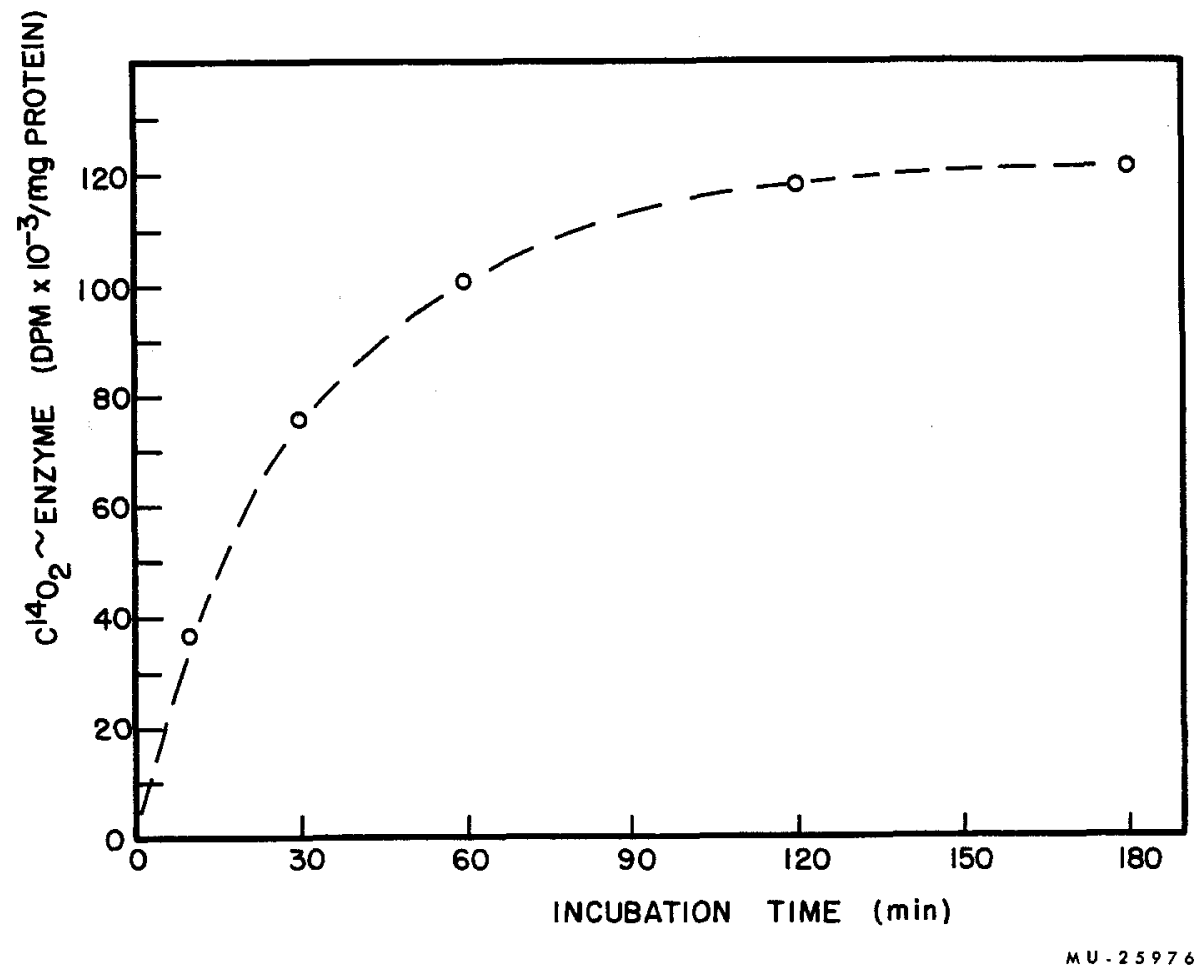

Fig. 7-3. Rate of $\mathrm{C}^{14} \mathrm{O}_{2} \sim$ enzyme formation at $0^{\circ}$.

Carboxylation of enzyme: Each reaction mixture contained (umoles): tris buffer $(\mathrm{pH} 8.0), 36 ; \mathrm{MgCl}_{2}, 7 ; \mathrm{NaHC}^{14} \mathrm{O}_{3}, 1.8$ (specific activity $21 \mu \mathrm{C} / \mu \mathrm{mole}$ ) (final concentration of bicarbonate $3.6 \times 10^{-3} \mathrm{M}$ ); and enzyme [extracted from chloroplasts of Spinacea oleracea and fractionated with $\left.\left(\mathrm{NH}_{4}\right)_{2} \mathrm{SO}_{4}\right], 2 \mathrm{mg}$. Final volume, $0.5 \mathrm{ml}$. Preincubation (without bicarbonate) $5 \mathrm{~min}$ at $00^{\circ}$. Incubation time, see curve. The $\mathrm{C}^{14} \mathrm{O}_{2} \sim$ enzyme complex was isolated by ionexchange chromatography. 
Isolation of $\mathrm{C}^{14} \mathrm{O}_{2} \sim$ Enzyme

The $\mathrm{C}^{14} \mathrm{O}_{2}$ enzyme was separated from the reaction mixture by use of an ion-exchange column. Dowex l-Cl (X8, 200 to $400 \mathrm{mesh}$ ) was washed and equilibrated with $0.02 \mathrm{M}$ tris-HCl buffer, $\mathrm{pH} 8.0$, and packed into a $1.0 \times 4.0-\mathrm{cm}$ column. The column was washed with $3.0 \mathrm{ml}$ of $0.02 \mathrm{Mtris- \textrm {HCl }}$ buffer, $\mathrm{pH}$ 8.0, containing $0.001 \mathrm{M}$ GSH, immediately before use. The column was loaded with the reaction mixture (usually $0.5 \mathrm{ml}$ ) and subsequently washed with $0.6 \mathrm{ml} 0.02 \mathrm{M}$ tris-HCl-GSH buffer; $0.02 \mathrm{M}$ tris-HCl-GSH buffer $(1.8 \mathrm{ml})$ was used for the elution of the column. The eluate contained $40 \%(\mathrm{w} / \mathrm{w})$ of the initial protein. An aliquot sample of the eluate was placed in a liquid scintillation counter for determination of $\mathrm{C}^{14}$ content. Toluene$\mathrm{C}^{14}$ was used as an internal standard. Preliminary experime nts showed that all free bicarbonate ion from a reaction mixture that contained all the components except the enzyme stayed on the column after elution with $8.0 \mathrm{ml}$ of $0.02 \mathrm{M}$ tris-HCl-GHS buffer, $\mathrm{pH} 8.0$. In the presence of enzyme the $1.8 \mathrm{ml}$ of eluat $\bar{e}$ contained all the enzyme that could be eluted - - the effluent, wash, and further eluate being free of enzyme. All the operations were carried out in the cold room $\left(0^{\circ}-2^{\circ}\right)$.

\section{Results}

Dependence of $\mathrm{C}^{14} \mathrm{O}_{2}$ Enzyme formed on Bicarbonate Concentration

The effect of bicarbonate concentration on the rate of $\mathrm{C}^{14} \mathrm{O}_{2} \sim$ enzyme formation is shown in Fig. 7-1. The reaction was carried out at $00^{\circ} \mathrm{C}$ for $10 \mathrm{~min}$, and as the rate of the reaction at that temperature was slow, it may be considered the initial rate. The rate increased as the concentration of bicarbonate was increased up to $34 \times 10^{-3} \mathrm{M}$. At greater concentrations the rate was approximately constant. The value of Michaelis constant for bicarbonate (the bicarbonate concentration at which the carboxydismutase reaction rate is one-half the maximum rate) is $0.009 \pm .001 \mathrm{M}$. This value compares well with those quoted by other investigators, viz., 0.01 to $0.02 \mathrm{M}, 6,7$ and greater than $0.006 \mathrm{M}$.

Figure $7-2$ shows the rate of $\mathrm{C}^{14} \mathrm{O}_{2} \sim$ enzyme formation at $0^{\circ}, 4^{\circ}$, and $8^{\circ}$. The reaction is complete after 2 to $3 \mathrm{hr}$ at $0^{\circ}$, and goes much faster as the temperature increases.

Figure 7-3 shows again the rate of the reaction, but at a smaller bicarbonate concentration.

By using a high concentration of bicarbonate and leaving the mixture to react for a long time (Fig. $7-2,0^{\circ}$ ), we would expect virtually all the active sites of the enzyme to be saturated with carbon dioxide. It was found

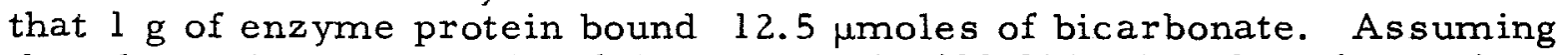
that the molecular weight of the enzyme is 400,000 , then $1 \mathrm{~g}$ of protein contains about $2.5 \times 10^{-6}$ mole, which corresponds to 5 molecules of $\mathrm{CO}_{2}$ per molecule of protein.

\footnotetext{
${ }^{6}$ A. Weissbach, H. L. Horecker, and J. Hurwitz, J. Biol. Chem. 218, 795 (1956).

${ }^{7}$ E. Racker, Arch. Biochem. Biophys. 69, 300 (1957).
} 
It is known that the $\mathrm{Mg}^{++}$ions are necessary for the activation of carboxydimutase. 1 In order to find whether these M.gt+ ions are necessary for the carboxylation of the enzyme, or for the transcarboxylation from the $\mathrm{CO}_{2}$ enzyme to the $\mathrm{RuDP}$, we performed experiments in the presence and absence of $\mathrm{Mg}^{++}$. In the experiments the radioactivity found as the complex was as follows: Complete system $\left(\mathrm{Mg}^{++}\right.$, enzyme, buffer, $\left.\mathrm{NaHC}^{14} \mathrm{O}_{3}\right)$, $450,000 \mathrm{dpm} / \mathrm{g}$ of protein; incomplete system (enzyme, $\mathrm{NaHC}^{14} \mathrm{O}_{3} \mathrm{tris}$ buffer $, 40,000 \mathrm{dpm} / \mathrm{g}$ of protein. Thus carboxylation of the enzyme is dependent on the presence of $\mathrm{Mg}^{++}$ions. These results suggest the following mechanism for the RuDP carboxylase reaction:

$$
\begin{aligned}
& \text { enzyme }+\mathrm{Mg}^{++} \rightarrow \text { enzyme }-\mathrm{Mg}^{++},
\end{aligned}
$$

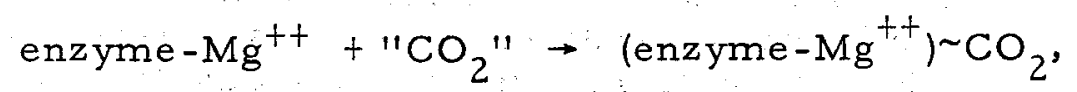

$$
\begin{aligned}
& \left(\text { enzyme }-\mathrm{Mg}^{++}\right) \sim \mathrm{CO}_{2}+\mathrm{RuDP}+\mathrm{H}_{2} \mathrm{O} \rightarrow \text { enzyme-Mg}{ }^{++}+2 \mathrm{PGA}
\end{aligned}
$$

Sum: "CO ${ }_{2}$ " enzyme $+\mathrm{RuDP}+\mathrm{H}_{2} \mathrm{O} \stackrel{\mathrm{Mg}^{++} \longrightarrow}{\longrightarrow}$ enzyme + 2 PGA.

Experiments with enzyme and RuDP-C $\mathrm{C}^{14}$ in the absence of $\mathrm{CO}_{2}$ showed either that a RuDP enzyme complex is not formed, or if it is formed, the bond between RuDP and enzyme is not stronger than the bond between RuDP and the ion-exchange resin. 
8. THE METABOLISM OF $\mathrm{C}^{14}$-RIBULOSE DIPHOSPHATE BY NITROBACTER AGILIS

Ning G. Pon and M. I. H. Aleem

Introduction

The obligatory autotroph, Nitrobacter agilis, can oxidize nitrite to nitrate with a concomitant production of adenosine triphosphate (ATP) as an energy source for growth and cell synthesis. Since the organism is unable to utilize carbohydrates and other organic compounds for growth, it has to assimilate $\mathrm{CO}_{2}$ and convert it to carbohydrates. To study the fate of the $\mathrm{CO}_{2}$, one of the authors (Aleem) conducted preliminary experiments using radioactive bicarbonate as the sole source of carbon. His results are summarized briefly as follows:

1. The fixation of $\mathrm{CO}_{2}$ by intact cells of Nitrobacter is stimulated during the oxidation of nitrite.

2. Only the supernatant liquid obtained by centrifugation of the cellfree extract of this organism at $144,000 \times g$ for 60 min contains the RuDPdependent $\mathrm{CO}_{2}$ fixing enzymes (RuDP:ribulose-1, 5-diphosphate).

3. A mixture of reduced diphosphopyridine nucleotide (DPNH) plus ATP can replace RuDP for the $\mathrm{CO}_{2}$ assimilation by the cell-free preparation, although the fixation rate of the former is about $60 \%$ that of the latter.

There then remains the problem of whether phosphoglycerate (PGA) is formed from the $\mathrm{CO}_{2}$ fixation. An extension of this question is whether two molecules of PGA or one of PGA plus one of triose phosphate result from the carboxylation of one molecule of RuDP during the oxidation of nitrite. The answers lie in the identification of the products of both the $\mathrm{HC}^{14} \mathrm{O}_{3}^{-}$and RuDP - C 14 feeding experiments with the cell-free extracts. In the RuDP-C 14 feeding experiment, the ratios of the total $\mathrm{C}^{14}$-sugar monophosphates to the $C^{14}-$ PGA a re calculated and then plotted as a function of incubation time. 1 Extrapolation of these ratios to 1 at zero time would indicate that the products of the carboxylation are one triose phosphate and one PGA, whereas extrapolation to 0 at zero time would indicate that the product is only PGA.

\section{Method}

RuDP-C ${ }^{14}$ was prepared according to Mayaudon et al. ${ }^{2}$ In this method, Chlorella pyrenoidosa was allowed to photosynthesize in the presence of NaHC ${ }^{14} \mathrm{O}_{3}$. Ethanol was added to the reaction mixture, and the extracted products were separated by paper chromatography... The material from the diphosphate area, consisting mostly of RuDP-C 4 , was eluted, taken to dryness, and then redissolved with a solution of sodium bicarbonate (unlabeled).

\footnotetext{
IR. B. Park and N. G. Pon, Biochim. Biophys. Acta 57, 520 (1962).

${ }^{2}$ J. Mayaudon, A. A. Benson, and M. Calvin, Biochim. Biophys. Acta 23, 342 (1957).
} 
Incubation was performed in a specially designed vessel. Three needles were inserted into each vessel through rubber serum caps, one for injecting the RuDP-C 14 plus bicarbonate, one for withdrawing the sample, and a short one (above the liquid level) for equalizing the pressure within the vessel.

Each reaction mixture contained, in a final volume of $1.2 \mathrm{ml}$ ( $\mu$ moles); 4.0 $\mu \mathrm{M} \mathrm{MgCl}_{2}, 1.6 \mu \mathrm{M} \mathrm{MnSO} \mathrm{M}_{4}, 1.0 \mu \mathrm{M}$ adenosine diphosphate, $1.0 \mu \mathrm{M}$ diphosphopyridine nucleotide $\left(\mathrm{DPN}^{+}\right), 1.4 \mu \mathrm{M}$ thiamine pyrophosphate, $2.5 \mu \mathrm{M}$ ascorbate, and $1.3 \mu \mathrm{M}$ glutathione. One $\mathrm{ml}$ of cell-free extract of Nitrobacter, prepared by sonically rupturing the cells for $90 \mathrm{sec}$ and separating the whole cells by centrifugation, was added to each incubation mixture. Boiled cellfree extract was substituted for the cell-free extract in the control. The substrate solution, containing the RuDP-C 14 plus bicarbonate, was added. At the indicated time intervals, $0.1-\mathrm{ml}$ samples were withdrawn and injected into ethanol to stop the reaction. The whole suspension was applied to paper for chromatography. The products were counted on paper in the usual manner. 3 After counting, some spots were eluted and rechromatographed with authentic samples. Other eluates were treated with acid phosphatase before rechromatography.

As each aliquot withdrawn varied slightly in volume, the results are expressed in percent of the total aqueous-alcohol-soluble radioactivity on the paper. We estimate that approximately 90 to $95 \%$ of the total radioactivity applied was in those spots which were counted.

\section{Results}

Figure 8-1 shows the complex pattern of products formed from the reaction of the $\mathrm{C}^{14}$-diphosphate with the cell-free extract. The first eight pronounced spots are found in the control, this being typical of all the control samples whether taken at $30 \mathrm{sec}$ or at $100 \mathrm{~min}$. The experimental series, on the other hand, starts with at least ten spots visible at $30 \mathrm{sec}$ and, by $100 \mathrm{~min}$ five more spots have appeared. Only a few of these spots so far have been identified. The results, summarized in Tables 8-I and 8-II, include the changes in the levels of each compound. These changes are shown more conspicuously in Figs. 8-2 and 8-3. Noteworthy are the decrease in the sugar monophosphate level and the increase in the phosphogluconate level. The PGA level also seems to decrease, but when compared with the control values, this change appears to be only at one point, namely, at 100 min. The amount of sugar diphosphate changes significantly as compared with the control while those of other radioactive spots, such as Nos. $7+8$ and 10, although still unidentified, rise with time. (Spot No. $7+8$ is the same substance as shown by rechromatography). Finally, one important point should be made: The values of the PGA and the sugar monophosphate levels for the boiled-extract series are almost always equal to or larger than those of the "live"! cell-free-extract series. This fact made it impossible to obtain reliable ratios of sugar monophosphate to PGA. Hence the original intent of this experiment could not be fulfilled.

\footnotetext{
${ }^{3}$ J. A. Bassham and M. Calvin, The Path of Carbon in Photosynthesis
} (Prentice-Hall, Inc., Englewood Cliffs, N. J., 1957), 104 pp. 


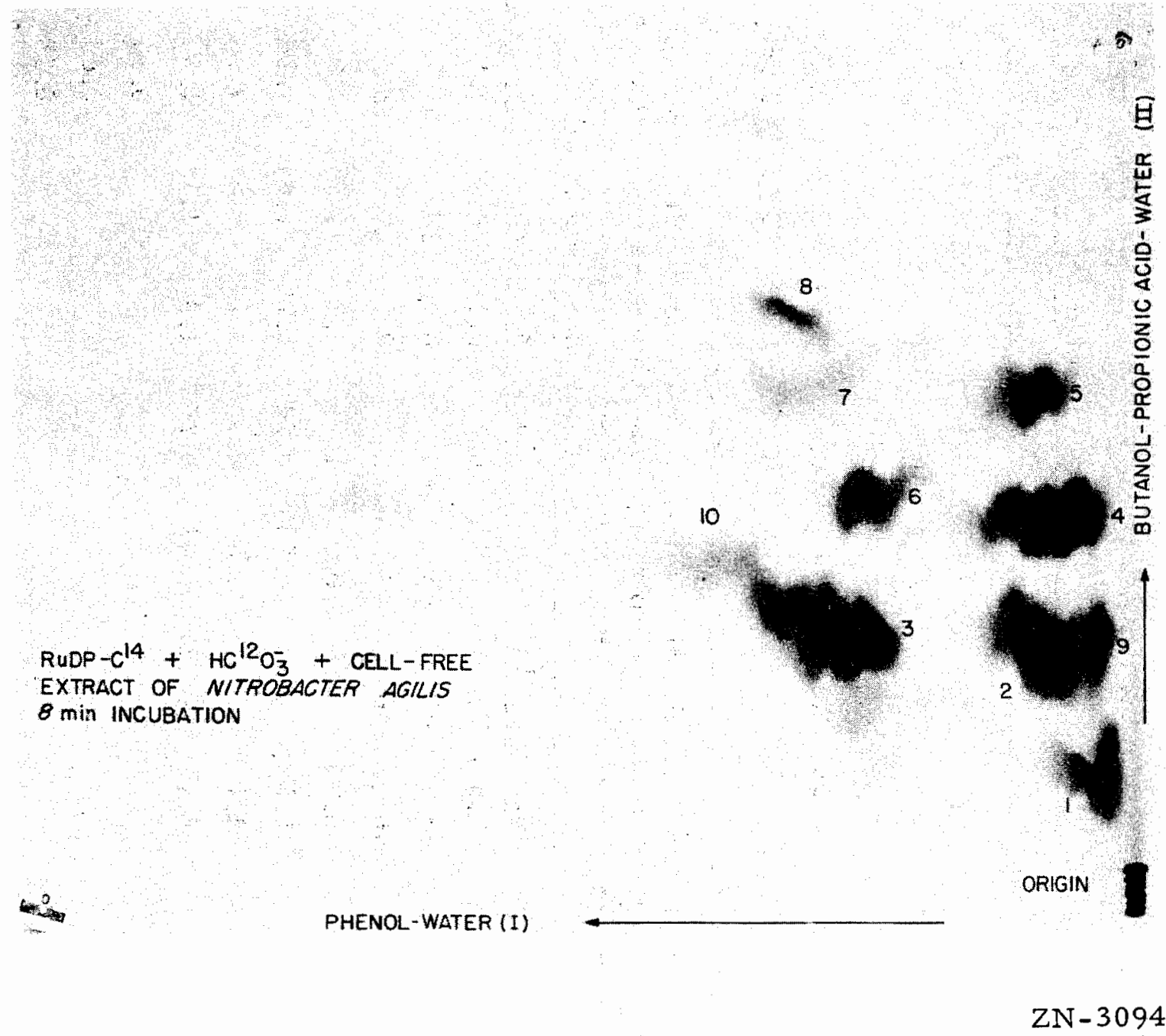

Fig. 8-1. Radioactive products from RuDP-C ${ }^{14}$ after 8 min incubation with the cell-free extract of Nitrobacter agilis. Spot No. 1, diphosphates; $2+3$, monophosphates; $4+6$, PGA; 9, phosphogluconate. All other spots are still unidentified. 


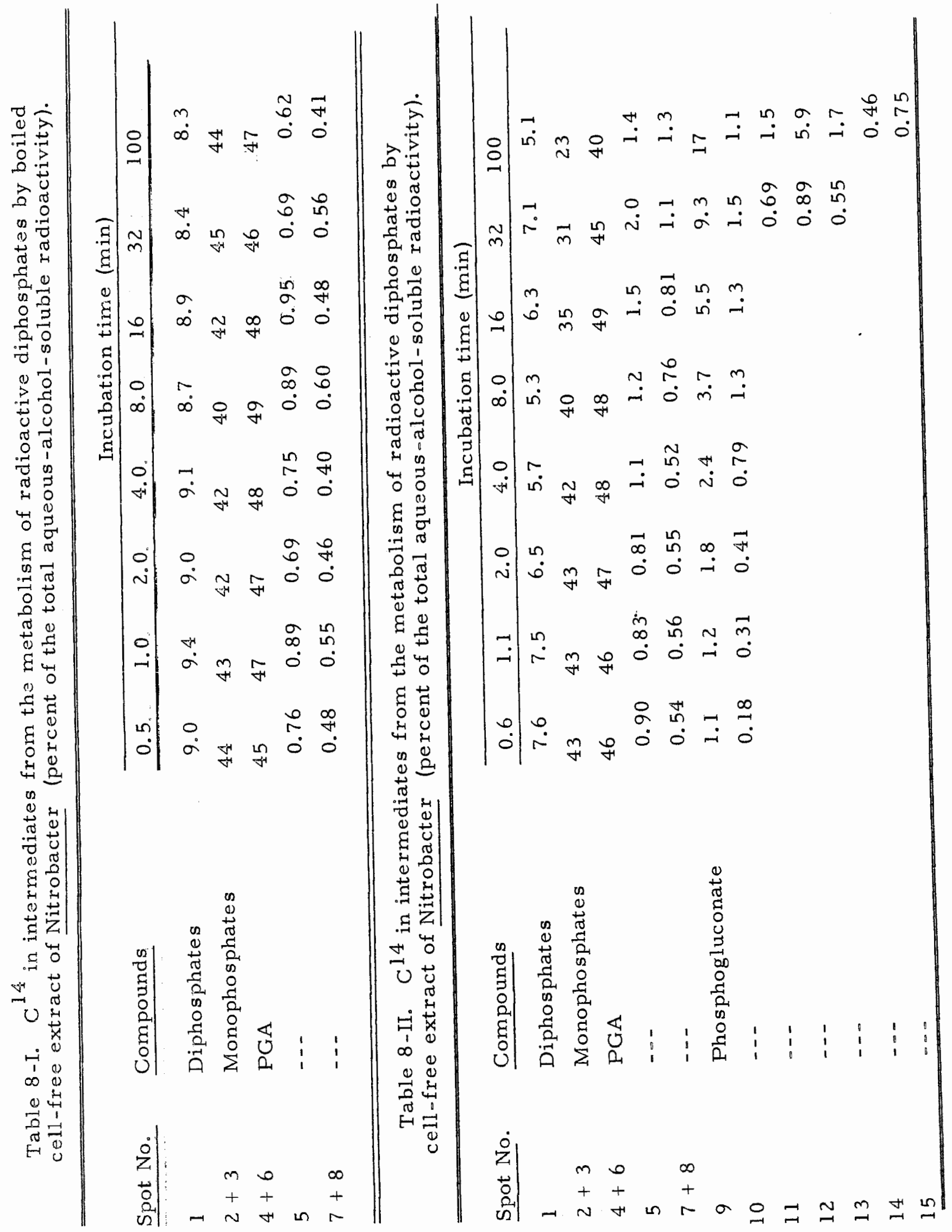




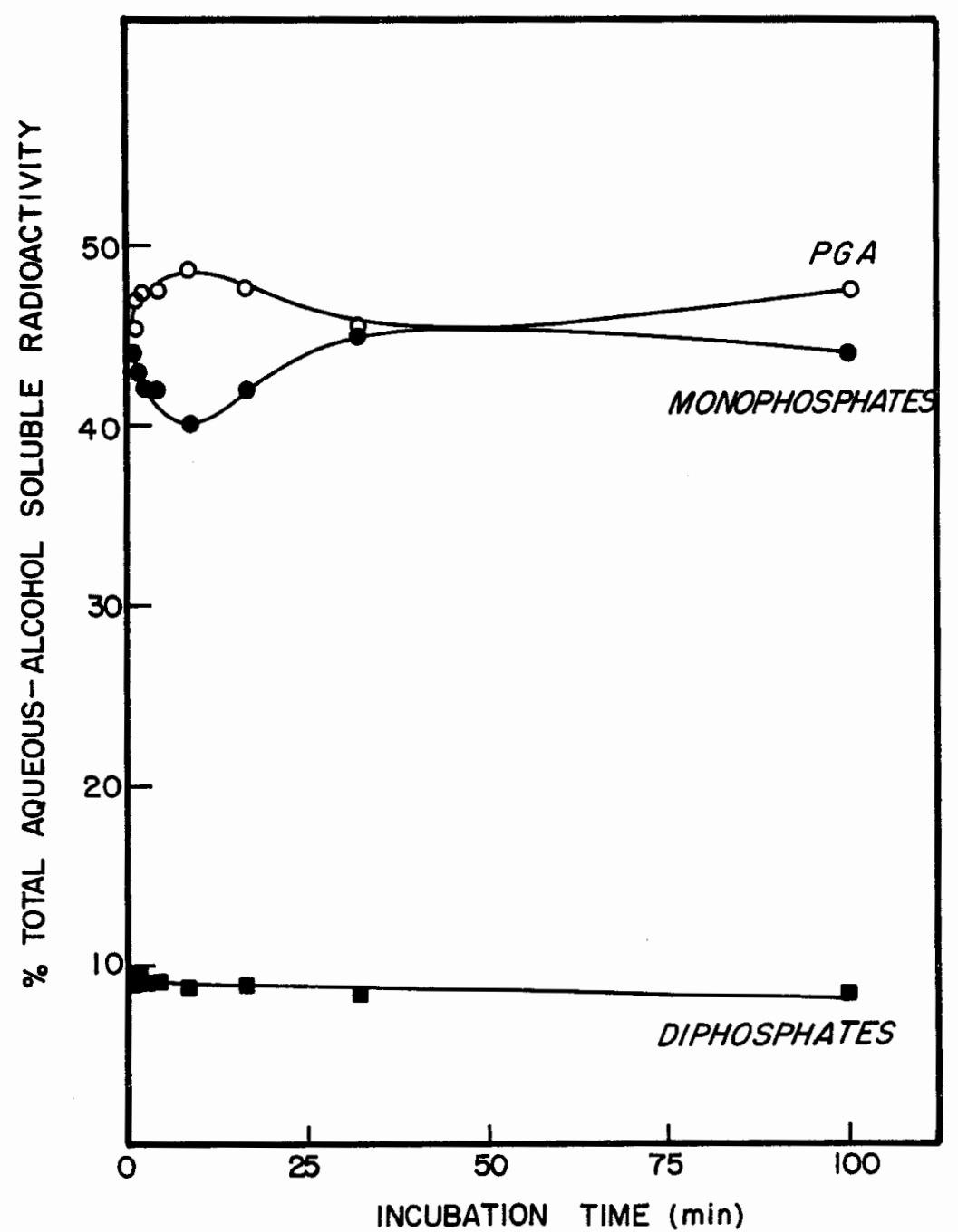

MU. 26029

Fig. 8-2. The levels of various intermediates from RuDP-C 14 after incubation with the boiled cellfree extract of Nitrobacter agilis. 


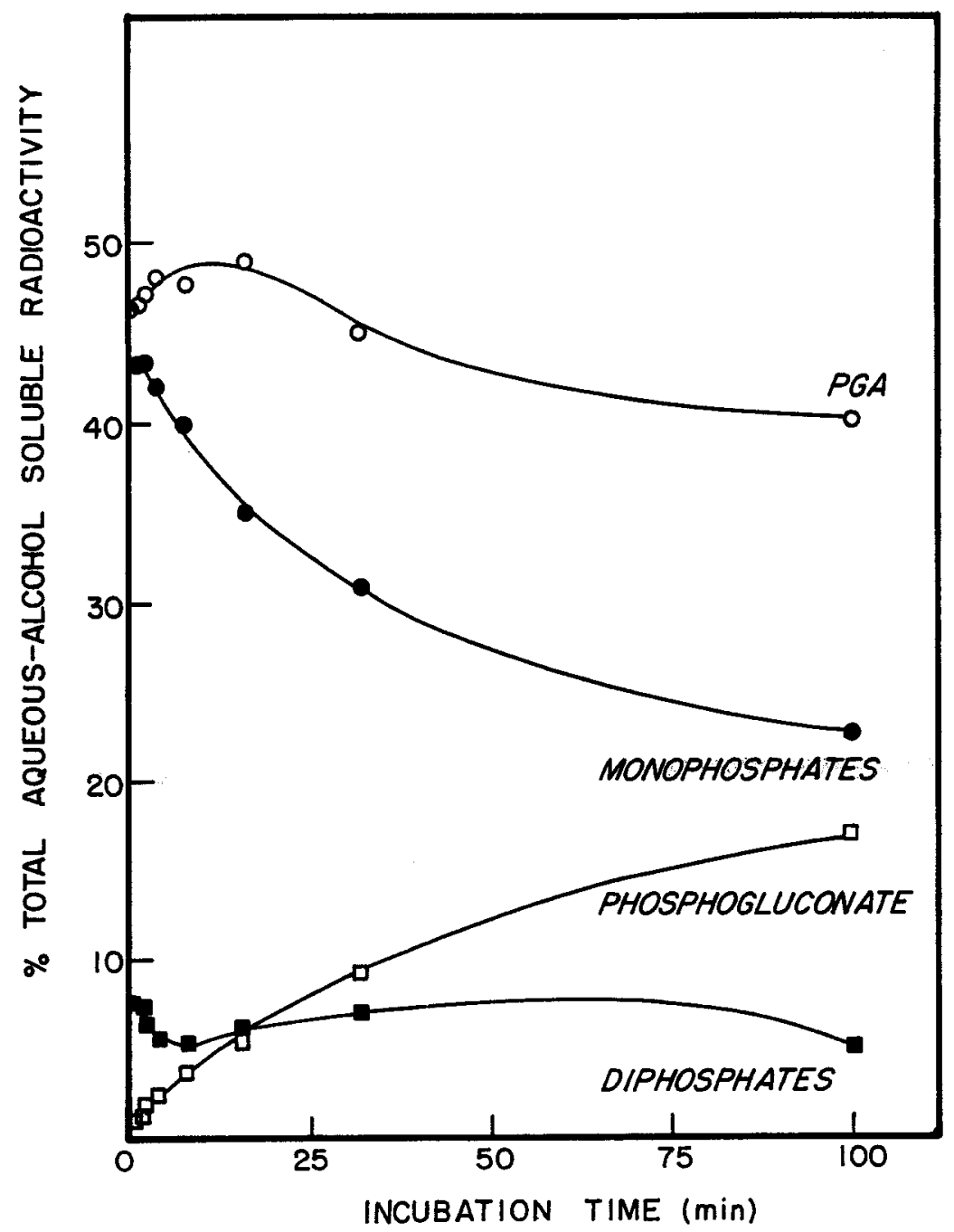

$M U-26030$

Fig. 8-3. The levels of various intermediates from RuDP-C 14 after incubation with the cell-free extract of Nitrobacter agilis. 


\section{Discussion}

Carboxydismutase and glucose-6-phosphate dehydrogenase apparently exist in the cell-free extract of Nitrobacter agilis. We arrived at this conclusion because of the presence of an RuDP-linked $\mathrm{CO}_{2}$ fixing enzyme system and the presence of 6-phosphogluconate in the cell-free preparations. PGA must be demonstrated as the product of the $\mathrm{CO}_{2}$ fixation, however, Large amounts of PGA-C 14 were found in the RuDP-C 14 feeding experiments, but most of the PGA probably arose from the oxidative cleavage of the RuDP-C 14 as evident in the control series. On the other hand, 6-phosphogluconate may originate from the reversal of the reaction catalyzed by 6 -phosphogluconate dehydrogenase. Since no pentose phosphates were found in the sugar monophosphates and since phosphogluconate seems to increase at the expense of the sugar monophosphates, which consist mainly of glucose monophosphate, the more probable pathway for the formation of phosphogluconate is via glucose phosphate dehydrogenase. Nevertheless, the phosphogluconate pathway cannot be completely excluded owing to the possible rapid conversion of any pentose phosphates to phosphogluconate, which might prevent the accumulation of pentose phosphates. Both questions may be settled by performing experiments with radioactive bicarbonate and unlabeled RuDP.

Generally glucose-6-phosphate dehydrogenase is $\mathrm{TPN}^{+}$-dependent (TPN: triphosphopyridine), but some microorganisms contain $\mathrm{DPN}^{+}-$linked dehydrogenases. 4 In Nitrobacter, although DPN ${ }^{+}$was added as a cofactor, a catalytic amount of $\overline{\mathrm{TPN}}^{+}$may have been present in the cell-free extract. $\mathrm{TPNH}$, generated by the dehydrogenase reaction, can be reconverted to the oxidized form via a transhydrogenase action on $\mathrm{DPN}^{+}$. To clarify this point, experiments with cell-free preparations passed through charcoal need to be performed.

Finally, the fate of $\mathrm{CO}_{2}$ in this organism still remains obscure. Also unresolved is the problem of what happens to PGA and phosphogluconate. Moreover, is glucose-6-phosphate formed from PGA or from pentose phosphates via the oxidative pathway? These and many other questions may be solved by kinetic studies with radioactive bicarbonate in the presence and absence of unlabeled RuDP.

${ }^{4} \mathrm{~J}$. de Ley, in Proceedings of the Third International Congress on Biochemistry, Brussels, 1955, Claude Liebecq, ed。 (Academic Press, New York, 1956) p. 182 . 
9. $\mathrm{C}^{14} \mathrm{O}_{2}$ METABOLISM OF HORDEUM VULGARE SEEDLINGS DURING THE DEVELOPMENT OF THE PHOTOSYNTHETIC APPARATUS

\author{
John Biggins and Roderic B. Park
}

\title{
$\underline{\text { Introduction }}$
}

Barley seedlings, germinated and grown in the dark, are, at this stage, heterotrophic and develop at the expense of energy liberated by the breakdown of seed reserves. Exposure of such plants to light results in the conversion of protochlorophyll to chlorophyll, followed by net synthesis of chlorophyll in the immature plastid. After the initial pigment conversion the plastid undergoes a marked structural reorganization concurrent with the formation of a photosynthetic system and development of an autotrophic metabolism.

Of direct interest is an elucidation of the photosynthetic microstructure operative during the initial stages of plastid development prior to the formation of stroma and grana lamellae. Before proceeding to in vitro studies, we have conducted in vivo experiments in order to determine the first indications of photosynthetic potential following illumination of the seedlings.

\section{Materials and Methods}

1. Preparation of etiolated barley seedlings

Seeds of Hordeum vulgare (variety "Tennessee Winter," 1956 crop) were imbibed in aerated water for $24 \mathrm{hr}$ and sown on cheesecloth supported by glass frames. The frames were placed in photographic trays containing $0.5 \%$ Hoagland's solution in such a way that the seeds were above the solution surface but were in contact with the nutrient by the capillary action of the cheesecloth, whose edges were immersed in the solution. The seeds were germinated and grown in complete darkness for 6 days, and then illuminated by a bank of fluorescent tubes at a light intensity of 500 foot candles. Samples were taken at intervals during this illumination period.

2. In vivo $\mathrm{C}^{14} \mathrm{O}_{2}$ assimilation

$\mathrm{C}^{14} \mathrm{O}_{2}$ assimilation was conducted in an apparatus (shown in Fig. 9-1) which contained three whole seedlings. Seedlings were sampled during an illumination period of $24 \mathrm{hr}$ and their $\mathrm{CO}_{2}$ assimilation measured in the light and dark. The apparatus and seedlings were equilibrated for $10 \mathrm{~min}$ in the dark or in $5000 \mathrm{ft}-\mathrm{c}$ (photoflood and infrared filter) and gassed with $1 \% \mathrm{CO}_{2}$-air. The side arm of the apparatus contained phosphoric acid. At the start of the reaction, the apparatus was closed and $200 \mu 10.06 \mathrm{M} \mathrm{NaHC}{ }^{14} \mathrm{O}_{3}$ $(1.98 \mathrm{mC} / \mathrm{ml})$ was injected into the acid through the serum cap, liberating $12 \mu$ moles of $\mathrm{C}^{14} \mathrm{O}_{2}(400 \mu \mathrm{C})$. The seedlings were exposed to $\mathrm{C}^{14} \mathrm{O}_{2}$ for 4 min and the reaction was concluded by rapidly disassembling the apparatus, cutting off the leaves, and plunging them into liquid nitrogen. The leaves were then homogenized in warm $80 \% \mathrm{MeOH}$ by use of a mechanically driven glass pestle, and the resulting macerate was transferred quantitatively to a tube and boiled for 1 min. 


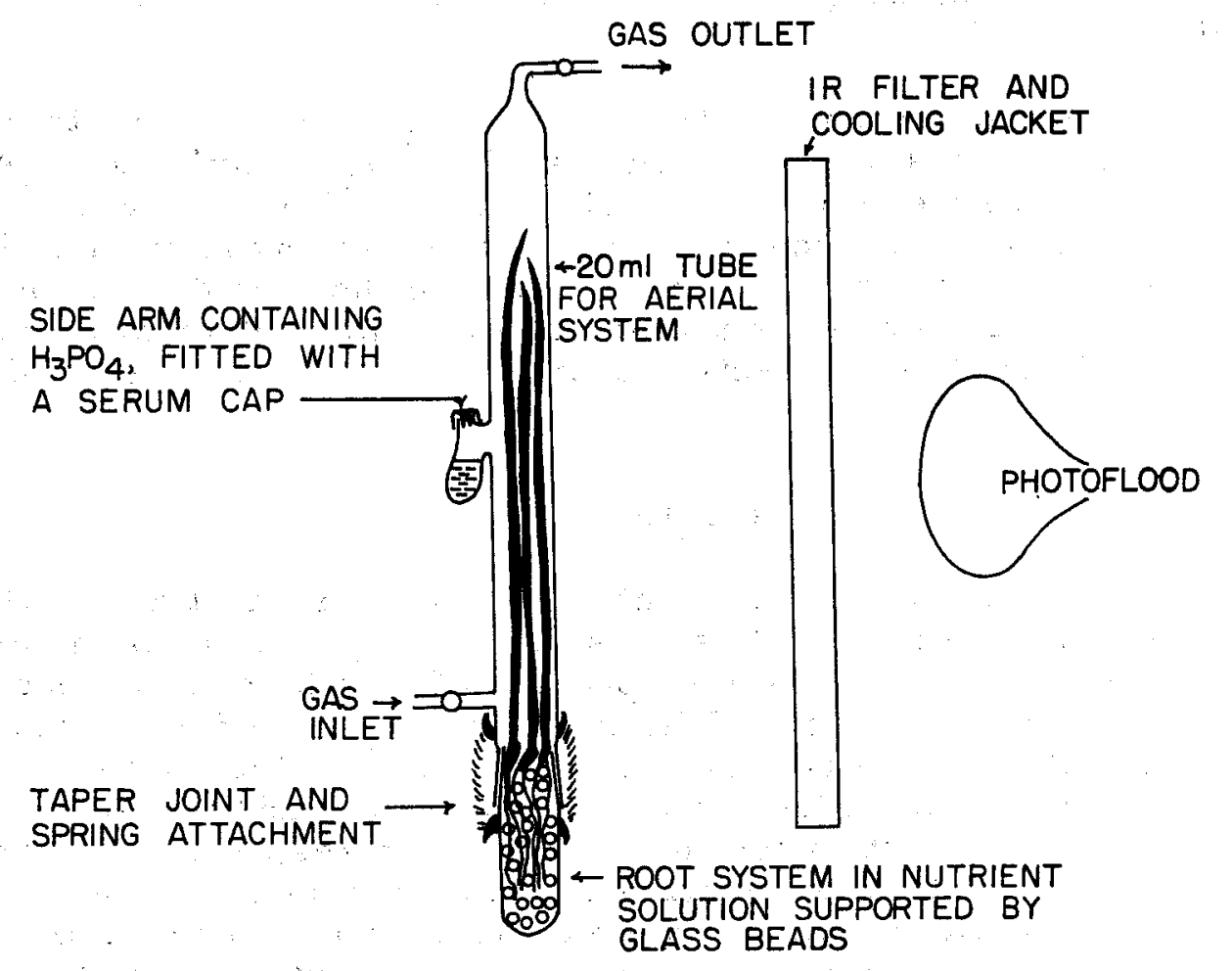

$M U-25943$

Fig. 9-1. Apparatus for in vivo $\mathrm{C}^{14} \mathrm{O}_{2}$ assimilation in Hordeum vulgare seedlings. 


\section{Extraction}

Residues were extracted by the procedure of Bassham and Calvin, ${ }^{1}$ and the resulting supernatants were reduced in volume by distillation in vacuo.

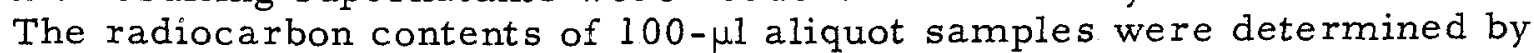
means of a Packard Tri-Carb automatic liquid scintillation spectrometer using $10 \mathrm{ml}$ scintillation solution and one drop of commercial bleach ( $\mathrm{NaClO}$ ). An internal standard $\left(250 \mu 1 \mathrm{C}^{14}\right.$-toluene, $\left.123 \mathrm{dpm} / \mu 1\right)$ was added after initial counting. (The solutions was $2000 \mathrm{ml}$ toluene, $2000 \mathrm{ml} \mathrm{n}$-dioxane, $1200 \mathrm{ml}$ EtOH, $200 \mathrm{~g}$ naphthalene, $26 \mathrm{~g} \mathrm{2,5-diphenyloxazole,} 0.5 \mathrm{~g} \mathrm{1,4-bis} \mathrm{2-(5-}$ phenyloxazol) benzene.)

We determined the isotope distribution in early samples (up to $3 \mathrm{hr}$ ) by chromatographic analysis of the products of $\mathrm{C}^{14} \mathrm{O}_{2}$ assimilation. Aliquot samples of the extracts were placed on. Whatman No. 4 paper and run in two dimensions with a new chromatographic solvent containing ammonia, isobutyric acid, $\mathrm{H}_{2} \mathrm{O}$ and several aliphatic alcohols in the long dimension ${ }^{2}$ and $\mathrm{n}$-butanol-propionic acid-water in the other dimension. Radioautograms were prepared and then the radioactive spots were cut out and counted automatically. 3

\section{Results}

Table 9-I shows the total assimilated $\mathrm{C}^{14} \mathrm{O}_{2}$ in the light and in the dark during the illumination period. These results are expressed graphically in Fig. 9-2. Light-dark differences are apparent after $1 \mathrm{hr}$ of illumination, and significant changes occur after $2 \mathrm{hr}$ illumination. The data in Table 9-II and Fig. $9-3$ show the distribution of assimilated $\mathrm{C}^{14}$ in the individual products of the soluble fraction. These results indicate the addition of the carbon-reduction cycle during the illumination period to respiratory carboxylative mechanisms existing in all dark reactions. With respect to $\mathrm{CO}_{2}$ assimilation, plants after $24 \mathrm{hr}$ illumination are capable of photosynthesizing at $3 / 4$ the rate of control seedlings grown from germination in continuous light.

\section{Discussion}

Results show that the intact etiolated seedling is capable of respiratory carboxylation, the products being citric acid, malic acid, and aspartic acid. This suggests the participation of phosphoenolpyruvate carboxylase or malic enzyme as principal enzymatic mechanisms, and is in accordance with in vitro studies on barley homogenates by Hall et al. 4

I. A. Bassham and M. Calvin, The Path of Carbon in Photosynthesis (Prentice-Hall, Englewood Cliffs, N. J., 1956).

${ }^{2}$ G. J. Crowley, V. Moses, and J. Ullrich, submitted to J. Chromatog. ${ }^{3} \mathrm{~V}$. Moses and K. K. Lonberg-Holm, in Bio-Organic Chemistry Quarterly Report, UCRI-9772, June 1961, p. 112.

${ }^{4}$ D. Hall et al. Biochim. Biophys. Acta 35, 540 (1959). 
Table 9-I. Assimilation of $\mathrm{C}^{14} \mathrm{O}_{2}$ by barley seedlings during the illumination period (conditions described in text)

\begin{tabular}{|c|c|c|}
\hline \multirow{2}{*}{$\begin{array}{l}\text { Time in } \\
\text { light } \\
(500 \mathrm{ft}-\mathrm{c}) \\
(\mathrm{hr}) \\
\end{array}$} & \multicolumn{2}{|c|}{$\begin{array}{c}\text { Total } \mathrm{C}^{14} \text { in soluble fraction after } 4 \text { min reaction } \\
\left(\text { counts } / \min \times 10^{-3}\right)\end{array}$} \\
\hline & Light $(5000 \mathrm{ft}-\mathrm{c})$ & Dark \\
\hline 0 , etiolated & 9 & 7 \\
\hline 1 & 12 & 5 \\
\hline 2 & 40 & 7 \\
\hline 3 & 70 & 9 \\
\hline 4 & 78 & 2 \\
\hline 5 & 133 & 2 \\
\hline 6 & 160 & 5 \\
\hline 8 & 1250 & 8 \\
\hline 12 & 1170 & 9 \\
\hline 24 & 1890 & 3 \\
\hline $\begin{array}{l}\text { control (grown in } \\
\text { continuous light } \\
\text { from germination) }\end{array}$ & 2410 & 21 \\
\hline
\end{tabular}




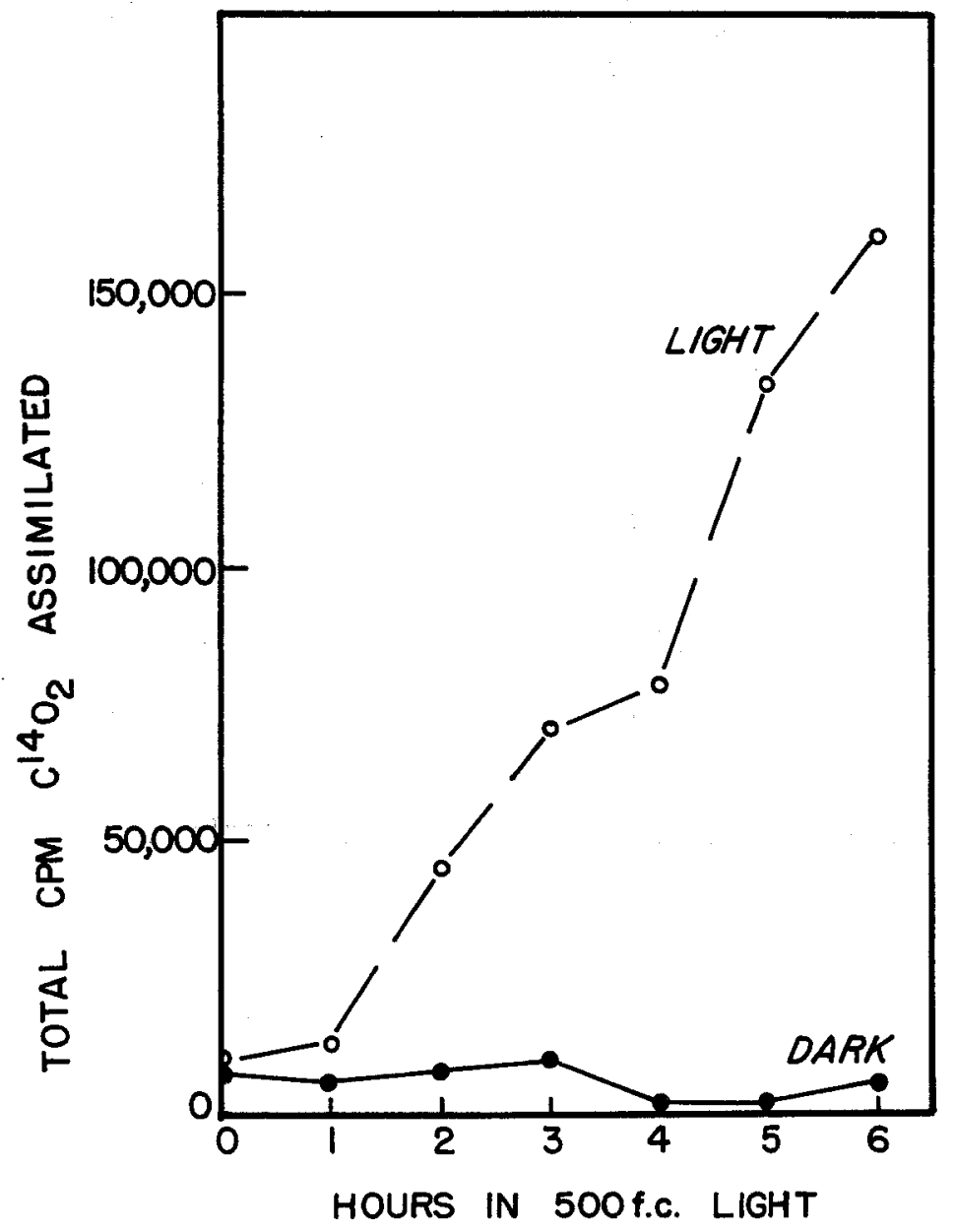

MU. 25944

Fig. 9-2. Total $\mathrm{C}^{14} \mathrm{O}_{2}$ assimilation of Hordeum vulgare seedlings during the illumination period. Gas phase: $1 \% \mathrm{CO}_{2}-a i r$. $12 \mu$ moles $\mathrm{C}^{14} \mathrm{O}_{2}$ liberated. 4 min reaction in light or dark. 
Table 9-II. Distribution of $\mathrm{C}^{14}$ in products of $\mathrm{C}^{14} \mathrm{O}_{2}$ assimilation by barley seedlings

\begin{tabular}{|c|c|c|c|c|c|c|c|c|c|c|}
\hline \multirow{3}{*}{$\begin{array}{l}\text { Time in } \\
\text { light } \\
(500 \mathrm{ft}-\mathrm{c}) \\
(\mathrm{hr})\end{array}$} & \multirow{3}{*}{$\begin{array}{c}\text { Reaction } \\
\text { system }\end{array}$} & \multicolumn{8}{|c|}{$\mathrm{C}^{14}$ found $(\%)$} & \\
\hline & & \multicolumn{2}{|c|}{ Organic acids } & \multicolumn{3}{|c|}{ Amino acids } & \multicolumn{4}{|c|}{ Carbon cycle intermediates } \\
\hline & & Malic & Citric & Aspartic & Glutamic & Alanine & $\mathrm{PGA}^{\mathrm{a}}$ & $\mathrm{HMP}^{\mathrm{b}}$ & $\mathrm{HDP}^{\mathrm{C}}$ & Sucrose \\
\hline \multirow{2}{*}{0} & Light & 33 & 32 & 26 & 8 & 0 & 0 & 0 & 0 & 0 \\
\hline & Dark & 43 & 23 & 23 & 8 & 0 & 0 & 0 & 0 & 0 \\
\hline \multirow{2}{*}{1} & Light & 12 & 18 & 11 & 2 & 1 & 4 & 34 & 16 & 1 \\
\hline & Dark & 43 & 23 & 20 & 9 & 0 & 0 & 0 & 0 & 0 \\
\hline \multirow{2}{*}{2} & Light & 8 & 5 & 11 & 1 & 1 & 7 & 33 & 15 & 8 \\
\hline & Dark & 37 & 28 & 27 & 8 & 0 & 0 & 0 & 0 & 0 \\
\hline \multirow{2}{*}{3} & Light & 6 & 5 & 18 & 1 & 2 & 10 & 24 & 13 & 18 \\
\hline & Dark & 33 & 32 & 26 & 8 & 0 & 0 & 0 & 0 & 0 \\
\hline
\end{tabular}
a. $\quad$ PGA $=3$ phosphoglyceric acid
b. HMP = hexose monophosphates
c. $H D P=$ hexose diphosphates 


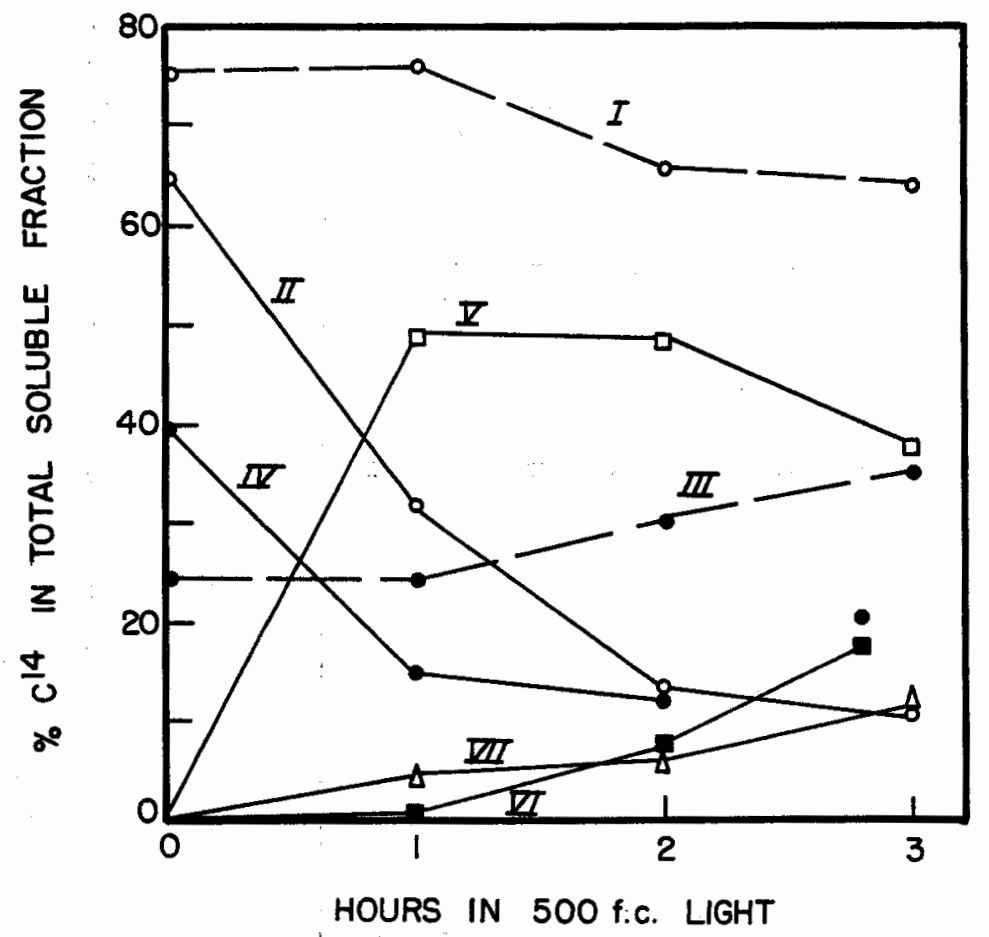

MU -25945

Fig. 9-3. $\mathrm{C}^{14}$ distribution $(\%)$ in the soluble fraction of Hordeum vulgare seedlings after $\mathrm{C}^{4} \mathrm{O}_{2}$ assimilation during the illumination period. Solid line, light; dashed line, dark; $\bullet$, amino acids; o, organic acids; $P G A ; \square$, sugar phosphates; $\Delta$, sucrose. 
Illumination of the etiolate initiates the development of the photosynthetic apparatus. The proplastid contains protochlorophyll, 5 carotenoids, 5 and cytochromes $f$ and $b_{6}, 6,7$ although the re is no differentiated plastid lamellae system in the 6-day etiolated plant. 8 Light converts the protochlorophyll to chlorophyll and photosynthesis is initiated. Several hours of illumination results in the formation of stroma and grana lamellae and subsequent development into a mature chloroplast. 8 Our results show that quantum conversion is in operation within $1 \mathrm{hr}$ of illumination at $500 \mathrm{ft}-\mathrm{c}$. A direct result of this energy supply is massive plastid organization leading to higher rates of photosynthesis and associated metabolic pathways. These results are in qualitative accordance with previous work, 9,10 but Tolbert 9 reported that $4 \mathrm{hr}$ illumination was found to be necessary before any appreciable $\mathrm{CO}_{2}$ assimilation occurred in excised leaves, and a further $2 \mathrm{hr}$ illumination was required before phosphorylation and reduction took place, and sugar phosphates appeared as principal products. We attribute this difference to the higher sensitivity of our methods and the fact that intact seedlings were used.

\section{Summary}

The assimilation of $\mathrm{C}^{14} \mathrm{O}_{2}$ by barley etiolates during an illumination period indicates a conversion of the organisms from heterotrophy to autotrophy。

Litht-dark differences become apparent after $1 \mathrm{hr}$ of illumination of the etiolates, and the distribution of $\mathrm{C}^{14}$ is found chiefly in carbon-reductioncycle intermediates in the light reactions. This suggests that photosynthetic phosphorylation and reducing mechanisms are operative at a very early stage of plastid development and that subsequent increases in photosynthetic rates are concurrent with the maturation of the plastid.

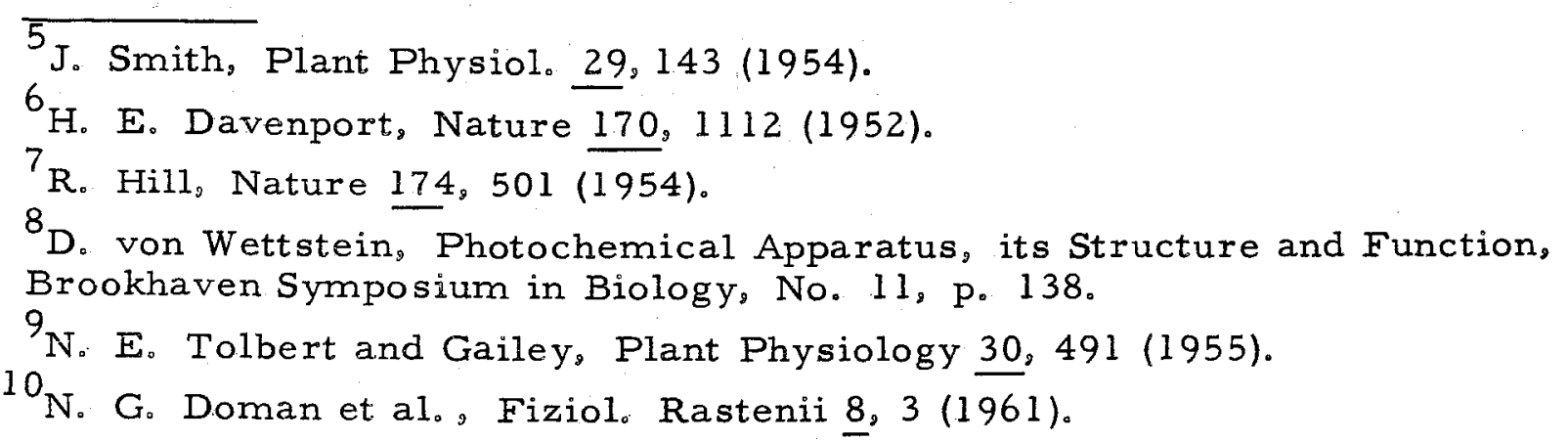




\section{THE LOCATION AND CHEMICAL CHARACTERIZATION OF RNA IN THE CHLOROPLASTS OF SPINACEA OLERACEA}

John Biggins and Roderic B. Park

Introduction

Our preliminary experiments concerning the total polynucleotide content of spinach chloroplasts yielded higher values than those reported by other authors. We attributed these differences to our method of plastid isolation. We argued that the nonaqueous technique minimized the leaching of polar material from the plastids during their isolation. 1

Further work was directed toward elucidation of the exact location and character of the polynucleotide within the chloroplast in order to test the validity of our assumption that the polynucleotide is soluble and easily lost from aqueous plastid preparations.

\section{Materials and Methods}

Whole chloroplasts were sedimented from spinach leaf homogenates in $0.35 \mathrm{M} \cdot \mathrm{NaCl}$. Two fractions were analyzed subsequent to lysis of the chloroplast by osmotic rupture.

1. Particulate quantasome fraction

Whole chloroplasts, washed in $0.35 \mathrm{M} \mathrm{NaCl}$, were lysed by the addition of ice-cold $10^{-2} \mathrm{M}$ tris at $\mathrm{pH} 7.5$. The preparation was allowed to stand at $0^{\circ}$ for 30 min with occasional stirring and the soluble fraction removed by ultracentrifugation at $20,000 \mathrm{~g}$ for $10 \mathrm{~min}$. This was repeated three times and the final pellet resuspended in $15 \mathrm{ml}$ of $10^{-2} \mathrm{M}$ tris and sonicated for 2 min (Raytheon oscillator at $9 \mathrm{kc}$ ). Membranes and large lamellar struc tures were removed in low-g fractions by ultracentrifugation, and the 50,000 to $105,000 \mathrm{~g}$ sediment was collected. This was washed three times with $10^{-2} \mathrm{M}$ tris and yielded a quantasome fraction, entirely free of stroma protein, which contained $10 \mathrm{mg}$ chlorophyll.

\section{Soluble (stroma) protein fraction}

Whole chloroplasts were prepared and lysed osmotically as described in 1 , and the particulate fraction (approximately $10 \mathrm{mg}$ chlorophyll) was removed by ultracentrifugation at $20,000 \mathrm{~g}$ for $10 \mathrm{~min}$. The sediment was washed with $10^{-2} \mathrm{M}$ tris and recentrifuged. The supernatants were combined and were free of any particulate components. This stroma protein was dialyzed against 4 liters of $10^{-3} \mathrm{M}$ tris at $4^{\circ}$ for $76 \mathrm{hr}$ and the resulting dialyzate analyzed.

IJohn Biggins and Roderic B. Park, in Bio-Organic Chemistry Quarterly Report, UCRL-9900, Oct. 1961, p. 39. 


\section{Analytical methods}

Nucleic acid was determined spectrophotometrically after hydrolysis of the extracted preparations ${ }^{2}$ with $5 \%$ perchloric acid at $90^{\circ}$ for 15 min or, for RNA, mild alkaline hydrolysis with $0.3 \mathrm{~N} \mathrm{KOH}$ for $18 \mathrm{hr}$ at $37^{\circ}$. Yeast RNA (Schwarz Lab.) was used as a standard.

Ion-exchange column chromatography of the alkaline hydrolyzate was conducted on a column $11 \mathrm{~cm}$ long $\times 1 \mathrm{~cm}$ diam, filled with Dowex-1, 200 to

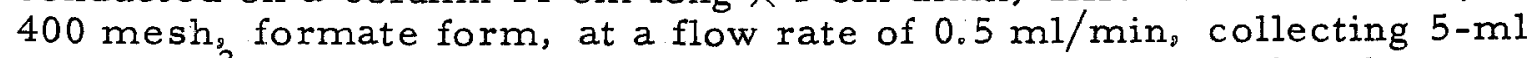
samples. 3 Nucleotides were estimated by measuring the absorbance at $260 \mathrm{m \mu}$, using a Beckman DU Spectrophotometer. Nucleotides were tentatively identified from their elution sequence. Identification was confirmed by complete spectral analysis at $\mathrm{pH} 2$ and $\mathrm{pH} \mathrm{12,} \mathrm{and} \mathrm{neutrality} \mathrm{on} \mathrm{the} \mathrm{basis}$ of 250/260-, 280/260-。 and 240/260-m ratios, using a Cary Recording Spectrophotometer.

\section{Results}

Figure 10-1 shows complete spectra of acid hydrolyzates of quantasome and stroma preparations, and it is apparent that all the plastid polynucleotide is in the soluble fraction of the chloroplasts. The RNA concentration was found to be $0.00532 \mathrm{mg}$ per $\mathrm{mg}$ stroma protein.

The stroma RNA was characterized, and Fig. 10-2 shows the elution pattern of an alkaline hydrolyzate sorbed onto a formate column and removed by decreasing acidity and increasing the ionic concentration of the eluent. Elution peaks were examined by ultraviolet spectrophotometry and identified with cytidylic (CMP), adenylic (AMP), uridylic (UMP), and guanylic (GMP) acids. Isomers $\left(2^{\prime}\right.$ and $\left.3^{\prime}\right)$ of CMP and AMP were separated during elution (Table 10-I).

The dialyzed stroma preparation was centrifuged for $150 \mathrm{~min}$ at $125,000 \mathrm{~g}$ using a Spinco Model L ultracentrifuge and a SW39L rotor head. The sediment was resuspended in $10^{-3} \mathrm{M}$ tris buffer. The resuspended sediment and the supernatant were each examined by uv spectrophotometry. The data in Table 10-II show the RNA sediments, as indicated by the $\lambda$ max shift to a shorter wavelength and decrease of the $280 / 260 \mathrm{~m} \mu$ absorbance ratio upon sedimentation.

\section{Discussion}

The results presented here are in accordance with the assumption that plastid RNA is of a soluble nature and located in the stroma. Therefore it is likely that plastids suffer losses of RNA during preparations by aqueous techniques and that our value for polynucleotide levels obtained by direct analysis of plastids prepared by a nonaqueous technique approximate the in vivo concentrations. 1

\footnotetext{
$\overline{{ }^{2} R_{0} \cdot M_{0}}$ Smillie and G. Kratkov, Can. J. Bot. 38, 31 (1960). 3

W. E. Cohn and E. Volkin, Ann. N. Y. Acad. Sci. (1953), p. 204.
} 
UCRL- 10156

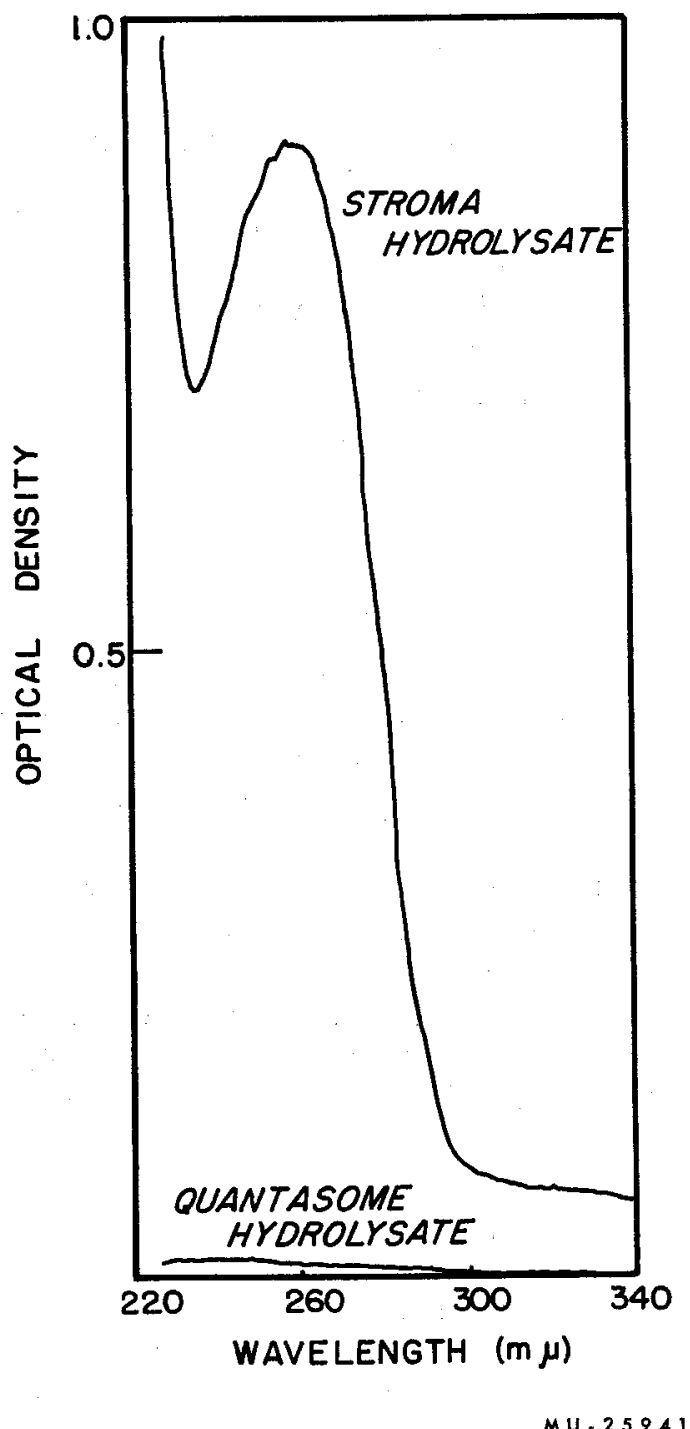

Fig. 10-1. Ultraviolet spectra of stroma and quantasome acid hydrolyzates. 


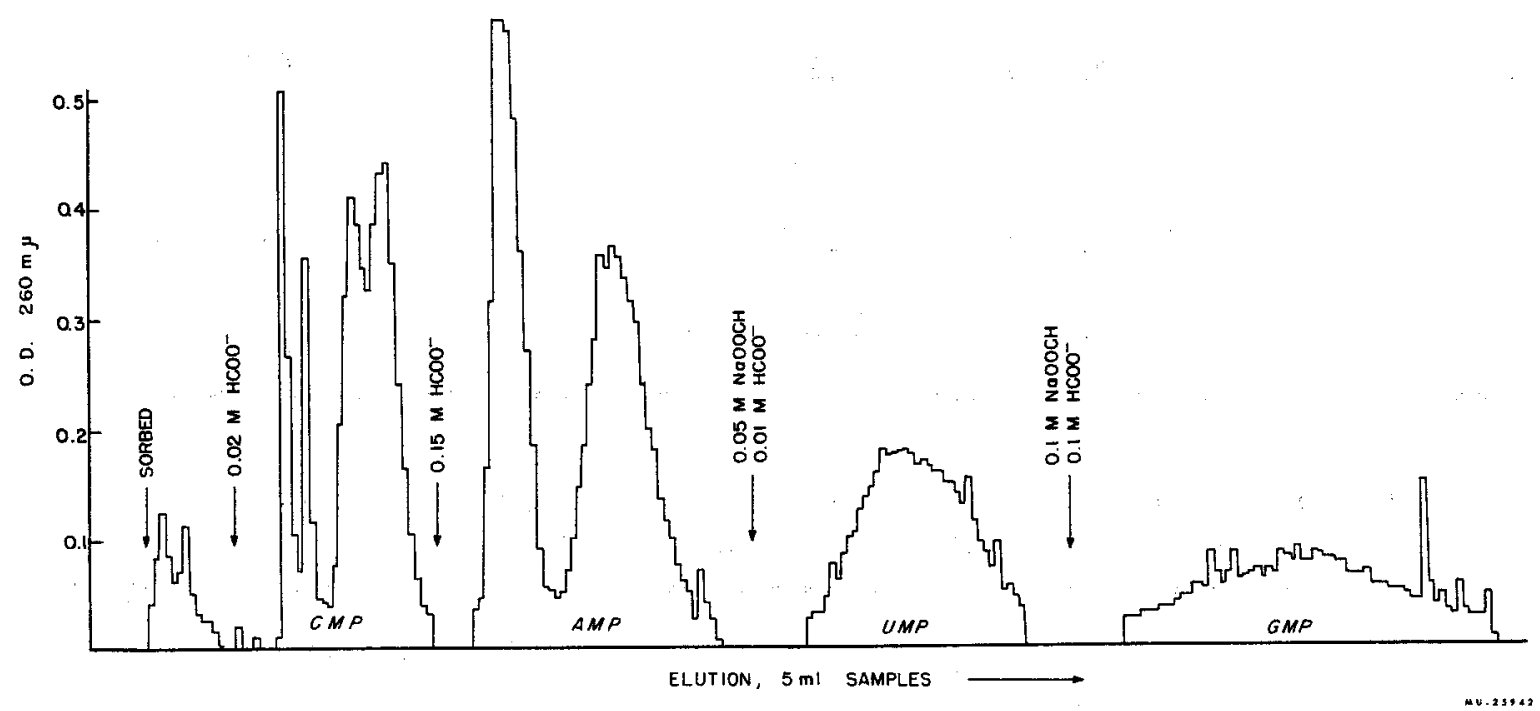

Fig. 10-2. Elution pattern of stroma-RNA nucleotides separated on a formate column, $11 \mathrm{~cm} \times 1 \mathrm{~cm}$ diam, $0.5 \mathrm{ml} / \mathrm{min}$, 5-ml fractions collected. 
Table 10-I. Ultraviolet absorbance ratios of elution maxima of stroma-RNA nucleotides separated by ion-exchange chromatography.

\begin{tabular}{|c|c|c|c|c|c|c|}
\hline \multirow{3}{*}{ Nucleotide } & \multicolumn{6}{|c|}{ Absorbance ratio } \\
\hline & \multicolumn{2}{|c|}{$250 / 260 \mathrm{m \mu}$} & \multicolumn{2}{|c|}{$280 / 260 \mathrm{m \mu}$} & \multicolumn{2}{|c|}{$290 / 260 \mathrm{m \mu}$} \\
\hline & $\underline{\mathrm{pH}}=2$ & $\mathrm{pH}=12$ & $\mathrm{pH}=2$ & $\mathrm{pH}=12$ & $\underline{\mathrm{pH}}=2$ & $\underline{\mathrm{pH}=12}$ \\
\hline 21 & $\overline{0.526}$ & 1.1 & 1.89 & 0.84 & 1.31 & 0.37 \\
\hline $3^{\prime}$ & 0.485 & 1.08 & 2.00 & 0.95 & 1.37 & 0.405 \\
\hline $2^{\prime}$ & 0.965 & 0.825 & 0.232 & 0.19 & 0.0357 & 0.048 \\
\hline $3^{\prime}$ & 1.03 & 0.86 & 0.25 & 0.02 & 0.054 & 0.0835 \\
\hline UMP & 0.924 & 0.954 & 0.376 & 0.32 & -- & -- \\
\hline GMP & 1.265 & 2.02 & 1.33 & 0.607 & -- & -- \\
\hline
\end{tabular}

Table 10-II. Spectral characteristics of stroma dialyzate before and after ultracentrifugation.

\begin{tabular}{|c|c|c|}
\hline Fraction & $\begin{array}{l}\lambda_{\max } \\
(\mathrm{m} \mu) \\
\end{array}$ & $\begin{array}{l}\text { Absorbance ratio } \\
280 / 260 \mathrm{m \mu} \\
\end{array}$ \\
\hline Stroma dialyzate & 270 & 0.965 \\
\hline Resuspended sediment ${ }^{a}$ & 260 & 0.75 \\
\hline Supernatant ${ }^{a}$ & 270 & 1.028 \\
\hline
\end{tabular}


Characterization of the nucleotides derived from degradation of the extracted stroma show that the polynucleotide consists of CMP, AMP, UMP, and GMP.

The stroma RNA is associated with the stroma protein after chloroplast lysis. However, Lyttleton and Ts'o found that it could be detached from fraction I protein by dialysis against potassium maleate, and removed by ultracentrifugation. 4 However, dialysis against $10^{-3} \mathrm{M}$ tris does not detach the RNA, and it is sedimented with protein at $125, \overline{000} \mathrm{~g}, 150 \mathrm{~min}$. The ease of detachment with potassium maleate indicates a loose bonding between this RNA and other substances in the plastid.

\section{Summary}

RNA analysis of Spinecea oleracea plastids has shown that the polynucleotide is soluble and located in the stroma areas. Preparation of a particulate fraction of quantasome aggregates was found to be free of RNA on the basis of analytical methods used.

By ion-exchange chromatography, the stroma RNA-nucleotides were characterized as cytidylic, adenylic, uridylic, and guanylic acids.

${ }^{4}$ J. W. Lyttleton and P. O. P. Ts'o, Arch. Biochem. Biophys. 73, 120 (1958). 


\title{
11. ABSORPTION SPECTRA OF SPINACH QUANTASOMES
} AND STABILITY OF THE PIGMENTS. II. INHIBITION OF DARK BLEACHING BY STROMA EXTRACTS AND BY INERT GASES

\author{
Kenneth Sauer*
}

The observation of both photoinduced and dark bleaching of spinach chloroplast pigments was reported in the first part of this study. I Special note was made of the dark bleaching of carotenoids prior to the bleaching of chlorophyll. In the study presented here the investigation of this phenomenon has been extended and accurate difference spectra of the selective bleaching have been obtained. Additional evidence for the effectiveness of inert gases in retarding the dark bleaching is presented. It has also been found that some substance present in the colorless stroma material of the spinach chloroplast is highly effective in preventing the selective bleaching of carotenoids in the dark. Further data on the general properties of the absorption spectra of spinach quantasomes are presented along with more precise measurements of the extent of light scattering in these samples.

The term "quantasome" has been proposed to designate the individual particles of the chloroplast grana and stroma lamellae. 2 In spinach chloroplasts the quantasomes have been shown to be oblate ellipsoids with molecular weight of about 400,000 , about $200 \mathrm{~A}$ in diameter and $100 \mathrm{~A} \mathrm{thick}{ }^{3}$ The same study showed that they are able to carry out the "light reactions" of photosynthesis.

\section{Experimental Procedure}

Much of the experimental procedure of this study is identical with or similar to that reported previously. 1 The difference spectra to be reported here, however, were obtained directly, with a Cary Model 14 recording spectrophotometer, by placing the bleached sample in the reference beam and the relatively unbleached one in the sample beam. Precise cancellation of absorption bands that were unaffected by the bleaching process was obtained by using portions of a single initial suspension for the two samples of a given experiment. This technique of obtaining difference spectra directly has resulted in a substantial improvement over the method of the previous study, which involved point-by-point subtraction of successive absorption spectra of a single preparation.

\footnotetext{
*U. S. Public Health Service Fellow, 1960-62.

$\mathrm{l}_{\mathrm{K}}$ enneth Sauer, in Bio-Organic Chemistry Quarterly Report UCRL-9900, Oct. 1961, pp.1-11.

${ }^{2}$. B. Park, Advances in Photosynthesis, J. Chem. Ed., in press.

${ }^{3}$ R. B. Park and No G. Pon, Jo Mol。 Biol. 3, 1 (1961)。
} 
The stroma extract from spinach chloroplasts was obtained by osmotic rupture against deionized water at $0^{\circ}$, in which $3 \mathrm{ml}$ (wet-packed volume) of spinach chloroplasts was extracted with $30 \mathrm{ml}$ of water for 30 min with occasional stirring. The prepared extract was kindly provided by $\mathrm{Mr}$. John Biggins.

Samples were stored in glass-stoppered flasks wrapped in aluminum foil and kept in a refrigerator at $5^{\circ}$. The argon used $\left(0.5\right.$ to $\left.1 \mathrm{ppm} \mathrm{O}_{2}\right)$ was first passed over copper turnings at $350^{\circ}$. Dry nitrogen $\left(0.2 \% \mathrm{O}_{2}\right)$ was used directly from the high-pressure tank.

\section{Absorption Spectra}

The measurements of the absorption spectrum of spinach quantasomes reported previously ${ }^{1}$ have been extended in this study. Figure $11-1$ shows the spectrum of from 230 to $900 \mathrm{m \mu}$ of spinach quantasome sheets resulting from resuspension of the $145,000 \mathrm{~g}$ precipitate, followed by a second sonication. The sonicate was centrifuged at $20,000 \mathrm{~g}$ for $10 \mathrm{~min}$ and the spectrum of the supernatant was recorded. The curve at the right is the spectrum from 720 to $900 \mathrm{m \mu}$ of the undiluted sample, whereas the curve at shorter wave lengths was obtained after 20 -fold dilution. The measurements on the concentrated suspension give a good measure of the turbidity of the sample. In this particular case the ratio $A^{\prime}$ far red $/ A_{\text {red }}$ where $A^{\prime}$ far red is the contribution of the turbidity of the sample to the apparent absorbance at $750 \mathrm{~m} \mu$ and $A_{\text {red }}$ is the calculated absorbance at $678 \mathrm{m \mu}$, is found to be 0.006 . This value is somewhat lower than those reported previously. 1 Upon extrapolation of the smooth curve from $900 \mathrm{m \mu}$ to shorter wave lengths it is evident that the onset of pigment absorption in the quantasomes occurs at $755 \mathrm{~m} \mu$. The curve from 755 to $720 \mathrm{m \mu}$ is a smooth one and does not give evidence of any long -wave-length pigment absorption of the type found by Govindjee, Cederstrand and Rabinowitch in this region of the spectra of Anacystis, Chlorella, and Porphyridium.4 The sensitivity of the present measurement is such that the relative absorption of such long -wave-length bands cannot be greater than about $10 \%$ of the values found by Govindjee et al. for Chlorella and Porphyridium. Although the presence of these long-wavelength bands in algae could be observed only through the use of an integrating sphere spectrophotometer, it is assumed here that the low level of scattering of the spinach chloroplast sonicates would permit the detection of such bands, if present, in the conventional absorption spectra.

The spectrum of the spinach quantasomes in the ultraviolet region is seen to exhibit a shoulder at about $383 \mathrm{~m} \mu$, a small peak at $340 \mathrm{~m} \mu$, and a somewhat larger one at $264 \mathrm{m \mu}$. The onset of strong absorption at wave lengths below $245 \mathrm{m \mu}$ is assumed to be largely due to the substantial amounts of protein present in the quantasomes. Very similar features were noted by Shibata, Benson, and Calvin at 382, 340, and $262 \mathrm{m \mu}$ in the cell suspensions of Chlorella and Scenedesmus. 5 These features appeared in the spectra of alcohol extracts of the algae as well.

${ }^{4}$ Govindjee, C. Cederstrand, and E. Rabinowitch, Science 134, 391 (1961).

${ }^{5}$ K. Shibata, A. A. Benson, and M. Calvin, Biochim. Biophys, Acta 15 , 461 (1954). 

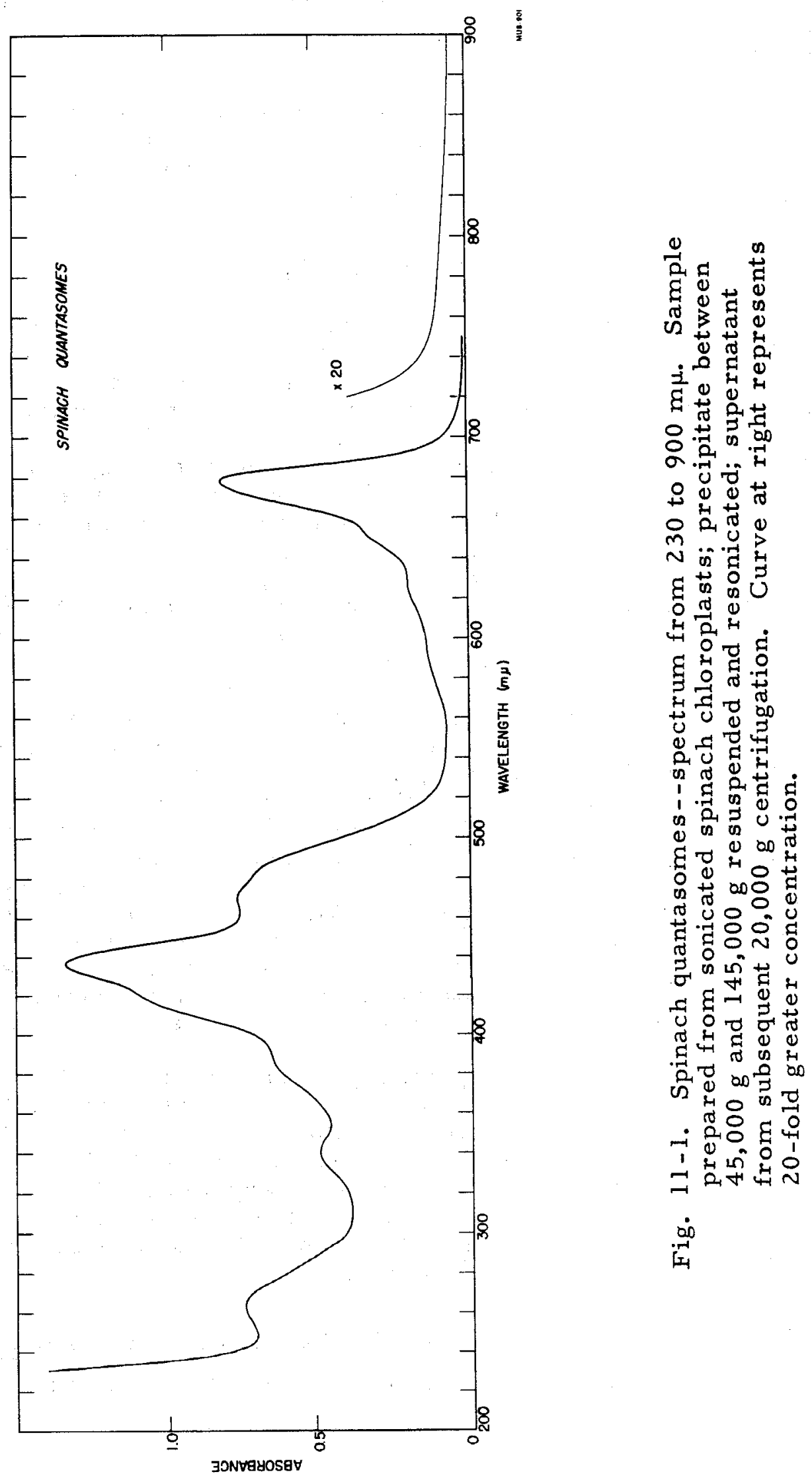
Table 11 -I gives a summary of the positions of the absorption bands observed in the spectra of spinach chloroplasts, together with an assignment of the pigments largely responsible for each. For comparison, data summarized in a review by French 6 on the positions of the absorption maxima in ether solution and on the positions in other higher plants and green algae have been included. The data on carotenoids (carotenes and xanthophylls) are discussed further below。

Spectra of the final supernatant from ultracentrifugation of the spinach chloroplast sonicate at $145,000 \mathrm{~g}$ showed relatively much stronger absorption in the ultraviolet. A comparison of the spectra, normalized at $678 \mathrm{m \mu}$, is shown in Fig. 11-2. In addition to the increment in absorption through the blue and near-ultraviolet regions, the onset of strong absorption below $305 \mathrm{~m} \mu$ was observed for the supernatant fraction. Such absorption is consistent with the presence of large amounts of colorless proteins along with the smallest quantasome aggregates in the supernatant. Measurements of the chlorophyll/nitrogen ratio by Park and Pon lead to the same conclusion. 3

In the final supernatant fraction, accurate measurement of the ratio $A^{\prime}$ far red/A red gave a value of 0.022 . The fourfold increase over the corresponding ratio for the sample of resuspended larger quantasome sheets is presumably due to the increased scattering resulting from the presence of the colorless protein in the supernatant fraction.

A correlation was also noted in the values obtained for the ratio $A_{\text {violet }} / A_{\text {red }}$ For resuspended samples of freshly prepared spinach quantasomes, a survey of all the spectra taken to date gives a value of $1.62 \pm .02$. This is in good agreement with the preliminary value of 1.63 reported in the first part of this study. 1 For the final supernatant from the centrifugation, a somewhat higher value of $1.72 \pm .02$ was obtained. (In the weakly pigmented stroma extracts to be discussed below, the corresponding value was about 2.0.) Evidence for the small difference in the magnitudes of the blue absorption bands relative to those in the red is evident in the spectra shown in Fig。 $11-2$.

Aging and Dark Bleaching

Inert gases

The effect of storage under argon or nitrogen on the dark bleaching of spinach quantasomes has been determined. Samples of the final precipitate resulting from centrifugation of the spinach chloroplast sonicate at $145,000 \mathrm{~g}$ were resuspended in deionized water and diluted to give an optical density of approximately 1 at $678 \mathrm{~m} \mu$. The samples were divided into two portions, one of which was treated by bubbling of inert gas for a 10-min interval immediately following preparation and again at 1 -day intervals during the course of the experiment. The second portion was not so treated, but was allowed to age in the presence of the dissolved air initially in the solution.

${ }^{6} C_{\text {. S. French, }}$ in Handbook of Plant Physiology, Vol. V, part 1, A. Pirson, Editor (Springer-Verlag, Berlin, 1960), ppo 252-97. 
Table $11-$ I. Some chlorophyll and carotenoid absorption bands identifiable in ether solution, in plants and algae and in spinach quantasomes.

\begin{tabular}{|c|c|c|c|c|c|}
\hline & \multicolumn{5}{|c|}{ Wave length $(\mathrm{m} \mu)$} \\
\hline & $\begin{array}{l}\text { Ether } \\
\text { solutiona }\end{array}$ & $\begin{array}{l}\text { Prunus } \\
\text { leafa } \\
\end{array}$ & $\begin{array}{l}\text { Glycine } \\
\text { leafa } \\
\end{array}$ & $\begin{array}{l}\text { Chlorella } \\
\underline{\text { pyrenoidosa }}\end{array}$ & $\begin{array}{l}\text { Spinach } \\
\text { quantasomes }\end{array}$ \\
\hline Chlorophyll a & 662 & 676 & 676 & 678 & 678.5 \\
\hline Chlorophyll b & 644 & & & 650 & 650 \\
\hline Chlorophyll a & 615 & 624 & 626 & 626 & 624 \\
\hline Chlorophyll a & 578 & & 592 & 592 & 594 \\
\hline Carotenes & $475 \zeta \mathrm{b}$ & & & & 485 \\
\hline Xanthophylls & 4701 & & & & \\
\hline Chlorophyll b & 455 & 490 & 470 & 475 & 470 \\
\hline Carotenes & $448\} \mathrm{b}$ & & & & 455 \\
\hline Xanthophylls & 4421 & & & & \\
\hline Chlorophyll a & 430 & 436 & 438 & 438 & 437 \\
\hline Carotenes & $424\} \mathrm{b}$ & & & & 428 \\
\hline Xanthophylls & 418 & & & & \\
\hline Chlorophyll a & 410 & & & 418 & 418 \\
\hline Carotenes & $400 / \mathrm{b}$ & & & & 400 \\
\hline Xanthophylls & $393\}$ & & & & \\
\hline Chlorophyll a & 380 & & & 382 & 383 \\
\hline Chlorophyll a & 326 & & & 340 & 340 \\
\hline Carotenes & $270\} \mathrm{b}$ & & & & 264 \\
\hline Xanthophylls & 2701 & & & & \\
\hline
\end{tabular}




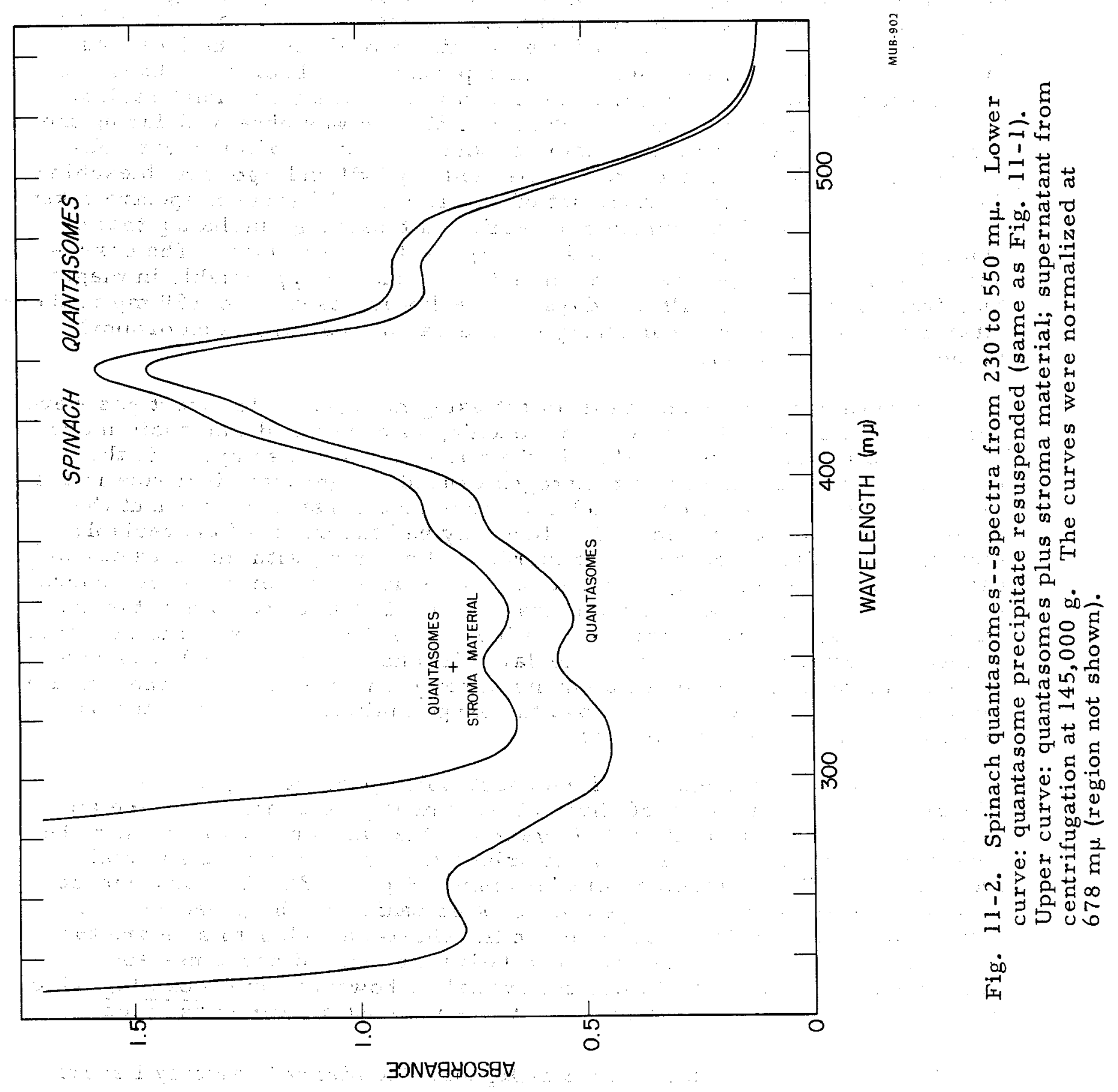


Spectra of samples withdrawn from both the air-stored and the argonstored suspensions showed the effects of dark bleaching. In both cases selective carotenoid bleaching occurs; however, the process proceeds appreciably more rapidly in the air-stored sample, especially in the early stages. Figure 11-3 shows difference spectra recorded at intervals following the preparation. The curves result from the more rapid selective bleaching of carotenoids in the air-stored sample. The maxima that occur at 428,455 , and $485 \mathrm{~m} \mu$ do not appear to shift significantly during the initial stages of the bleaching. The measurements were extended down to $250 \mathrm{~m} \mu$. A small negative peak of about 0.1 the magnitude of tho se in the blue was observed to grow in at $287 \mathrm{~m} \mu$. No other pronounced absorption changes or maxima in the difference spectra were observed in the ultraviolet region. No appreciable change in the absorbance at $678 \mathrm{~m} \mu$ was observed during the initial 2-day interval for either sample, and no peaks at $678 \mathrm{m \mu}$ were observed in the difference spectra. Thus, chlorophyll undergoes no bleaching during this interval under either set of conditions. Subsequent spectra taken up to the sixth day of the experiment exhibited bleaching, including that of chlorophyll, in both the air-stored and argon-stored samples. The corresponding difference spectra in the blue did not change appreciably in magnitude from that observed after 2 days. A peak was observed at $680 \mathrm{~m} \mu$ in these late $r$ difference spectra, indicating a more rapid bleaching of chlorophyll in the air-stored sample.

Results from a second experiment using nitrogen as the inert gas were somewhat different. The selective bleaching of carotenoid was again more pronounced in the air-stored than in the nitrogen-stored sample. In this case, the initial treatment with nitrogen caused a significant increase in the turbidity of the preparation, which then remained constant throughout the remainder of the experiment. The turbidity had the effect of appreciably distorting the difference spectra recorded. Beginning with the third day of the experiment, the nitrogen-stored sample underwent a pronounced general bleaching (chlorophyll and carotenoids) at roughly twice the rate of the airstored sample. These effects are not held to be due directly to the influence of nitrogen rather than argon on the dark bleaching, but rather due to causes such as the presence of small amounts of oxygen in the nitrogen, the different abilities of the two gases to remove the oxygen initially present in the suspensions, sample variability, etc.

Extracts were prepared of the carotenoids present in green cells. Figure 11-4 shows spectra of chromatographically separated carotene and xanthophyll fractions in ether. 7 In general, the xanthophyll rather than the carotene spectrum more closely resembles the difference spectra obtained from the spinach quantasome dark bleaching (Fig。11-3). The pronounced minimum between the two largest absorption bands and the presence of a distinct band rather than a shoulder on the short-wave-length side are the most obvious features. Data on the relative amounts of carotenes and xanthophylls in higher plants are not available; however, in Chlorella, which has a similar pattern of carotenoids, there is about six times as mach

\footnotetext{
7 A. Anderson and M. Calvin, in Bio-Organic Chemistry Quarterly Report UCRL-9652, Apri1 1961, pp. 83-98.
} 


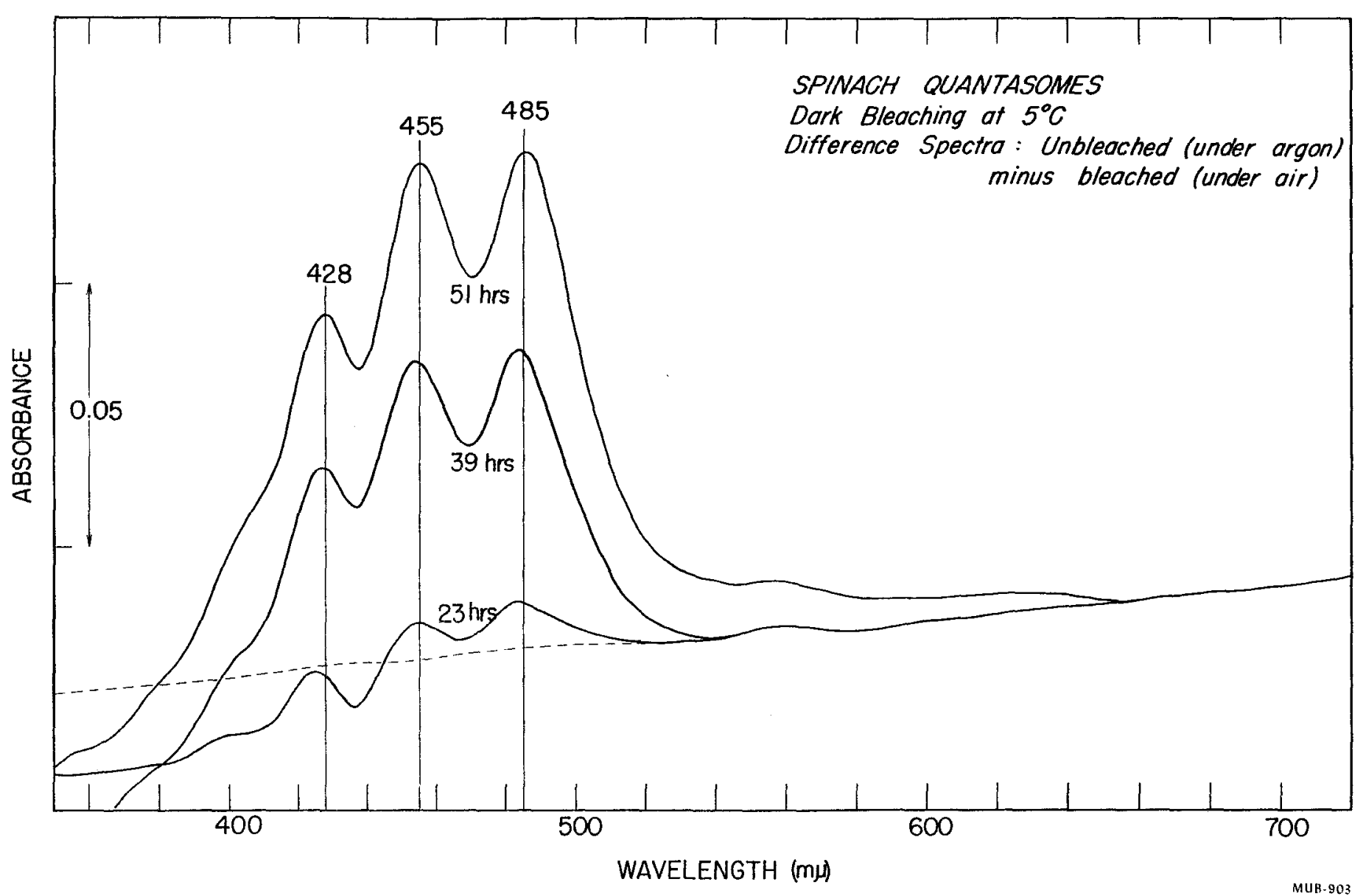

Fig. 11-3. Dark bleaching of spinach quantasomes--difference spectra from 350 to $720 \mathrm{~m} \mu$. Samples prepared from sonicated spinach chloroplasts; precipitate between $45,000 \mathrm{~g}$ and $145,000 \mathrm{~g}$ resuspended. Difference spectra recorded by using Cary Model 14 spectrophotometer, slide-wire corresponding to full-scale absorbance of 0.1 ; sample beam, suspension stored under argon; reference beam, suspension stored under air; both kept in dark at $5^{\circ}$. Initial absorbance 1.0 at $678 \mathrm{m \mu}$. 


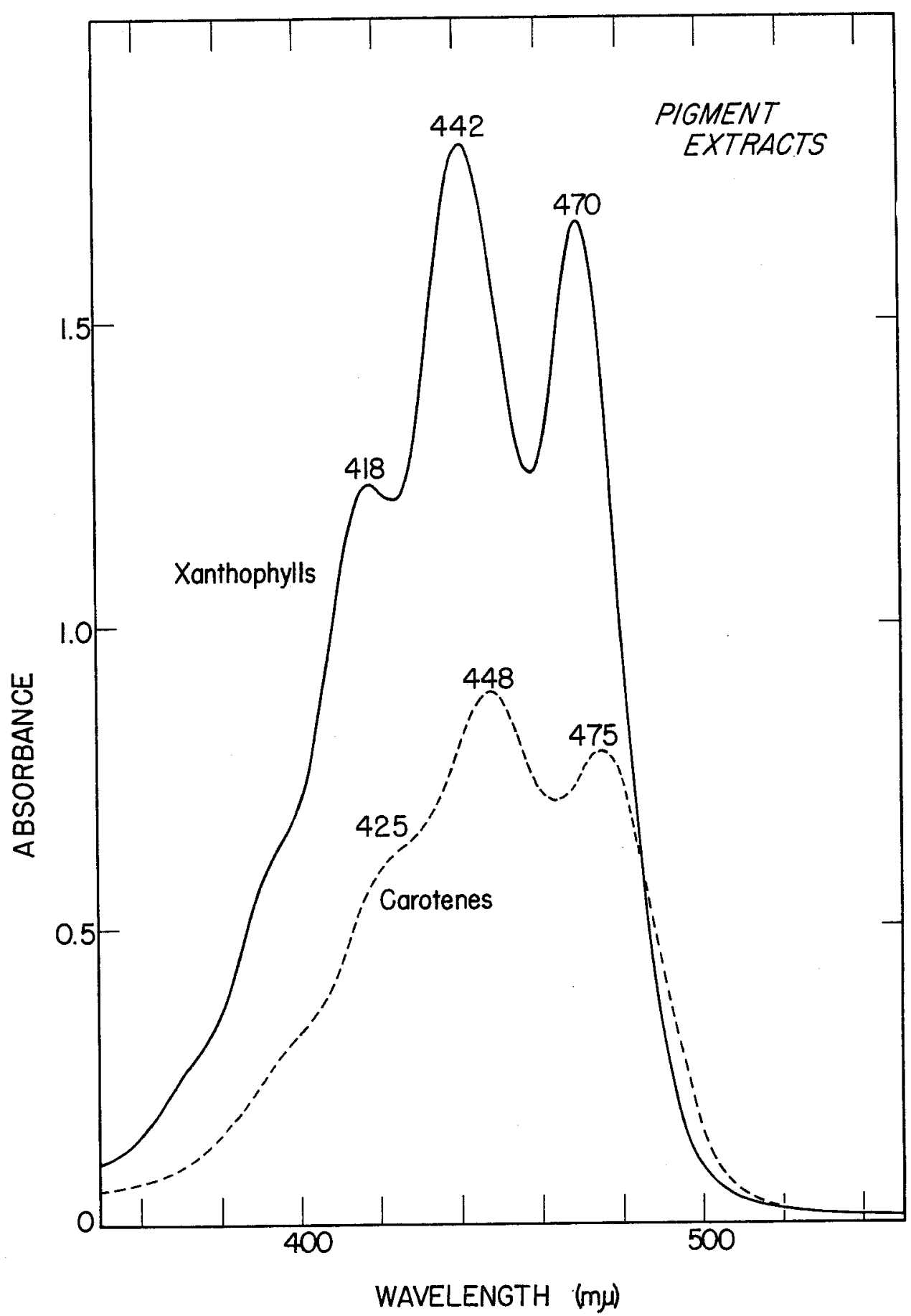

Fig. 11-4. Pigment extracts--partial separation by column chromatography; spectrum from 350 to $550 \mathrm{m \mu}$. Xanthophylls from spinach, solution in ether: solid curve. Carotenes from Chlorella, solution in ether (Ref. 7): dashed curve (a bsorbance multiplied twofold). The separated xanthophyll extract was kindly provided by Mr. A. F. H. Anderson. 
xanthophyll as carotene. 8 It is not possible to say from the spectra whether xanthophylls in spinach quantasomes are bleached selectively or whether all the carotenoids are bleached simultaneously. It does seem, at least, that the carotenes are not selectively bleached. Preliminary chromatographic studies indicate that carotenes and xanthophylls do, in fact, disappear simultaneously during the initial stages of the dark bleaching of spinach quanta somes. 9

Assuming that the difference spectra of Fig. 11-3 are predominantly due to xanthophylls, one can compare them with the spectrum of xanthophylls in ether. The maxima at 485,455, and $428 \mathrm{m \mu}$ and the shoulder at $400 \mathrm{m \mu}$ in the quantasome spectra appear at $470,442,418$, and $393 \mathrm{m \mu}$, respectively, in the ether-solution spectra. Thus, the strongest in vivo absorption bands are shifted 10 to $15 \mathrm{~m} \mu$ to longer wave lengths - - in the same direction as is observed for the chlorophylls.

\section{Stroma extract}

When the final supernatant fraction from the spinach chloroplast sonicate was used for the study of the effects of dark aging, negligible bleaching was observed even after 6 days at $5^{\circ}$ either under air or under inert gas. The difference between the results from these preparations and from those on the resuspended quantasome sheets was quite striking and suggested that some substance in the supernatant liquid was acting as a powerful inhibitor of both the selective carotenoid dark bleaching and of the general dark bleaching phenomena.

An aqueous extract of stroma substances was prepared from osmotically swollen spinach chloroplasts. The extract had a faint yellow color and was somewhat turbid and viscous. The absorption spectrum of the stroma extract is given in Fig. $11-5$. Some absorption due to the pigments is seen in the visible region of the spectrum. The absorbance in the violet and near-ultraviolet regions is very strong, as would be expected from a protein suspension. The chloroplasts from which this stroma material had been extracted were then sonicated and fractionated by ultracentrifugation, as described previously. The final supernatant containing the smallest quantasome sheets, but from which the soluble colorless stroma materials had been largely removed, was divided into four equal portions. To two of these were added portions of the concentrated stroma extract (representing 16\% of the final volume). All four were then diluted to the same final volume, giving an absorbance of 0.93 at $678 \mathrm{~m} \mu$ (and 0.96 at $678 \mathrm{~m} \mu$ for the preparations to which the weakly pigmented stroma extract had been added).

One from each pair of identical samples was immediately treated with nitrogen for $10 \mathrm{~min}$ and again at daily intervals. The other of each pair was kept under air. All four were stored in the dark at $5^{\circ}$.

\footnotetext{
8. M. Anderson, Research in Photosynthesis. I. Biosynthetic Studies on the Chlorophylls and Carotenoids of Algae, (Thesis), UCRL-8870, Sept. 1959.

${ }^{9}$ Elie A. Shneour and Kenneth Sauer (Lawrence Radiation Laboratory), unpublished results.
} 


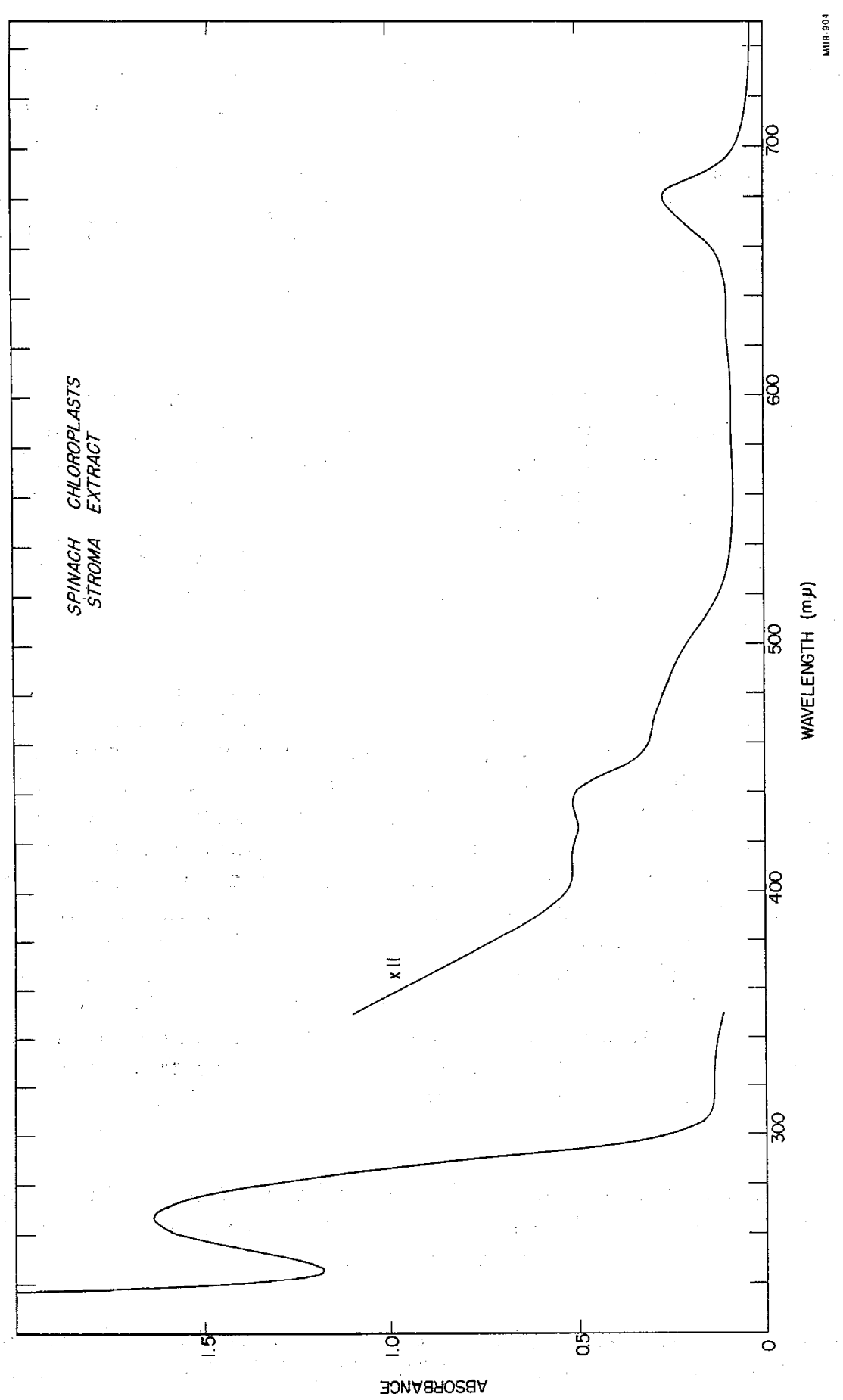

in

त U

तथ

엉혀

일

를 ت्म

르

的 0

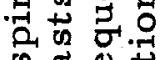

क त

구용 풍

+4 돈

응올

on 0 म

द्वि究告

吕

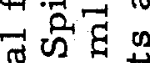

采

त् हृ

द्व 0 㟧

तथ no क्ष

दृ $0_{0}^{\circ}$

मे +

क 讨

แN岳

० द्व

त

世

文

กं

$\begin{array}{llll}1 & 0 & 0 \\ \rightarrow & 0 & 0 & 0\end{array}$

in 
The samples without added stroma extract behaved very much as those discussed in the previous section prepared from the resuspended precipitate of larger quantasome aggregates. The air-stored sample showed selective carotenoid bleaching and the nitrogen-stored sample showed virtually none during the first 2 days. For the next 5 days both samples exhibited general bleaching.

The samples with added stroma extract showed a completely different behavior. The specimen stored under air exhibited virtually no bleaching for the first 5 days. Spectra taken initially and after 1 -day intervals during this period were almost identically superimposed from 350 to $750 \mathrm{m \mu}$. On the seventh day the sample had become significantly turbid. The specimen stored under nitrogen in this case did exhibit appreciable bleaching right from the start. This bleaching was general, however, rather than specific for carotenoids. The formation of a minimum in absorbance at $460 \mathrm{m \mu}$ and other features characteristic of selective carotenoid bleaching were not at all apparent even on the seventh day of the experiment. The reason for the occurrence of pronounced general dark bleaching of the nitrogen-stored sample containing the stroma extract is not clear. A large amount of frothing occurred each time gas was bubbled through this sample, presumably because of the large concentration of protein present. The effect observed was much greater than in any other experiment of the entire study. It was thought that perhaps some of the quantasome aggregates were coagulating and settling out in the concentrated protein suspension, giving rise to an apparent general bleaching of the supernatant. Examination of the contents of the flask at the end of the experiment yielded no visible evidence to support this postulate, however.

The experiments demonstrate the presence of some substance that inhibits dark bleaching of the pigments in the final supernatant following centrifugation of the sonicate of spinach chloroplasts. When the stroma material is extracted osmotically from the intact chloroplasts, the same supernatant fraction bleaches in the normal manner observed for resuspended spinach quantasomes. When the stroma extract is re-added, the dark bleaching is completely inhibited.

Red absorption band

In the first part of this study it was reported that in several cases a shift in the red absorption band of chlorophyll from 680.5 to $678.5 \mathrm{~m} \mu$ was observed in the early stages of the bleaching process. 1 In subsequent experiments this shift did not appear." Such is uniformly the case in this part of the study as well. In no case was any measurable shift observed in the position of the red band in the early stages of bleaching. In all cases the initial position of the maximum of absorption in the red was $678.5 \pm .5 \mathrm{~m} \mu$. It seems, therefore, that in the absence of confirmatory evidence the shift reported earlier must be treated as an experimental artifact. Whether this occurred in the spinach itself, in the preparation of the quantasomes, or in the process of making the spectrophotometric measurements is a moot question. 
When difference spectra were recorded for air-stored versus inert gas-stored samples beyond the stage of selective carotenoid bleaching, it was generally observed that the general bleaching, including that of the chlorophyll red band, occurred more rapidly in the air-stored sample. In such cases a peak appeared in the difference spectrum at $680 \mathrm{~m} \mu$. This peak was always observed to be about $2 \mathrm{~m} \mu$ further to the red than the absorption maximum, and suggests a somewhat selective bleaching of a long wavelength form of chlorophyll a. Coupled with this was a slow shift of the 678-m $\mu$ absorption maximum toward the blue. This shift was noted in the photobleaching as well as in the dark bleaching, as noted previously. I At the same time, the peak in the difference spectrum was much more symmetric than was that of the absorption spectrum. The failure to observe a shoulder on the short-wave-length side suggests that chlorophyll $\underline{\mathrm{b}}$ was bleached more slowly than was chlorophyll a.

\section{Discussion}

The bleaching of the pigments of photosynthetic organisms has been the subject of a number of studies reported in the literature. In most cases, the bleaching phenomena observed have been light-induced and, furthermore, attention has been focused chiefly on the red absorption bands of the chlorophylls. Krasnovsky and Kosobutskaya have described the bleaching in strong light of chloroplasts from sugar beet leaves. 10 The irreversible decrease in absorption of the red absorption band of chlorophyll was coupled with a shift of the absorption maximum 1.5 to $2 \mathrm{~m} \mu$ toward the red. This was taken to indicate that, of the two principal forms of chlorophyll present in the leaves of higher plants, the one absorbing at shorter wave lengths is more photolabile than the one absorbing at longer wave lengthis.

The studies by French and others $11,12,13$ using the technique of derivative spectrophotometry have shown that the red absorption band in most photosynthetic systems can be resolved into contributions from one or more forms of chlorophyll b, at least three forms of chlorophyll $a$, and, in some cases, a form of pheophytin a. Recent studies by Govindjee et al. describe still further components absorbing weakly at wave lengths longer than $700 \mathrm{m \mu} .4$ In the case of Chlorella it has been estimated that the

I0 A. A. Krasnovsky and L. M. Kosobutskaya, Doklady Akad. Nauk S.S. S. R. 104,440 (1955).

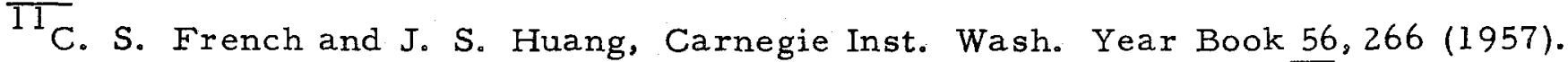

C. S. French and R. F. Elliott, ibid. 57, 286 (1958).

${ }^{13}$ Y. F. Frei, ibid. 59, 333 (1960).

${ }^{14}$ C. S. French, J. S. Brown, M. B. Allen and R. F. Elliott, ibid. 58,327 (1959). 
red absorption band is made up of the following components: $15 \%$ due to chlorophyll b with a maximum at $650 \mathrm{m \mu}\left(\mathrm{C}_{\mathrm{b}} 650\right), 40 \%$ due to a chlorophyll $\underline{\mathrm{a}}$ complex with a miximum at $673 \mathrm{m \mu}\left(\mathrm{C}_{\mathrm{a}} 673\right), 40 \%$ due to a chlorophyll a complex. with a maximum at $683 \mathrm{m \mu}\left(\mathrm{C}_{\mathrm{a}} 683\right)$, and $5 \%$ due to a chlorophyll a complex with a maximum at $694 \mathrm{m \mu}\left(\mathrm{C}_{\mathrm{a}}\right.$ 694). 14 In the chloroplasts of most higher plants studied the ratios were approximately the same. In other algae, however, appreciably different ratios of pigment components have been observed.

An attempt to repeat the experiments of Krasnovsky and Kosobutskaya using Swiss chard chloroplasts produced bleaching of the two principal chlorophyll a components at equal rates; ${ }^{15}$ however, studies on the photobleaching of Chlorella 14 and Euglena 16 did show selective bleaching effects. The order of stability for the se algae went from $\mathrm{C}_{\mathrm{b}} 650$, which did not seem to be bleached at a11, through $\mathrm{C}_{a} 673, \mathrm{C}_{\mathrm{a}} 683$ to $\mathrm{C}_{\mathrm{a}} 694$, which was the most sensitive to light. Since, of the two principal components, the $\mathrm{C}_{\mathrm{a}} 683$ was bleached more rapidly than $\mathrm{C}_{3} 6.73$, the net absorption underwent a slow blue shift during the course of bleaching. This was the opposite effect from that reported by Krasnovsky and Kosobutskaya on sugar beet chloroplasts.

In study presented here, photobleaching of spinach quantasomes was observed to cause a blue shift in the red.absorption band of chlorophyll. 1 This is in contrast to the results on higher plants by both the above groups, but is in agreement with the results on algae. It seems, therefore, that the relative photosensitivity of the two principal chlorophyll a components may be much more species-specific than had previously been supposed, although it must be noted that the preparations used for this study are appreciably different from the whole chloroplasts used by the other workers. Dark bleaching of spinach quantasomes also results in a blue shift of the red absorption band. Furthermore, the absence of a shoulder in the difference spectrum due to chlorophyll $b$ indicates that the order of stability of the pigments in spinach quantasomes is the same as that reported for green algae, with the possible exception of $\mathrm{C}_{a} 694$, on which no evidence is available from this study.

In none of the published studies on photobleaching was the region below $600 \mathrm{~m} \mu$ examined. Relatively little work has been reported on this region. in the literature. Goedheer has noted that in post-etiolated bean leaves, containing a relatively small amount of chlorophyll, the absorption due to chlorophyll can be decreased 2.5-fold by photobleaching without a measurable change in carotenoid absorption. 17 This is in contrast with the observations of the present study on quantasomes of mature spinach chloroplasts, in which photobleaching of carotenoids occur, if anything, somewhat more rapidly than that of chlorophyll. Both light and oxygen have been observed to effect

\footnotetext{
15 J. S. Brown and C. S. French, ibid. 57, 286 (1958).

16 J. S. Brown, ibid. 59, 330 (1960).

17 J. C. Goedheer, Biochim. Biophys. Acta 51, 494 (1961)。
} 
carotenoid absorption changes in green cells (Chlorella, Chlamydomonas, and Vallisnaria ${ }^{18}$ ) and photosynthetic bacteria (Rhodospirillum rubrum and Rhodopseudomonas spheroides ${ }^{19}$ ). These effects are of short duration and are largely reversible, and it is likely that they are not directly related to the phenomena observed here. Frank and Kenney report that about $60 \%$ of the carotenoids of maize seedlings are destroyed by keeping them in the dark. 20 The effect can be completely prevented by the addition of sucrose, which is considered an equivalent to maintaining the tissues under photosynthetic conditions. The enzymic nature of this destruction is demonstrated by the fact that it can be inhibited by boiling or by the addition of cyanide. 21

As discussed previously, the dark bleaching of spinach quantasomes starts with the selective bleaching of pigments which have absorption spectra characteristic of carotenoids. 1 Direct measurement of the difference spectra shows that the bleached pigments give rise to absorption maxima at 428, 455, and $485 \mathrm{~m} \mu$. Preliminary chromatographic studies indicate that several, if not all, of the carotenoid components are involved in this bleaching phenomenon. The presence of an inert gas has the effect of markedly slowing down the dark bleaching, suggesting that the process is one of oxidation. Furthermore, a powerful inhibitor to the oxidation is present in the stroma material. This is of particular interest in connection with the role of carotenoids as oxidation inhibitors, which has been proposed. 22 In the light of the present studies the mechanism of the inhibition of chlorophyll photooxidation appears to be more complex than had been supposed. This inhibition appears to involve some substance in the stroma material which has a protective effect against oxidation of carotenoids, which in turn serve to prevent chlorophyll oxidation. Further studies of this chain of events are clearly required.

B. Chance, Brookhaven Symposia in Biology 11, 74 (1959).

${ }^{19}$ L. Smith and J. Ramirez, ibid. 310 (1959).

20 S. R. Frank and A. L. Kenney, Plant Physiol. 30, 413 (1955).

${ }^{21}$ K. A. Walsh and S. M. Hauge, J. Agric. Food Chem. 1, 1001 (1953).

${ }^{22}$ M. Griffiths, W. R. Sistrom, G. Cohen-Bazire, and R. Y. Stanier, Nature 176, 1211 (1955); G. Cohen-Bazire and R. Y. Stannier, ibid. $181,25 \overline{0(1958)}$. 


\title{
12. ESR STUDIES ON CHROMATOPHORES FROM RHODOSPIRILLUM RUBRUM AND ON QUANTASOMES FROM SPINACH CHLOROPLASTS
}

\author{
Mary F. Singleton and Gaylord M. Androes
}

Progress toward identifying the sites of the photoinduced unpaired electrons produced in photosynthetic materials has been slow. As a new approach to the problem we have attempted to simplify the sample material to its bare essentials. Thus, we have been studying chromatophores from R. rubrum l and, more redently, the quantasome particles from spinach chloroplasts, 2,3 the smallest units thus far removed from photosynthetic materials which will carry out some of the fundamental reactions of the complete photosynthetic system, 3,4

For both types of particle we have determined the electron paramagnetic resonance (EPR), line shapes (at low amplitude of modulation field), the kinetic behavior of the photoinduced EPR amplitude as a function of temperature. Although the EPR in the chromatophores behaved essentially as that in the whole $R$. rubrum cells, the resonance in the quantasome particles shows diffērent behavior from that in whole chloroplasts. The differences in the latter case have been investigated, and are summarized in Table $12-$ I.

One of the two overlapping EPR's observed in the whole chloroplasts may be characterized as having slow kinetics (minutes) and as being broad (about 20 gauss). This line is designated in the table as $(s, b)$. The other EPR has much faster kinetics (seconds) and is narrower (about 10 gauss). This one is designated $(f, n)$ in the table. The table classifies the various sample materials as to the type of EPR observed in them, whether or not the observed EPR is photosensitive, and - - when it is known - - the biological activity that they exhibit.

We have also determined the action spectra for production of unpaired electrons for both particle types in solutions sufficiently dilute optically to minimize self-absorption effects.

The detailed experimental results on the small particles, the comparisons with the more complete parent systems, and such conclusions as can be drawn are being put into a form suitable for publication.

IG. M. Androes and M. F. Singleton, in Bio-Organic Chemistry Quarterly Report, UCRL-9900, Oct. 1961, p. 17.

${ }^{2}$. B. Park, J。Chem.Ed。, in press。

${ }^{3}$ R. B. Park and N。G. Pon, J。 Mol。Biol。 3, 1 (1961).

${ }^{4}$ A. W. Frenkel and D. D. Hickman, J. Biophys. Biochem. Cytology 6 , 285 (1959). 


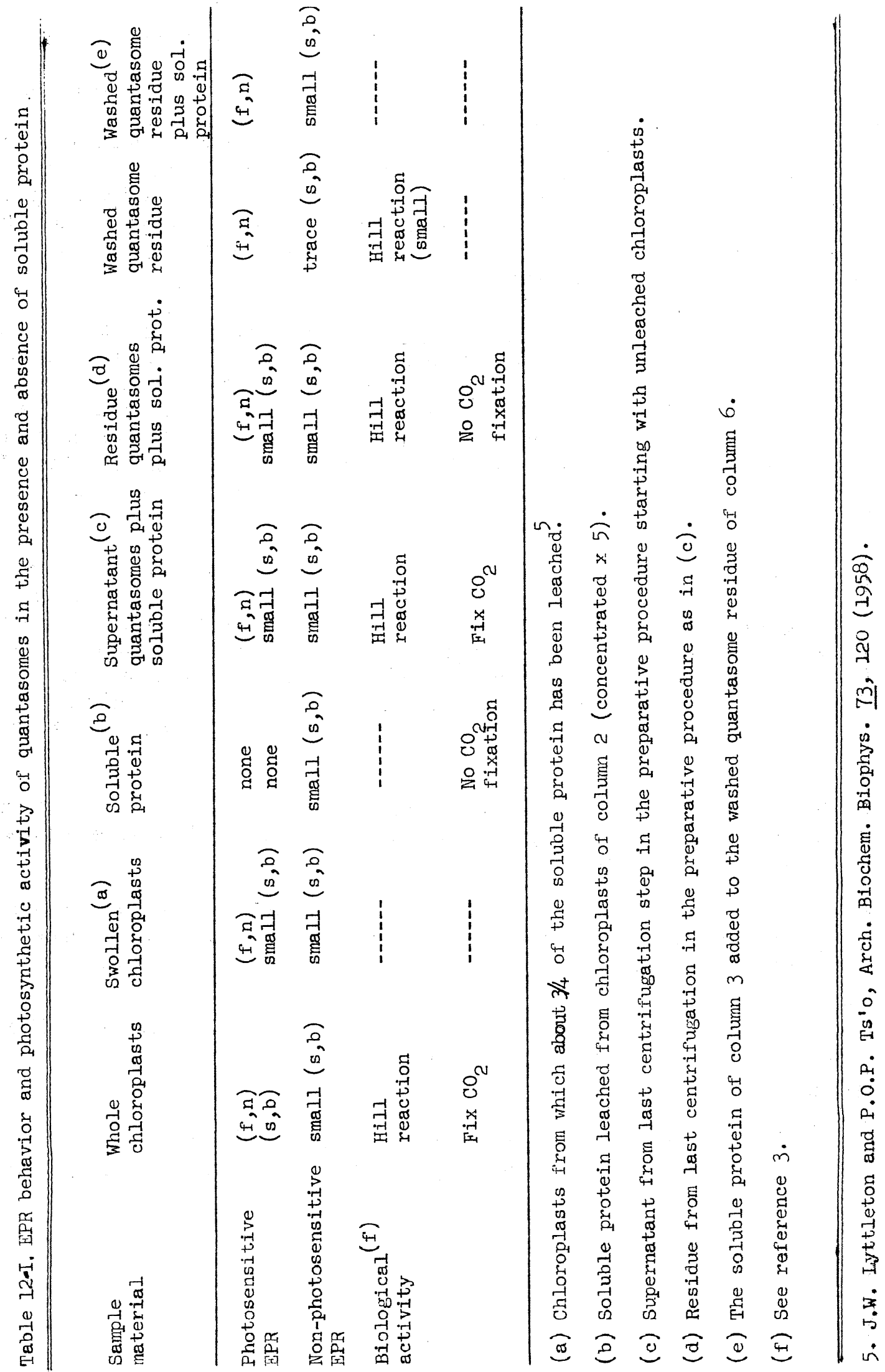




\title{
13. PHTHALOC YANINE MANGANESE AND \\ ETIOPOR PHYRIN MANGANESE COMPLEXES
}

\author{
Akio Yamamoto
}

\section{Introduction}

In our previous paper dealing with the oxidation and reduction reactions of phthalocyanine and etioporphyrin I manganese, 1 the following reaction scheme was proposed for the oxidation and reduction of phthalocyanine manganese complexes in pyridine:
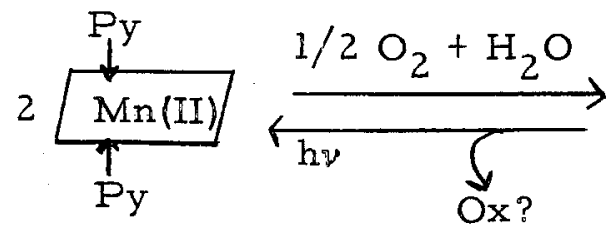

$880,660 \mathrm{~m} \mu$

$\underline{I}$<smiles>[Y10]C1(O)CCCCC1([Y])O</smiles>

$716 \mathrm{~m} \mu$

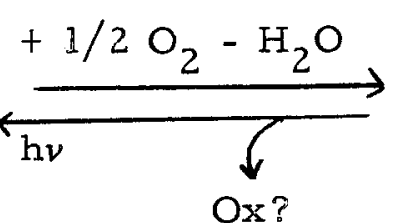

$\mathrm{Ox}$ ?

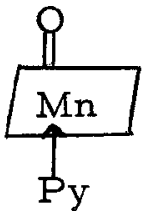

$620 \mathrm{m \mu}$

II

III

where $\mathrm{Mn}=\mathrm{PcMn}=$ phthalocyanine manganese $=\mathrm{C}_{32} \mathrm{H}_{16} \mathrm{~N}_{8} \mathrm{Mn}_{2}$ Py $=$ pyridine. Several problems remained unsettled in the paper:

(a) Evidence of coordination of pyridine on manganese in structure $I_{0}$

(b) Identification of the compound oxidized during the process of reduction of the compound II or III.

(c) The feasibility of the structure of the compound. III, for which we tentatively assigned a monomeric structure, phthalocyanine oxo pyridine manganese(IV), according to Elvidge and Lever。2

Although not all these problems have yet been solved, some of the information needed in order to solve them can be reported here.

\section{Reaction of Pyridine With Phthalocyanine Manganese(II)}

In my previous report ${ }^{3}$ a visible spectrum of phthalocyanine manganese(II) in the solid state was reported. The spectrum was taken with the sample prepared by sublimation in vacuo onto the walls of an optical cell. When pyridine vapor was introduced into the cell in the absence of air a remarkable change in the spectrum was observed (Fig. 13-1). This change is considered to be caused by the coordination of pyridine to the manganese atom of phthalocyanine

TAkio Yamamoto and others, The Effect of Light on Oxidation and Reduction Reactions Involving Phtalocyanine and Etioporphyrin I Manganese Complexes (preprint for Symposium on Reversible Photochemical Processes, Durham, N. Co, April 1962), submitted to Jo Phys。 Chem。

${ }^{2}$ J. A. Elvidge and A。 B. P. Lever, Proc. Chem. Soc. 195 (1959).

${ }^{3}$ A. Yamamoto, in Bio-Organic Chemistry Quarterly Report UCRL-9652。 April 1961, po 55。 


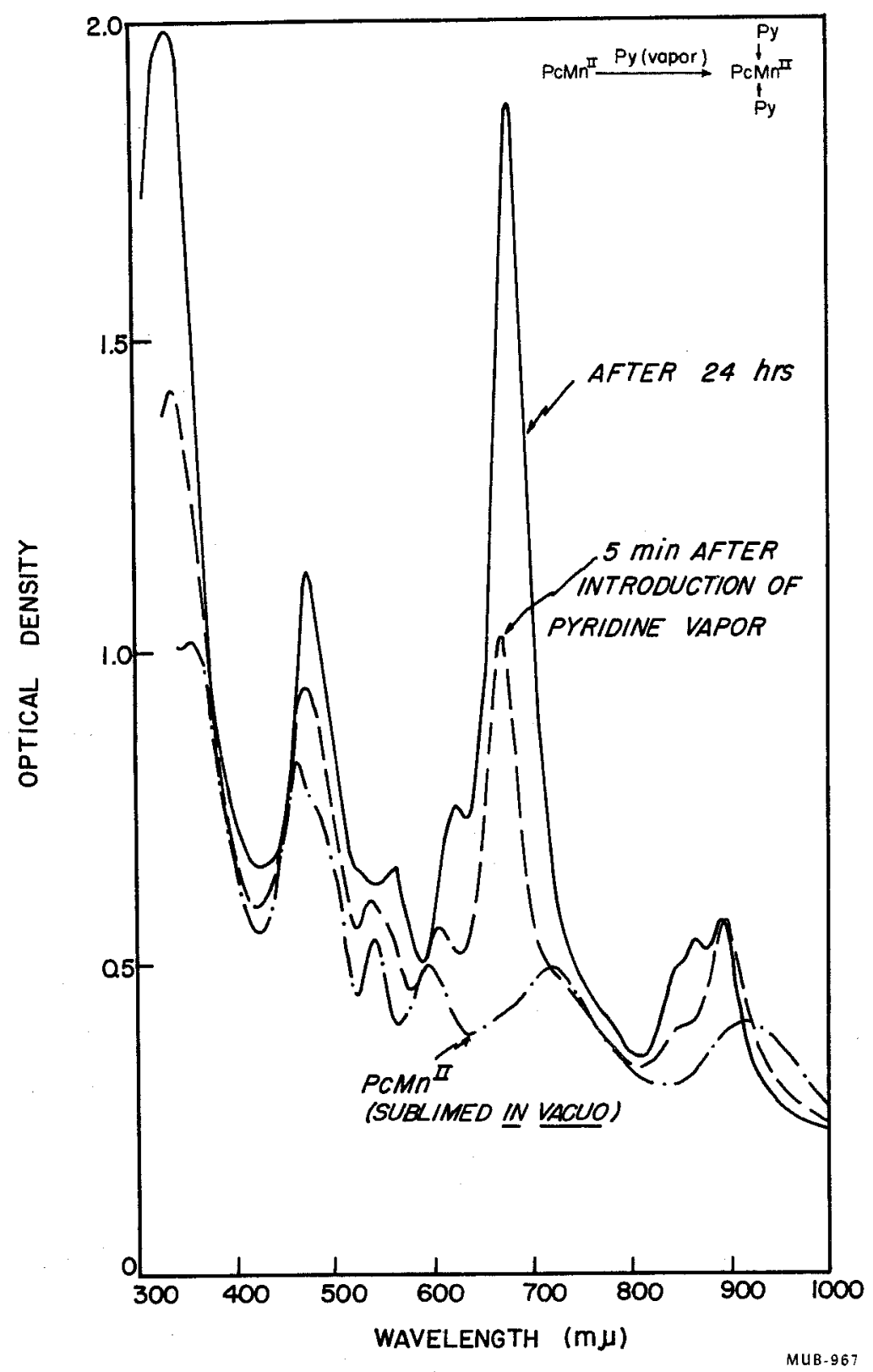

Fig. 13-1. Effect of coordination of pyridine on the visible and uv spectra of phthalocyanine manganese(II). 
manganese(II). The resemblance of the spectrum after coordination of pyridine to the spectrum of phthalocyanine manganese(II) in pyridine solution ${ }^{1}$ suggests that pyridine is coordinated with manganese in a manner similar to its coordination with manganese in pyridine solution. The change of the spectrum of the solid phthalocyanine after the introduction of pyridine takes place rapidly, followed by a further slow change, as can be seen in Fig. 13-1. It should be mentioned here that the spectrum of phthalocyanine manganese(II) coordinated with pyridine is affected by changes of temperature (Fig. 13-2). The spectrum observed at room temperature changed at temperatures higher than $35^{\circ} \mathrm{C}$. The first spectrum was restored when the cell was cooled to room temperature. When the cell was evacuated and heated at $100^{\circ}$ for $1 \mathrm{hr}$, pyridine was desorbed and the original spectrum of phthalocyanine manganese(II) was restored.

The amount of pyridine adsorbed on phthalocyanine manganese with air excluded was determined by using a sensitive quartz-helix balance. Phthalocyanine manganese(II) was placed in an aluminum pan hung from the balance and the whole system was evacuated. Pyridine vapor was introduced into the system and the gain of weight of the sample with time was observed. The ratio of pyridine absorbed to the total weight of the sample was plotted against time (Fig。 13-3, stage I). When the system was evacuated again some of the pyridine absorbed by the sample was removed readily at room temperature; however, about one molecule of pyridine per molecule of phthalocyanine manganese(II) was not removed by evacuation at room temperature (stage II)。 This remaining pyridine was removed by heating at 50 to $60^{\circ}$ in vacuo (stage III). Pyridine vapor was readmitted to the system and pyridine was resorbed in a manner different from the first absorption (stage IV). After removal of the loosely absorbed pyridine, two molecules of pyridine were still found to be adsorbed firmly on the phthalocyanine molecule (stage $V$ ). If the pyridine was again removed at 50 to $60^{\circ}$ the weight of the residue was the same as that of the original phthalocyanine manganese(II). (stage VI). This adsorption and desorption of two molecules of pyridine per one molecule of phthalocyanine manganese could subsequently be reproduced repeatedly.

From these observations the following conclusions may be drawn: Before the treatment of the sample at $60^{\circ}$ in vacuo, not all the surface of phthalocyanine manganese is accessible for the coordination of pyridine, and only one molecule of pyridine can coordinate with one molecule of phthalocyanine manganese, possibly because of a small amount of water already adsorbed. After the heat treatment, the whole surface of phthalocyanine manganese becomes accessible for the coordination of pyridine, and two molecules of pyridine can coordinate on the manganese atom. This observation appears consistent with the spectral change due to the introduction and removal of pyridine. The change of the spectrum of pyridinecoordinated phthalocyanine manganese accompanying the change of the ambient temperature may be due to a shift of the equilibrium
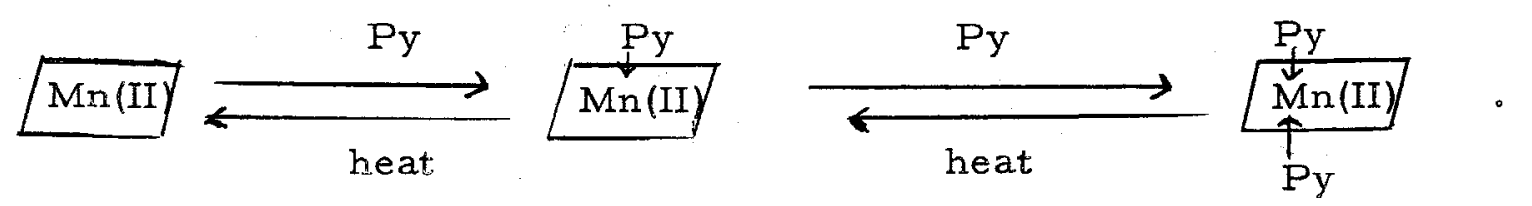


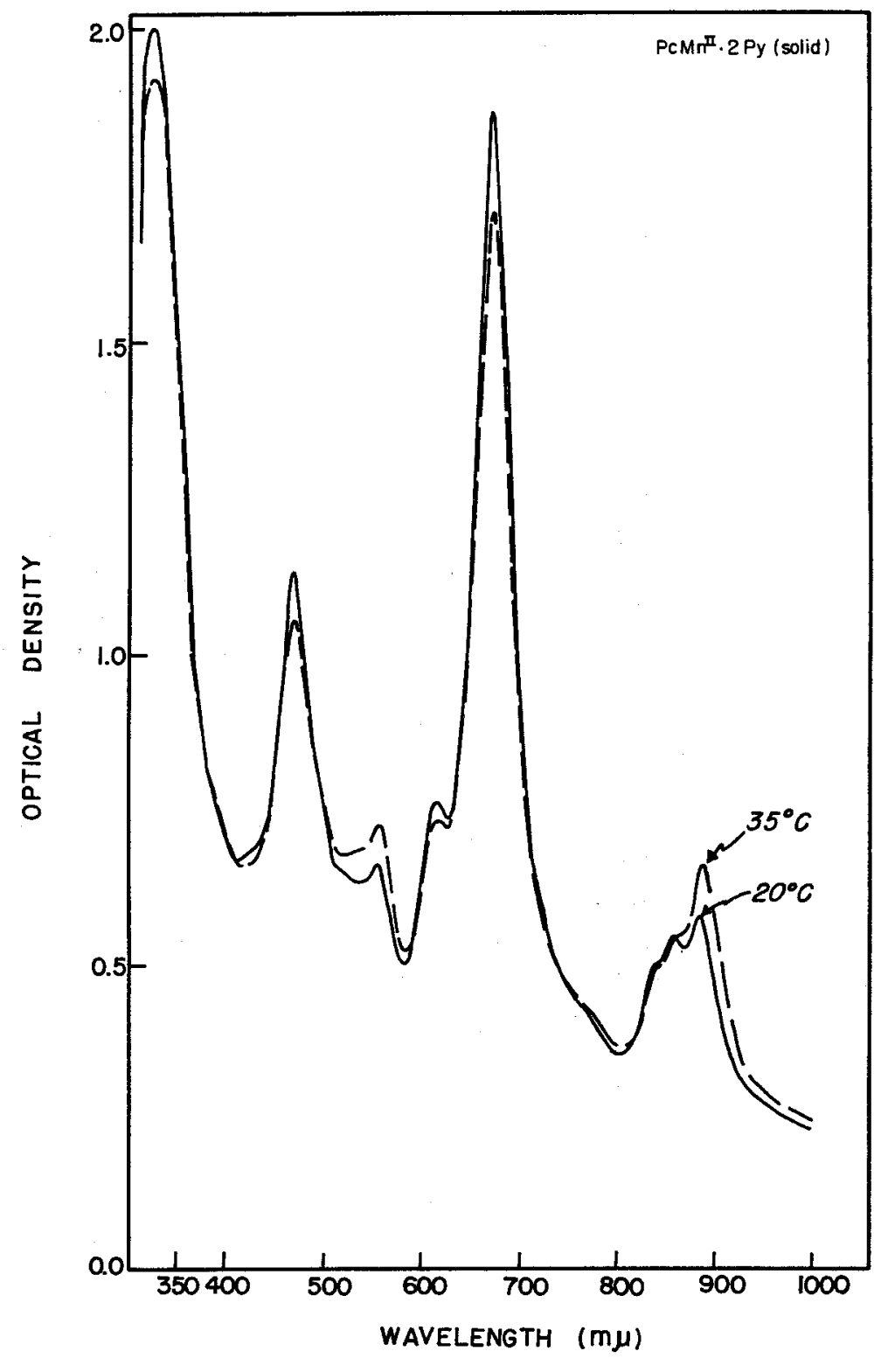

Fig. 13-2. Effect of temperature on the visible and uv spectra of solid phthalocyanine manganese(II) coordinated with pyridine. 


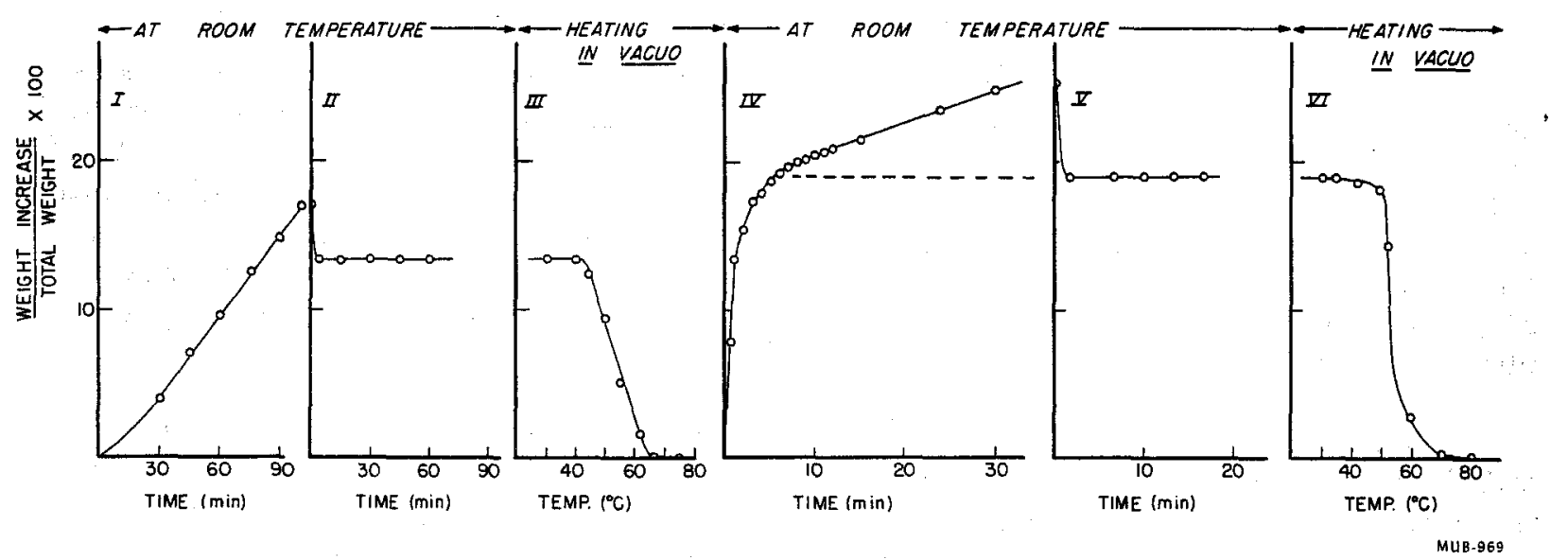

Fig. 13-3. Sorption of pyridine vapor on phthalocyanine manganese(II) in the absence of air.

I. Sorption of pyrindine vapor. IV. Pyridine vapor readmitted.

II. Evacuation at room temperature. V. Evacuated again at room

III. The sample heated in vacuo. temperature.

VI. Heated in vacuo.

In the heating experiments, temperature was increased at approx $10 / \mathrm{min}$. Calculated amount of pyridine adsorbed for two molecules of pyridine per PcMn(II)-2Py: $21.8 \%$. Weight increase observed (stage V) $19 \pm 1 \%$. Calculated for one molecule of pyridine per PcMN(II) Py: $12.2 \%$.

Weight increase observed (stage II): $13.5 \pm 1 \%$. 
When pyridine is distilled into the cell which contains vacuum-sublimed phthalocyanine manganese in the absence of air, and a pyridine solution of the resulting phthalocyanine dipyridine manganese(II)--i。 $e_{0}$, compound I-is prepared, the spectrum shown in Fig. 13-4 is obtained, as reported previously. 1,3 The solution is oxidized after the introduction of oxygen to compound III. A peak at $302 \mathrm{m \mu}$ which is observed in pyridine solution of pyridine-N-oxide was observed to develop after oxygen was introduced to pyridine solution of phthalocyanine manganese(II). This peak was not observed before oxygen was introduced, which suggests the formation of pyridine $-\mathrm{N}$-oxide during the process of oxidation of phthalocyanine manganese in pyridine.

The oxidation of solid phthalocyanine dipyridine manganese(II) takes place slowly and in a manner similar to oxidation in pyridine solution, as we can see from the spectral change.

\section{Reaction of Pyridine With Etioporphyrin I Manganese Complex}

An experiment similar to that performed with phthalocyanine manganese(II) was carried out with an etioporphyrin complex. Etioporphyrin I acetato (acetic acid) manganese(III) was sublimed in vacuo onto the wall of the optical cell. Introduction of pyridine vapor into the cell caused a change of the spectrum (Fig. 13-5). The overall intensity of absorption increased and a shift of a band at $402 \mathrm{m \mu}$ to $442 \mathrm{m \mu}$ was observed after the introduction of pyridine vapor. However, the spectral change was not so striking as in phthalocyanine manganese.

When pyridine was distilled in vacuo into the optical cell and the sublimed sample of the tioporphyrin I manganese complex was dissolved in pyridine, the spectrum shown in Fig. 13-6 was obtained. This spectrum was identical with that of etioporphyrin I manganese(II), which could be obtained only indirectly by photoreduction of etioporphyrin I acetato (acetic acid) manganese(III) in pyridine solution in the absence of air. When oxygen was introduced into the pyridine solution, oxidation to manganese(III) took place rapidly, as we have reported before ${ }^{1}$ (Fig. 13-6).

A similar rapid spectral change was observed with the sublimed solid etioporphyrin I di (acetic acid) manganese(II) upon introduction of air (Fig. 13-7). This explains why our attempts to prepare etioporphyrin manganese complex in the divalent state have so far failed. Etioporphyrin I di(acetic acid) manganese(II) is so susceptible to oxidation that when the compound is brought into contact with air the manganese is rapidly oxidized to the tervalent state.

The adsorption of pyridine by etioporphyrin acetato (acetic acid) manganese(III) was also investigated by using the quartz-helix balance. After the compound was heated at $120^{\circ}$ in vacuo to remove adsorbed moisture, pyridine vapor was introduced at room temperature. The sample absorbed pyridine as shown in Fig. 13-8. When the system was again evacuated, one molecule of pyridine was found to be held without being removed at room temperature. This pyridine was removed by heating at 50 to $110^{\circ}$ in vacuo. 


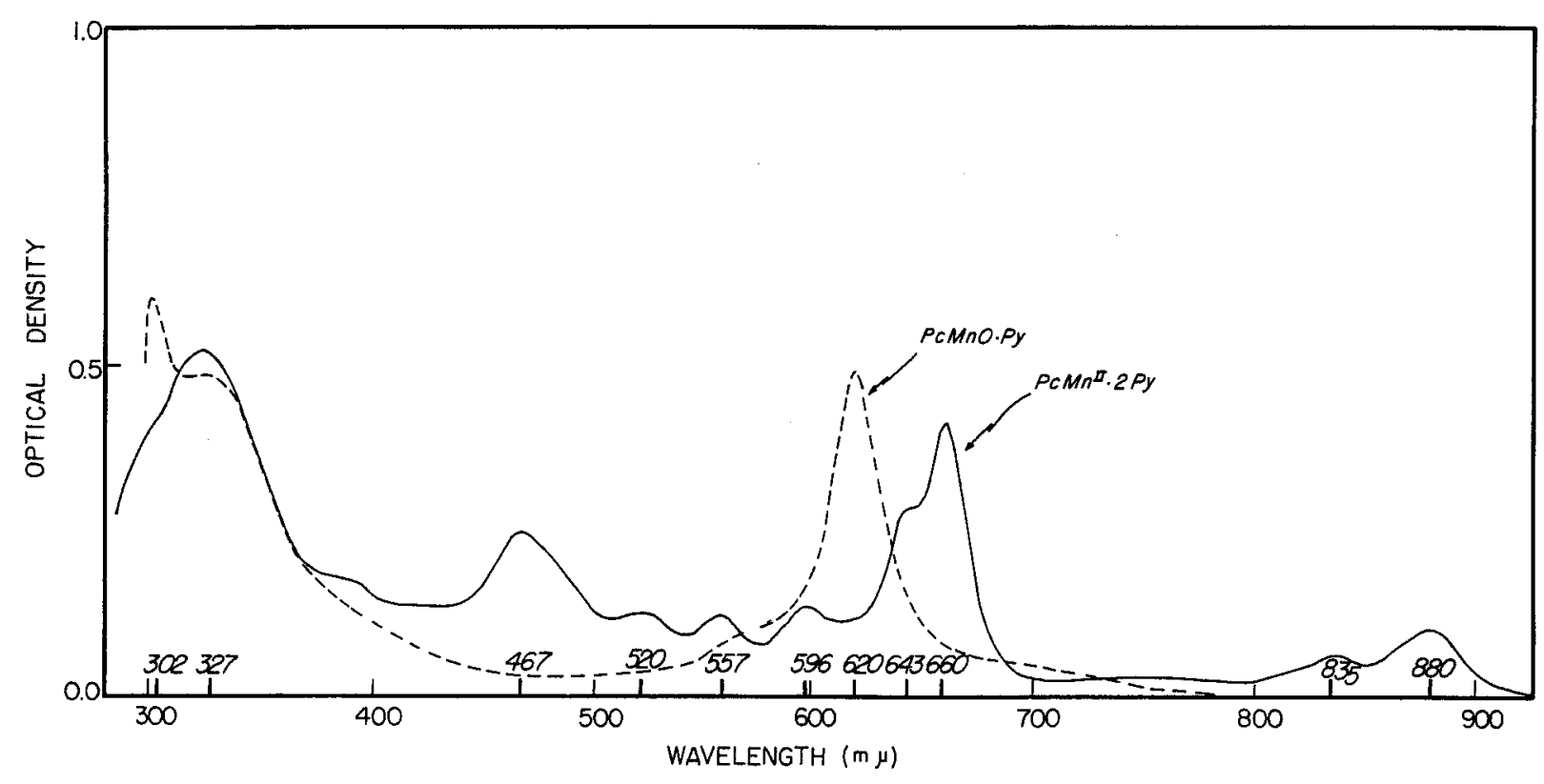

Fig. 13-4. Spectra of Mn(II)Pc. 2Py and the oxidation product in pyridine solution. 


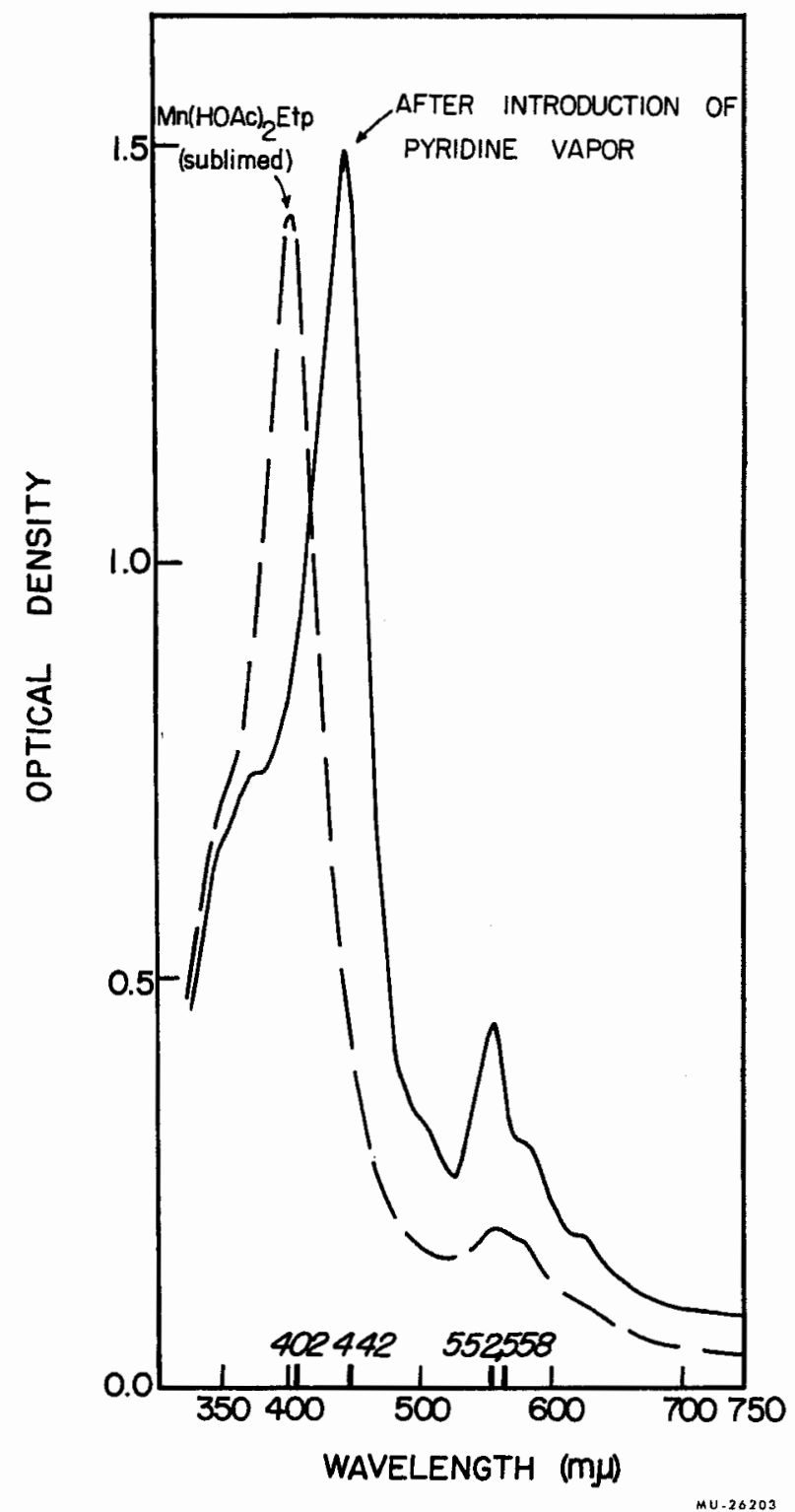

Fig. 13-5. Spectrum of etioporphyrin I di(acetic acid) manganese(II) in the solid state. Lower curve, sublimed in vacuo; upper curve, after the introduction of pyridine vapor. 


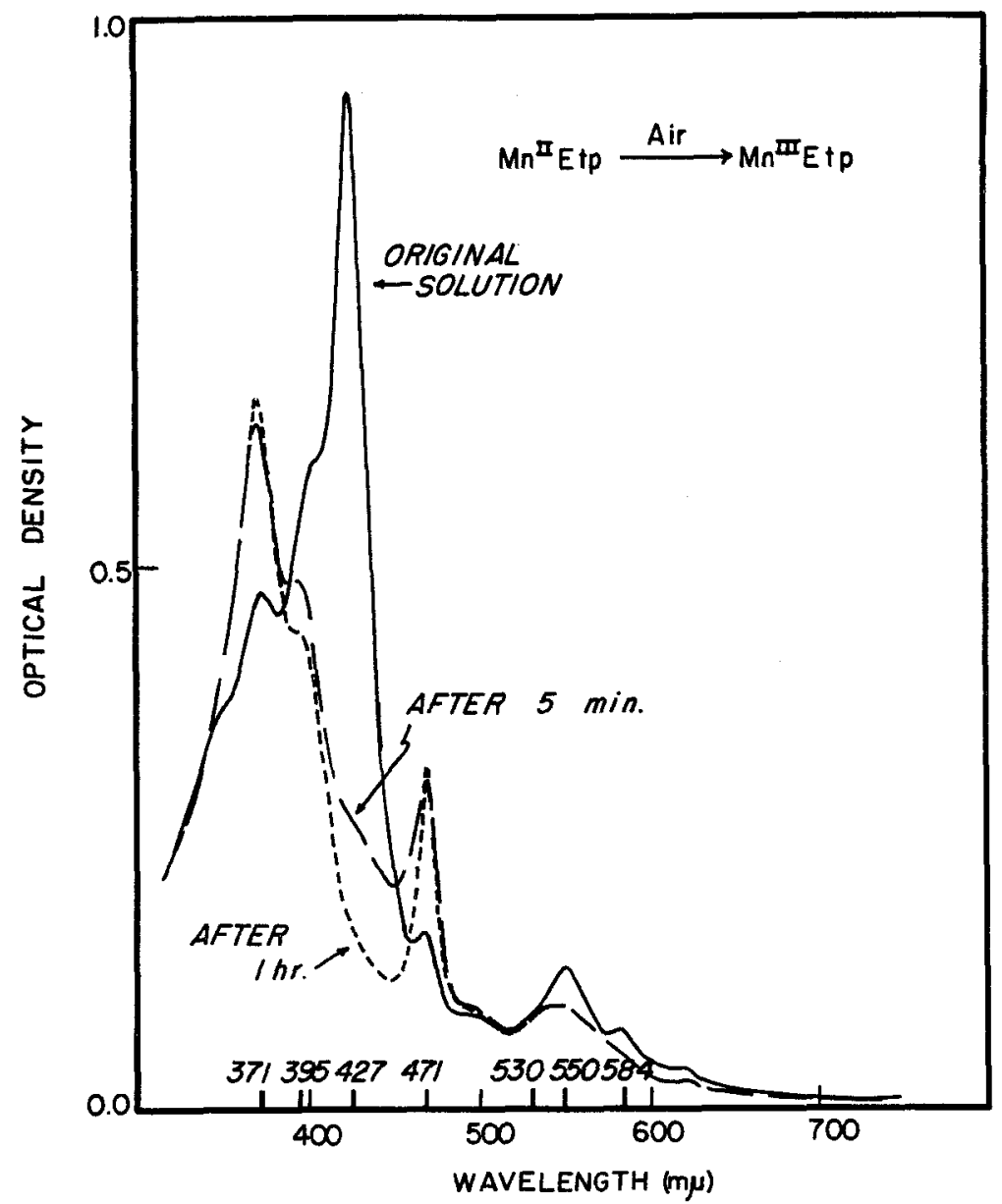

MU. 26204

Fig. 13-6. Spectra of etioporphyrin di(acetic acid) manganese(II) and of etioporphyrin acetato (acetic acid) manganese(III) in pyridine solution. before introduction of $\mathrm{O}_{2}$.

-1 min after introduction of $\mathrm{O}_{2}$.

.... $1 \mathrm{hr}$ after introduction of $\mathrm{O}_{2}$. 


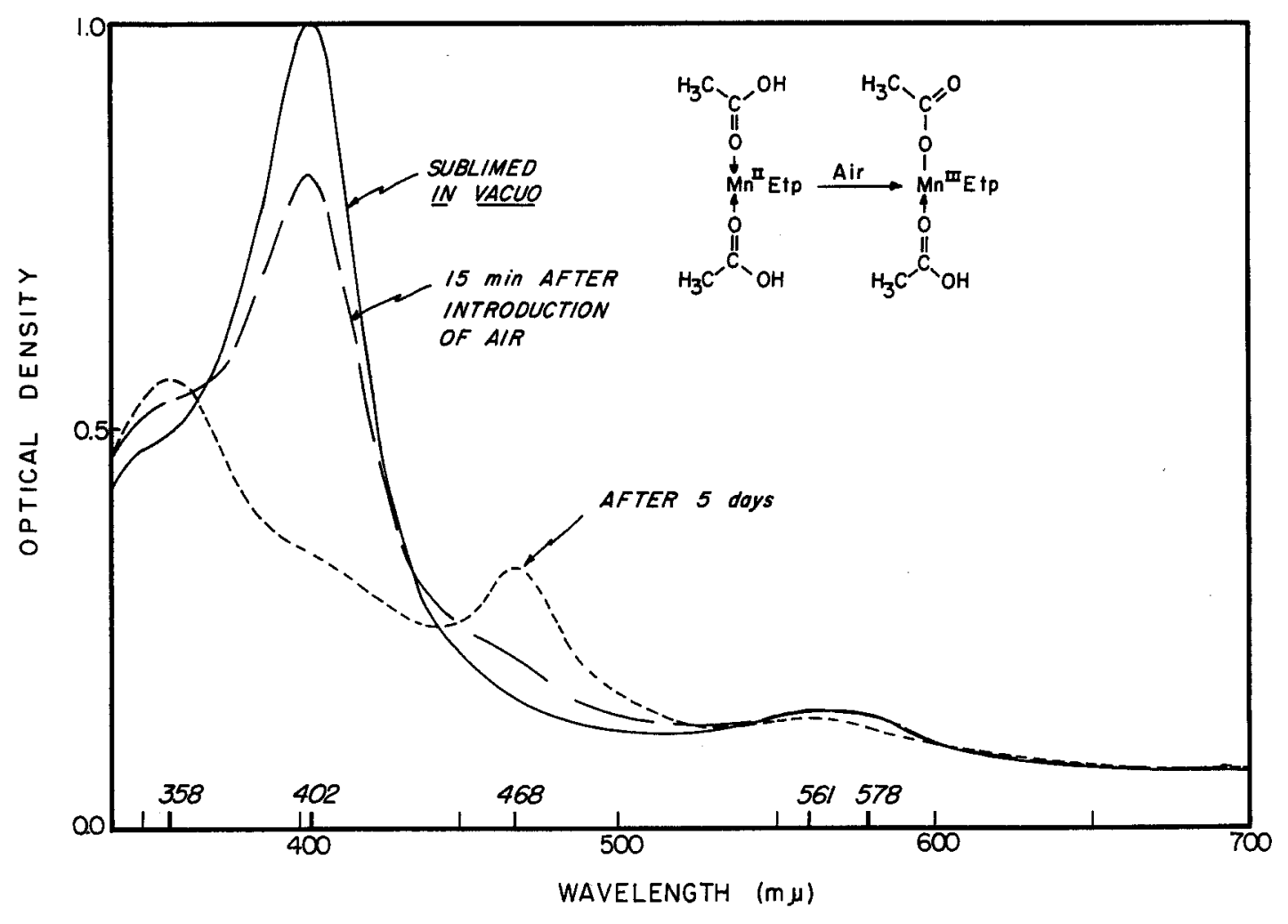

Fig. 13-7. Oxidation of the solid etioporphyrin I di(acetic acid) manganese (II) in air. 


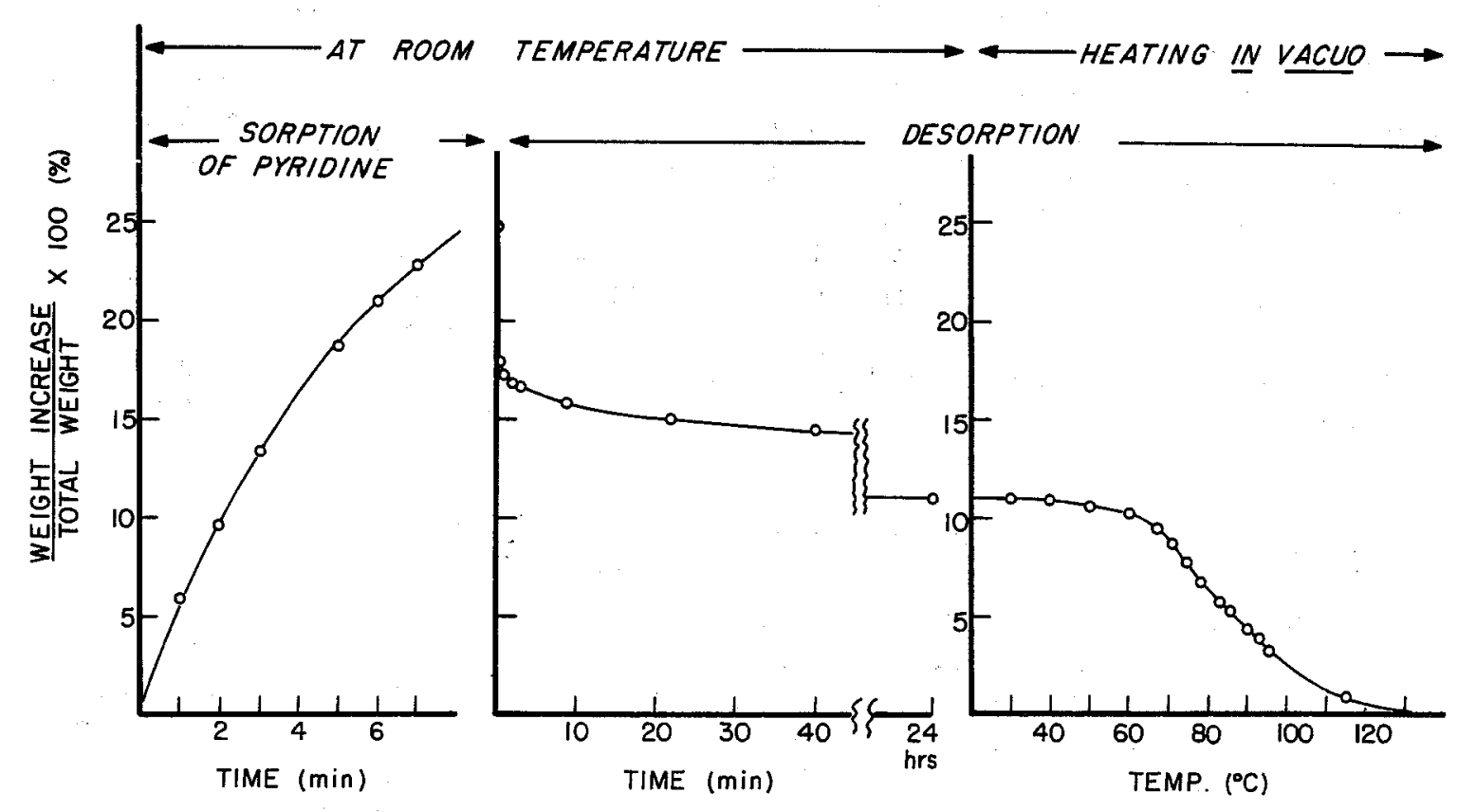

MU. 26206

Fig. 13-8. Sorption and desorption of pyridine by etioporphyrin acetato di(acetic acid) mangane se(III).

In the heating experiment, temperature was increased at approx $1 \% / \mathrm{min}$. Calculated amount of pyridine adsorbed for one molecule of pyridine per EtpMn(HOAc)(OA.c) Py: 10.8\%; observed: $11.0 \pm 1 \%$. 
Since the fifth and sixth positions of etioporphyrin I manganese are occupied by an acetato and an acetic acid group, the coordination of pyridine with manganese atom cannot take place as in phthalocyanine manganese(II), but pyridine is considered to be attached to the acetic acid group by hydrogen bonding.

\section{Oxidized Product}

In the process of thermal reduction and photoreduction of oxidized phthalocyanine complexes, pyridine was found to be essential for reduction. 1,3 If water is present in pyridine the thermal or photoreduction takes place faster than in dry pyridine solution. In order to find out if water is essential for the reduction the following experiment was carried out. Phthalocyanine manganese(IV) oxide $(9 \mathrm{mg})$ was dissolved in vacuo in $20 \mathrm{ml}$ of pyridine from which water was very rigorously excluded. This solution was heated at $70^{\circ}$ continuously and only $50 \%$ of phthalocyanine manganese(IV) oxide was found to be reduced after 4 months. When the same compound was refluxed in pyridine containing $20 \%$ water, reduction took place within $30 \mathrm{~min}$; however, concomitant destruction of the tetrapyrrole ring of phthalocyanine occurred, leading eventually to phthalimide. Apparently a more quantitative kinetic study is required to establish the dependency of the reduction rate on the water content, but it can already be concluded from the above observation that water is necessary for the reduction reaction.

Water in pyridine solution dissociates, giving rise to $\mathrm{OH}^{-}$and pyridinium ion, $\mathrm{C}_{5} \mathrm{H}_{5} \mathrm{NH}^{+}$. The $\mathrm{OH}^{-}$ions might reduce phthalocyanine(III) or (IV) and be themselves oxidized to $\cdot \mathrm{OH}$ radicals, the reaction being accelerated by heat or light energy. The $\cdot \mathrm{OH}$ radicals would attack the phthalocyanine ring directly or form hydrogen peroxide, which is known to react with phthalocyanine; phthalocyanine, under certain conditions, can react with hydrogen peroxide in a catalase-like manner. Hydrogen peroxide is also known to react with pyridine, forming pyridine-N-oxide. In order for the tetrapyrrole manganese compounds to be feasible as model compounds that might function in the photochemical splitting of water in the Hill reaction, some additional compound (or compounds) would have to be introduced into the system to react with $\mathrm{H}_{2} \mathrm{O}_{2}$ or hydroxyl radical and thus prevent the destruction of the tetrapyrrole ring.

\section{Structure of "Phthalocyanine Oxo Pyridine Manganese(IV)"}

Elvidge and Lever reported that they obtained a compound for which they proposed the structure III, phthalocyanine oxo pyridine manganese(IV). ${ }^{2}$ They advanced the following evidence in support of this structure:

(a) The infrared absorption spectrum of the compound shows characteristic bands of pyridine and a strong band at $1096 \mathrm{~cm}^{1}$ for the $\mathrm{Mn}=0$ linkage.

(b) Heating the compound at $180^{\circ}$ and $15 \mathrm{~mm}$ gives a thermostable product PcMn(IV)O ( $\mu_{\text {eff }} 3.77$ B. M.), which, they state, has an extended sixcoordinate lattice structure, IV, with a peak at $820 \mathrm{~cm}^{-1}$ assigned by them to $\mathrm{Mn}-\mathrm{O}-\mathrm{Mn}$ vibration. 


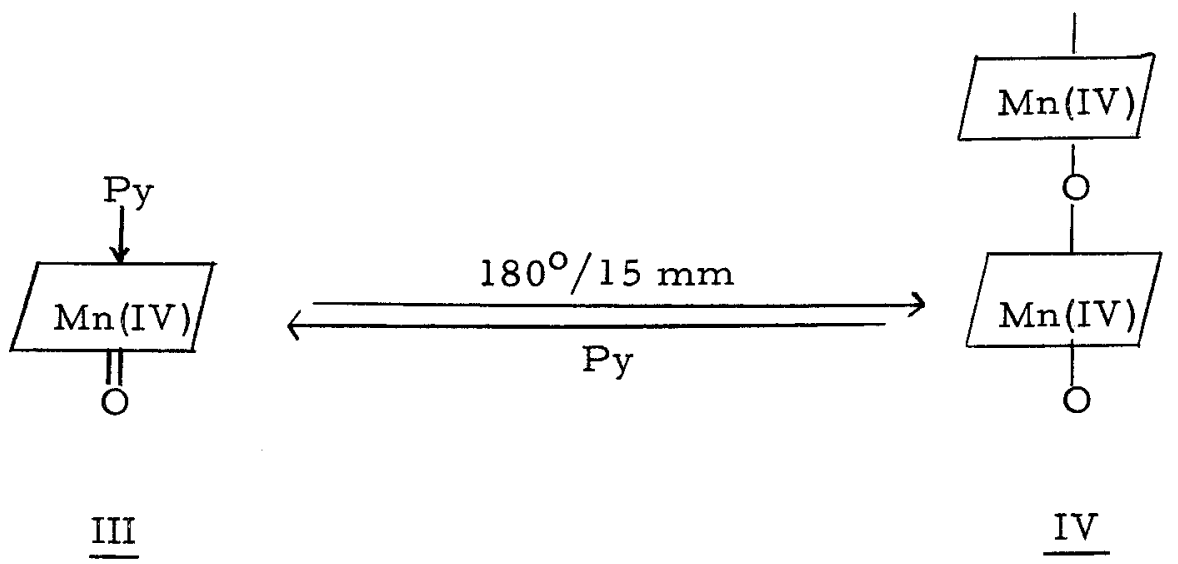

(c) Polarographic study in pyridine containing $0.05 \mathrm{M}$ lithium bromide shows two reduction steps corresponding to the process III $\rightarrow \mathrm{PcMn}(\mathrm{III})(\mathrm{OH}) \rightarrow$ $\mathrm{PcMn}(\mathrm{II})+\mathrm{H}_{2} \mathrm{O}$.

A question has arisen concerning the structure of compound III, since measurement of the magnetic susceptibility of this compound showed that it is almost diamagnetic, with a molar susceptibility of $-270 \times 10^{-6} \mathrm{cgs}$; this, when adjusted by diamagnetic correction for phthalocyanine, pyridine, and oxygen, gives a slightly paramagnetic moment of 0.71 Bohr magneton. This would require some kind of electron pairing either by dimerization through two oxygen atoms (the peroxide, which apparently is not present) or by metaloxygen-metal or metal-metal interaction.

The polarographic study using a lithium salt as a supporting electrolyte was found not to be adequate to establish the quadrivalency of manganese, because by addition of the supporting electrolyte lithium chloride, the pyridine solution turned from blue to green, the quadrivalent solution apparently being reduced by a small amount of water in the presence of lithium chloride.

The amount of pyridine contained in the compound was investigated by using the quartz-helix balance. The crystals prepared from phthalocyanine manganese(II) by oxidation in pyridine were washed with pure pyridine and dry diethyl ether, and dried in air. The sample lost about $5.5 \%$ of weight by evacuation at room temperature (Fig. 13-9, stage I). When the temperature was raised at a constant rate in vacuo a further $15 \%$ of the pyridine was lost at 70 to $80^{\circ}$ (Fig. 13-9, stage II). The los s of pyridine took place at lower temperature $\left(60^{\circ}\right)$ when the sample was heated for a long time. When pyridine vapor was introduced in the absence of air, pyridine was resorbed as shown in Fig. 13-9, stage III. On further evacuation, loosely absorbed pyridine was removed rapidly, and then one molecule of pyridine per one molecule of $\mathrm{PcMnO} \cdot 2 \mathrm{Py}$ was removed gradually at room temperature (stage IV). By heating in vacuo at 70 to $80^{\circ}$ the one remaining molecule of pyridine was removed. This procedure of adsorption and desorption of two molecules of pyridine in two steps could be reproduced repeatedly.

From this experiment it can be concluded that there are two types of pyridine bound to phthalocyanine manganese(IV) oxide. One molecule of pyridine firmly bound to the phthalocyanine oxide molecule can be removed 


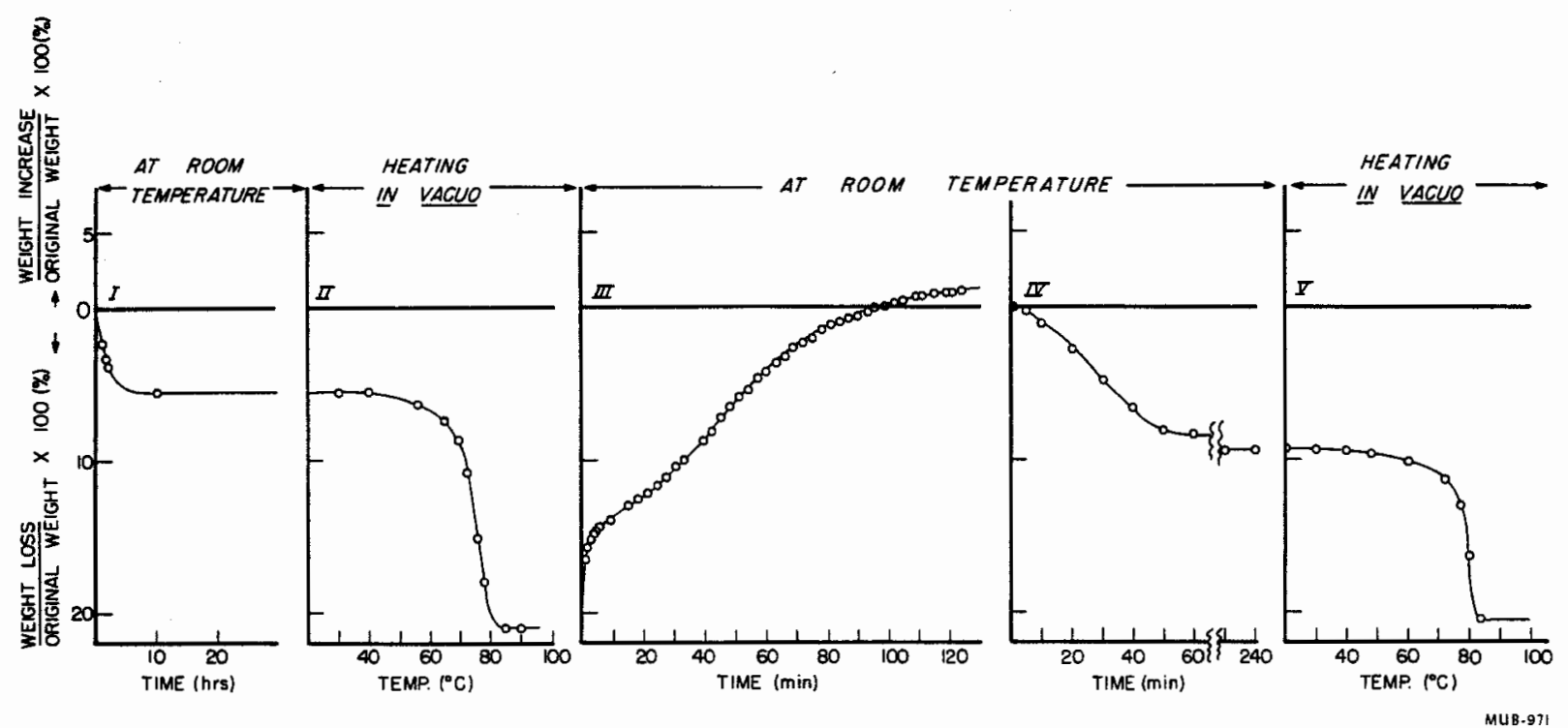

Fig. 13-9. Determination of pyridine contained in PcMnO. 2Py.

I. Evacuation at room temperature. IV. Evacuated again at room

II. The sample was heated in vacuo. temperature.

III. Pyridine vapor was admitted. V. Heated in vacuo. Calculated value for loss of a half molecule of pyridine per PcMnO. 2Py: 5.3\%; one molecule of pyridine per PcMnO. 2Py: $10.7 \%$; two molecules of pyridine per PcMnO. $2 \mathrm{Py}: 21.3 \%$. 
only by heating in vacuo, and one molecule of pyridine, probably pyridine of crystallization, can be removed by evacuation at room temperature. The fact that in stage I before heat treatment only half a molecule of pyridine can be removed at room temperature in vacuo may be because the other half molecule is held rather firmly within the crystal lattice.

When the compound after heating was dissolved in pyridine in the absence of air, a blue solution was obtained which had the same absorption maximum at $620 \mathrm{m \mu}$ as the compound before heating. This, together with a mass spectroscopic observation that pyridine alone is released from the original compound by heating in vacuo, indicates that no change of oxidation state of manganese takes place upon heating in vacuo.

In Table 13-I the results of chemical analyses of phthalocyanine manganese compounds are compared with calculated values.

Infrared spectra of $\mathrm{PcMn}(\mathrm{IV}) \mathrm{O}^{\circ} 2 \mathrm{Py}$ and $\mathrm{PcMnO}$ (heated in vacuo) were observed and compared with those of PcMn(II) and PcMn(II) 2 Py (Figs. $13-10$ and 13-11). The spectrum of PcMn(IV)O-2Py had some bands additional to the spectrum of PcMn(II). The bands observed in pyridine were seen in the spectrum of PcMn(IV)O. 2 Py as weak bands at 705, 755, 993, 1033, 1070, 1150, $1220,1440,1485,1583,1603$, and $1635 \mathrm{~cm}^{-1}$ (some of them overlapped other strong bands). In addition to these bands, several bands of medium intensity were observed at 1098,1220 , and $1440 \mathrm{~cm}^{-1}$, where no bands of PcMn(II) are observed. When the sample was heated in vacuo. at $100^{\circ}$ these bands disappeared and the spectrum obtained was essentially the same as that of PcMn(II). The band at $820 \mathrm{~cm}^{-1}$ which Elvidge and Lever observed with their heated sample, and which was ascribed by them to $\mathrm{Mn}-\mathrm{O}-\mathrm{Mn}$ vibration, was not observed.

The band at $1220 \mathrm{~cm}^{-1}$ of $\mathrm{PcMnO} \cdot 2 \mathrm{Py}$ is in the region where $\mathrm{N}-\mathrm{O}$ stretching vibration of pyridine $-\mathrm{N}$-oxide coordinated to metal atom is observed, 4 and it was suspected first that this compound might be a dimer with $\mathrm{Mn}-\mathrm{Mn}$ bond in the form

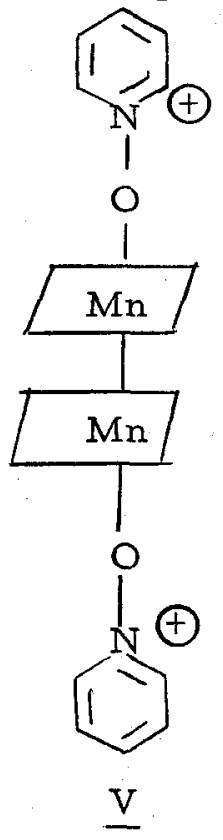

${ }^{4}$ J. V. Qualgliano, J. Fujita, G. Franz, D. J. Phillips, J. A. Walmsley, and S. Yo Tyree, JoAm。Chem。Soc。83, 3770 (1961). 
Table 13-I. Chemical analyses of phthalocyanine manganese compounds (in \%).

\begin{tabular}{|c|c|c|c|c|c|c|c|c|}
\hline \multirow[b]{2}{*}{ Compound } & \multicolumn{4}{|c|}{ Calculated } & \multicolumn{4}{|c|}{ Found } \\
\hline & $\mathrm{C}$ & $\mathrm{H}$ & $\mathrm{N}$ & $\mathrm{Mn}$ & $\mathrm{C}$ & $\mathrm{H}$ & $\mathrm{N}$ & $\mathrm{Mn}^{\mathrm{a}}$ \\
\hline $\mathrm{PcMnO} \cdot \mathrm{Py}$ & 67.07 & 3.20 & 19.03 & 8.29 & & & & \\
\hline $\mathrm{PcMnO} \cdot 2 \mathrm{Py}$ & 68.01 & 3.53 & 18.89 & 7.41 & 68.42 & 3.33 & 18.79 & 7.85 \\
\hline $\mathrm{PcMnO} \cdot 1 \frac{1}{2} \mathrm{Pyc}$ & 67.57 & 3.37 & 18.95 & 7.82 & 67.83 & 3.61 & 19.17 & 7.56 \\
\hline $\mathrm{PcMnO}^{\mathrm{d}}$ & 65.87 & 2.76 & 19.21 & 9.41 & 66.73 & 2.96 & 19.06 & 9.29 \\
\hline PcMn & 67.73 & 2.84 & 19.75 & 9.68 & 67.76 & 2.78 & 19.74 & 9.50 \\
\hline
\end{tabular}

${ }^{a}$ Manganese content was calculated from the amount of ash, assuming the ash is in the form of $\mathrm{Mn}_{3} \mathrm{O}_{4}$.

${ }^{b}$ Crystals prepared from PcMn by oxidation in pyridine were washed with pyridine and diethyl ether and dried in air.

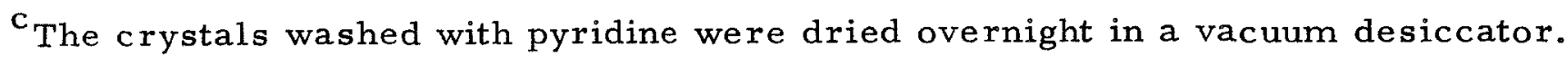

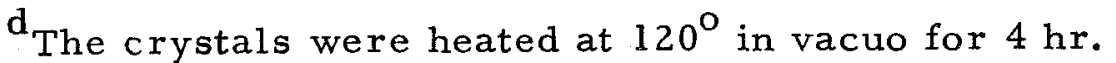




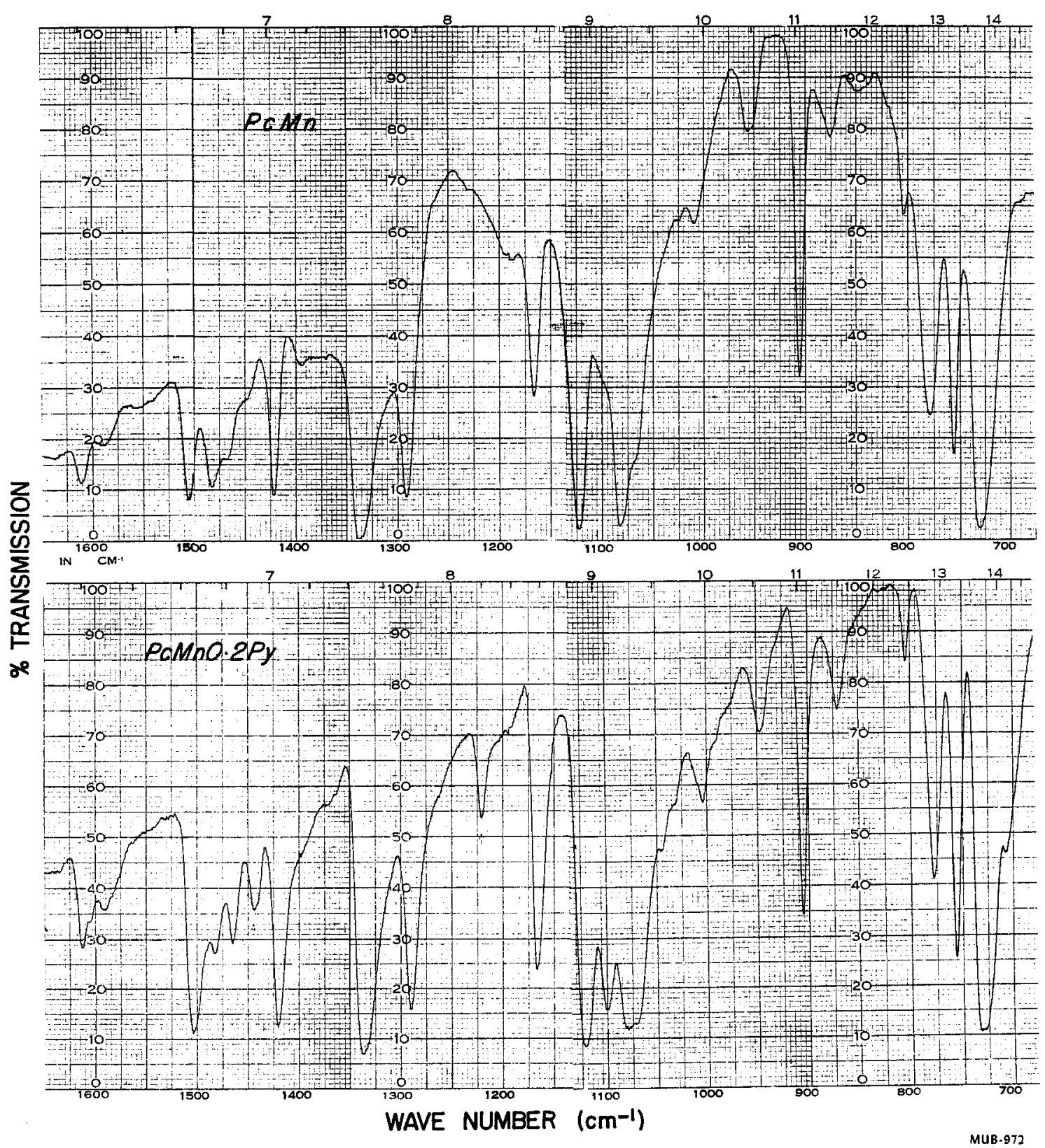

Fig. 13-10. Infrared spectra of PcMn(II) and PyMnO-2Py, $\mathrm{NaCl}$ region. 


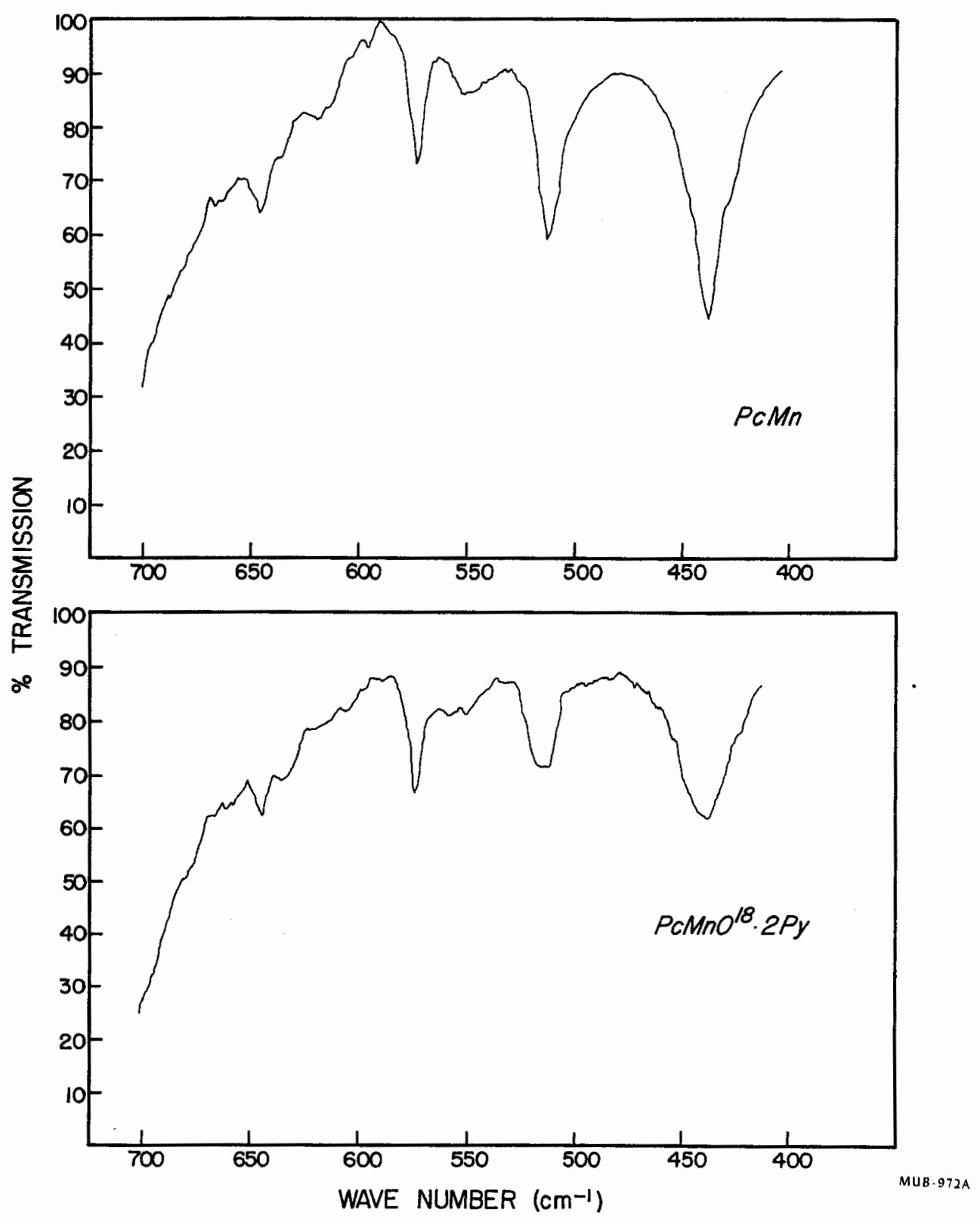

Fig. 13-11. Infrared spectra of PcMn(II) and PyMnO. 2Py, CsI region. 
In order to test this possibility, and also to test the validity of the assignment of the band at $1098 \mathrm{~cm}^{-1}$ to $\mathrm{Mn}=0$ stretching vibration, PcMnO 18. $2 \mathrm{Py}$ was prepared by the oxidation of $\mathrm{PcMn}$ (II) with $\mathrm{O}_{2}^{18}$ gas $1 \mathrm{O}^{18}$ enrichment: 98.4\%) in pyridine solution in the absence of air, and the infrared spectrum of the oxidized compound was observed. If the band at $1220 \mathrm{~cm}^{-1}$ were due to $\mathrm{N}-\mathrm{O}$ stretching of pyridine-N-oxide, it would be expected to shift to around $1190 \mathrm{~cm}^{-1}$ (based upon the assumption of simple harmonic oscillator), and the band at $1098 \mathrm{~cm}^{-1}$ would be shifted to $1050 \mathrm{~cm}^{-1}$, if the latter were due to $\mathrm{Mn}=\mathrm{O}$ stretching vibration. However, no shifting was observed by replacement of $\mathrm{O}^{16}$ by $\mathrm{O}^{18}$, either in the $\mathrm{NaCl}$ region or in the CsI region down to $350 \mathrm{~cm}^{-1}$. The bond between. manganese and oxygen atoms may be rather ionic and hence no band due to $\mathrm{Mn}-\mathrm{O}$ bonding would be observed in the region higher than $350 \mathrm{~cm}^{-1}$. Also, if there should be any interaction between pyridine and the oxygen atom, the bond between nitrogen and oxygen might not be so strong as in pyridine-N-oxide.

PcMn(II). 2Py showed essentially the same spectrum as PcMn(IV)O 2 Py, having bands at 1098,1220 , and $1440 \mathrm{~cm}^{-1}$ and other weak bands due to pyridine, except that the band at $1440 \mathrm{~cm}^{-1}$ was stronger than in PcMn(IV)O. $2 \mathrm{Py}$. Terenin and Sidorov have reported the appearance of similar bands by $\mathrm{co}_{5}$ ordination of pyridine on various metal derivatives of phthalocyanine. 5

The most direct approaches to a solution of this problem would be molecular weight determination and $x$-ray analysis. However, the solubility limitation and the susceptibility of the compound in the presence of a very small amount of water to thermal and photoreduction make the molecular weight determination very difficult. Molecular weight determination by isothermal distillation methods ${ }^{6}$ in dry pyridine solution at $60^{\circ}$ in vacuo with diazobenzene as a standard has been attempted, but values ranging between 200 and 350 were obtained. These values are less than half the molecular weight for the monomer.

$X$-ray analysis, which is now under way, offers the best hope for the ultimate determination of the structure of the compound.

\section{Experimental Notes}

Visible, near-infrared, and uv spectra were measured by use of Cary Model 14 and Beckman Model DK-2 spectrophotometers, with--when necessary--a special type of vacuum cell reported before. 1,3 Infrared spectra were measured with a Beckman IR-7 spectrophotometer. Magnetic susceptibility measurements were carried out by a Faraday method, as reported previously. 1

The quartz-helix balance (Microchemical Specialties Co. ) has a sensitivity of $0.975 \mathrm{~cm} / \mathrm{mg}$.

Pyridine used for the experiment was refluxed over $\mathrm{BaO}$ in vacuo and stored over BaO until use.

\footnotetext{
${ }^{5}$ A. N. Terenin and A. N. Sidorov, Spectrochimica Acta, Suppl. 1957, 573. ${ }^{6}$ R. Signer, Ann., 478, 246 (1930). E. P. Clar, Ind. Eng. Chem., Anal. Ed., 13, 820 (1941). 
This report was prepared as an account of Government sponsored work. Neither the United States, nor the Commission, nor any person acting on behalf of the Commission:

A. Makes any warranty or representation, expressed or implied, with respect to the accuracy, completeness, or usefulness of the information contained in this report, or that the use of any information, apparatus, method, or process disclosed in this report may not infringe privately owned rights; or

B. Assumes any liabilities with respect to the use of, or for damages resulting from the use of any information, apparatus, method, or process disclosed in this report.

As used in the above, "person acting on beha]f of the Commission" includes any employee or contractor of the Commission, or employee of such contractor, to the extent that such employee or contractor of the Commission, or employee of such contractor prepares, disseminates, or provides access to, any information pursuant to his employment or contract with the Commission, or his employment with such contractor. 